\title{
Comparison of Antibiotic Resistance Mechanisms in Antibiotic-Producing and Pathogenic Bacteria
}

\author{
Hiroshi Ogawara ${ }^{1,2}$ \\ 1 HO Bio Institute, 33-9, Yushima-2, Bunkyo-ku, Tokyo 113-0034, Japan; hogawara@sc5.so-net.ne.jp; \\ Tel.: +81-3-3832-3474 \\ 2 Department of Biochemistry, Meiji Pharmaceutical University, 522-1, Noshio-2, Kiyose, Tokyo 204-8588, \\ Japan
}

Received: 14 August 2019; Accepted: 20 September 2019; Published: 21 September 2019

\begin{abstract}
Antibiotic resistance poses a tremendous threat to human health. To overcome this problem, it is essential to know the mechanism of antibiotic resistance in antibiotic-producing and pathogenic bacteria. This paper deals with this problem from four points of view. First, the antibiotic resistance genes in producers are discussed related to their biosynthesis. Most resistance genes are present within the biosynthetic gene clusters, but some genes such as paromomycin acetyltransferases are located far outside the gene cluster. Second, when the antibiotic resistance genes in pathogens are compared with those in the producers, resistance mechanisms have dependency on antibiotic classes, and, in addition, new types of resistance mechanisms such as Eis aminoglycoside acetyltransferase and self-sacrifice proteins in enediyne antibiotics emerge in pathogens. Third, the relationships of the resistance genes between producers and pathogens are reevaluated at their amino acid sequence as well as nucleotide sequence levels. Pathogenic bacteria possess other resistance mechanisms than those in antibiotic producers. In addition, resistance mechanisms are little different between early stage of antibiotic use and the present time, e.g., $\beta$-lactam resistance in Staphylococcus aureus. Lastly, guanine + cytosine (GC) barrier in gene transfer to pathogenic bacteria is considered. Now, the resistance genes constitute resistome composed of complicated mixture from divergent environments.
\end{abstract}

Keywords: antibiotic resistance; self-resistance; bacterium; antibiotic producer; pathogenic bacteria

\section{Introduction}

The introduction of antibiotics once reduced human morbidity and mortality caused by infectious diseases dramatically. For example, human morbidity and mortality by tuberculosis were greatly reduced after the introduction of streptomycin and kanamycin. However, the emergence of multidrug resistant pathogenic bacteria reverted the situation drastically once again. Moreover, the situation of multidrug resistance is getting worse and worse. WHO calls attention to the infections especially by Klebsiella pneumoniae, Mycobacterium tuberculosis, and Neisseria gonorrhoeae, and blood poisoning and foodborne diseases, where these infections are becoming harder and sometimes impossible to treat [1]. Antibiotic resistance is mainly due to efflux of antibiotics by transporters, prevention of interaction of antibiotics with target by mutation, modification and protection of target, and modification of antibiotics. These mechanisms result from the inherent structural or functional resistant characteristics, the acquired resistance by mutational change or horizontal gene transfer, and the adaptive antibiotic resistance [2-4]. The fact that even before the rediscovery of penicillin resistant bacteria were reported suggests strongly that at least some resistance traits were intrinsically present in their genomes $[5,6]$. Together with the natural conception that antibiotic-producers should possess the self-resistance mechanisms for the prevention of their suicide, it was hypothesized that the genes for antibiotic modifying enzymes evolved in the antibiotic-producing bacteria and were transferred to pathogenic 
bacteria through transformation, transduction or conjugation [7-9]. This hypothesis has been accepted without dispute until recently [10]. However, the long-time misuse and overuse of antibiotics have resulted in the widespread dissemination of antibiotics as well as antibiotic resistance genes all over the environment, not only in sewage and wastewater treatment plants, hospital effluents, aquaculture, agricultural and slaughterhouse waste, but also in surface waters, soils, and so on. Consequently, multidrug resistance traits have migrated reciprocally among the various bacteria residing in these environments [11-14]. This review paper summarizes first the antibiotic resistance genes in producing bacteria from the point of view of antibiotic biosynthesis. Then the resistance genes in pathogenic bacteria are compared with those in the producers. Lastly, the relationships of the resistance genes between producing bacteria and pathogenic bacteria are reevaluated again at their amino acid sequence as well as nucleotide sequence levels.

\section{Protein Synthesis Inhibitors}

\subsection{Aminoglycosides}

On the basis of the mechanism of action, antibiotics can be classified into six categories: protein synthesis inhibitors, cell wall synthesis inhibitors, DNA synthesis inhibitors, DNA intercalators, RNA synthesis inhibitors, and others. Protein synthesis is one of the major targets for antibiotics in the cell, and can be divided into four distinct phases: initiation, elongation, termination and recycling [15-17]. Aminoglycoside antibiotics belong to the protein synthesis inhibitors, and are grouped into 4,6-disubstitued 2-deoxystreptamine (DOS)-containing (kanamycin, tobramycin, gentamicin, and others), 4,5-disubstitued DOS-containing (neomycin, paromomycin, lividomycin, and others), 4-monosubstitued DOS-containing (apramycin) aminoglycosides, and others (streptomycin, spectinomycin, hygromycin B, kasugamycin, and others). These aminoglycosides exert their antimicrobial action by binding primarily to helix 44 of $16 \mathrm{~S}$ rRNA of the small subunit of bacterial ribosome in the decoding region (A-site) and secondarily to helix 69 of $23 \mathrm{~S}$ rRNA of the large subunit, leading to the induction of translational misreading and inhibition of the translocation reaction [18-20]. In addition, streptomycin, one of the atypical aminoglycosides, interacts with the backbone phosphates and ribose hydroxyl groups. One characteristic of aminoglycoside antibiotics is that they are considered as a bactericidal class of antibiotics $[18,21]$, in contrast to the fact that most antibiotics that target the ribosome such as macrolides, tetracyclines, and chloramphenicol are bacteriostatic [22-24]. The detailed mechanisms of action of aminoglycosides are depending on their sophisticated chemical structures [25-28].

These aminoglycoside antibiotics are biosynthesized by Actinobacteria. Actinobacteria are prokaryotes, so they must protect themselves against attacks by their own biosynthetic products. Table S1 shows antibiotic names, their chemical structures (Kegg numbers), antibiotic resistance-related strategies in producing bacteria/fungi, analyzed bacteria/fungi, and references and GenBank accession numbers (GB No.). Kanamycin was isolated from Streptomyces kanamyceticus [29] and is a 4,6-disubstitued DOS-containing aminoglycoside antibiotic, together with tobramycin, gentamicin and sisomicin. Dibekacin, amikacin, netilmicin, and isepamicin are their semisynthetic analogues. The kanamycin biosynthetic gene clusters were cloned and sequenced [30,31] (GB Nos. AJ582817, AB164642, and AB254080). They contain genes for aminoglycoside 6'-N-acetyltransferase (kanM) and 16S rRNA methyltransferase $(\mathrm{kmr})$, indicating that they are involved in the self-resistance. In addition, there are several efflux ( $k a n O$ and $k a n N)$ and $\mathrm{ABC}$ transporter protein genes ( $k a n S, k a n R$ and $k a n Q$ ). Tobramycin is 3'-deoxykanamycin B. The biosynthetic gene clusters were cloned from Streptoalloteichus tenebrarius and Streptoalloteichus hindustanus [30,32,33] (GB Nos. AJ579650, and AJ810851). Two transporter genes (tobT and tobU) are present, but acetyltransferase and phosphotransferase genes [34] are absent within the clusters. A tobramycin producer, S. tenebrarius, was reported to produce rRNA methyltransferase (KgmB) [35]. These genes may be involved in the self-resistance. The gentamicin biosynthetic gene clusters were cloned from Micromonospora inyoensis [36,37] (GB Nos. AJ575934, 
AJ628149, AY524043]. Interestingly, four genes proposed to be involved in the self-resistance are present within the clusters, that is, the genes encoding two rRNA methyltransferases ( $g t m F$ and $g t m L)$, one aminoglycoside phosphotransferase $(\mathrm{gtmJ})$, and one transporter $(\mathrm{gtmK})$. Sisomicin is structurally related to gentamicin but has a unique unsaturated diaminosugar. G-52 is 6-methylsisomicin and G-418 (geneticin) is structurally similar to gentamicin. The sisomicin biosynthetic gene cluster was cloned from M. inyoensis [38] (GB No. FJ160413). Similar to the gentamicin gene cluster, the sisomicin biosynthetic gene cluster contains the genes encoding two rRNA methyltransferases (sis4 and sis9), one aminoglycoside phosphotransferase (sis17), and two but not one transporters (sis26 and sis27). In addition, the arrangement of the genes resembles very much with each other. Analysis of cell-free extracts of G-52 and G-418 producers showed that they were devoid of modification enzymes specific for aminoglycosides. Instead, they contained aminoglycoside highly resistant ribosomes [39-41]. As for verdamicin and sagamicin, 4,5-disubstituted DOS-containing, Micromonospora species-producing aminoglycosides, no report has been published on their biosynthetic genes yet. Only methylated and phosphorylated metabolites were detected in the fermentation broth [42].

Neomycin (fradiomycin), paromomycin, and lividomycin belong to 4,5-disubstitued DOS-containing aminoglycoside antibiotics. Their clinical use is limited by their toxicity. The neomycin biosynthetic gene cluster was cloned from $S$. fradiae as a $37 \mathrm{~kb}$ DNA fragment including 21 putative open reading frames [43-45] (GB No. AJ843080). They contain genes for AphA (GB No. CAF33306) and AacC8 (GB No, CAF33325) proposed to be involved in the self-resistance process. They are aminoglycoside $3^{\prime}$-phosphotransferase and aminoglycoside 3-acetyltransferase, respectively. In addition, genes for two putative ABC transporters (GB Nos. CAF33314 and CAF33315) were detected within the cluster. The search for the rRNA methyltransferase which may be involved in the self-resistance, using GrmA from M. echinospora (GB No. AAR98546), Kmr from S. kanamyceticus (GB No. CAE46946) and KamB (GB No. WP_063964000) from S. tenebrasius as probe proteins revealed that no similar protein is present in S. fradiae DSM40063, suggesting that no rRNA methyltransferase is detectable, although at least parts of the aminoglycoside biosynthetic genes are present in the genome. The paromomycin biosynthetic gene cluster was cloned from Streptomyces rimosus as a $48 \mathrm{~kb}$ DNA fragment (GB No. AJ628955). The self-resistant aminoglycoside 3'-phosphotransferase (parR/aphA) and $\mathrm{ABC}$ transporter genes (parT and parU) are located within the cluster, and their amino acid sequences are highly homologous to those in neomycin biosynthetic gene cluster. Interestingly, two acetyltransferases (AAC(3)-VII and AAC(6')-II, GB Nos. CAG44462 and CAG44463), which may be involved in the self-resistance, are present far outside the gene cluster [46] (GB No. AJ749845). It is intriguing to know how these enzymes are involved in the self-resistance. The lividomycin biosynthetic gene cluster was cloned from Streptomyces lividus as $40 \mathrm{~kb}$ DNA fragment (GB No. AJ748832). No resistance-related gene was reported in the producer except two ABC transporter genes (GB Nos. CAG38699 and CAG38700). This may be due to no detailed examination for the self-resistance gene in the strain. The ribostamycin biosynthetic gene cluster was published [47] (GB No. 744850). Similar to other 4,5-disubstituted aminoglycosides like neomycin, self-resistance-related genes, $r p h, r b m I$, rgmE and $r b m F$ were detected within the biosynthetic gene cluster. Butirosin is a 4,5-disubstituted DOS-containing aminoglycoside produced by Bacillus circulans. The chemical structure of butirosin is similar to ribostamycin except that a part of DOS is substituted by $\alpha$-hydroxy- $\gamma$-aminobutyric acid, but the organization of their biosynthetic gene cluster is completely different between them [47-49] (GB No. AB097196). Moreover, although an aminoglycoside $3^{\prime}$-phosphotransferase activity was detected in a butirosin producer [50], such gene is not detectable in the biosynthetic gene cluster. Apramycin is a mono-substituted DOS-containing aminoglycoside. The biosynthetic gene cluster was cloned from S. tenebrarius (GB No. AJ629123). It contains genes for 16S rRNA methyltransferase (kamB) and two exporters ( $a p r V$ and $a p r W$ ), which may be involved in the self-resistance. The antimicrobial activities of these 4,6- and 4,5-disubstituted and monosubstituted DOS-containing aminoglycosides are compromised by methylation of G1405 or A1408 in helix 44 of 16S rRNA [51]. 
Streptomycin is the first antibiotic isolated from Actinobacteria and the first aminoglycoside antibiotic [52]. Different from the aminoglycosides described above, streptomycin binds to the four nucleotides of $16 \mathrm{~S}$ rRNA (Nos. 13, 526, 915, and 1490) and lysine 45 of protein S12, and thereby its antibacterial activity is not affected by the methylation of G1405 and A1408 [53]. The biosynthetic gene cluster was cloned as 90kb DNA fragment [54,55] (GB No. AJ862840). It contains three putative phosphotransferase genes (strA/aphD/SGR_5932, strK/SGR_5938, and aphE/SGR_249) and two ABC-type transporter genes (strV/SGR_5915 and strW/SGR_5916) located adjacent to the cluster. In addition, one putative aminoglycoside acetyltransferase (SGR_292) and four RNA methyl-transferases are detected (SGR_1654, SGR_1886, SGR_4020, and SGR_6774). Not all but at least some of these proteins are implicated in the self-resistance in the producer [56] (GB No. NC_010572). The biosynthetic gene cluster of an aminocyclitol aminoglycoside antibiotic spectinomycin was cloned from S. spectabilis and other Streptomyces species [57,58] (GB No. EU255259). An aminoglycoside phosphotransferase, $\mathrm{SpcN}$ and an RNA methyltransferase, SpcM, were proposed to be involved in the self-resistance $[57,58]$. Hygromycin B is an aminocyclitol antibiotic that binds to discrete sites on the $30 \mathrm{~S}$ ribosomal subunit and inhibits protein synthesis [59]. The biosynthetic gene cluster was cloned from S. hygroscopicus [60,61] (GB No. AJ628642). The self-resistance-related proteins, HygA (phosphotransferase) and transporters (HygV and $\mathrm{HygW}$ ), are detected within the cluster. Hygromycin A, structurally distinct from hygromycin B, is an antibiotic isolated from S. hygroscopicus and inhibits the peptidyltransferase reaction of protein synthesis. The biosynthetic gene cluster of $31.5 \mathrm{~kb}$ DNA fragment was cloned [62]. Hyg21, a phosphotransferase, and Hyg19 and Hyg28, transporters, were proposed to be involved in the self-resistance $[62,63]$. Istamycin produced by S. tenjimariensis is an aminoglycoside antibiotic composed of two units. FmrT consisting of 211 amino acid residues was proposed to be the rRNA methyltransferase involved in the self-resistance [64]. Three transporter genes (steF24.1, steF24.27c, and steO22.6) were speculated within the cluster. Istamycin is also acetylated by kasugamycin-producing S. kasugaensis [65]. However, the relation of the acetylation to the self-resistance in the istamycin-producer has not been clarified. Kasugamycin is an aminoglycoside antibiotic mainly used for the prevention of the growth of a fungus causing rice blast disease, and specifically inhibits translation initiation [66]. Acetyltransferase activity was reported to be involved in the self-resistance in kasugamycin-producing S. kasugaensis [65]. In addition, the ABC transporter genes, kasKLM, are responsible for the self-resistance [67]. Fortimicin (astromicin) is an aminoglycoside antibiotic produced by Micromonospora olivasterospora. The biosynthetic gene cluster was cloned (GB No. AJ628421) and, fmrO encoding 16S rRNA methyltransferase (GB No. CAF31555) was assumed to play a role in the self-resistance [68]. Validamycin is a fungicidal aminoglycoside antibiotic produced by S. hygroscopicus var. limoneus. It is used as an inhibitor of trehalase. The biosynthetic gene cluster was cloned [69] (GB No. DQ223652). A putative transporter (VldJ) is present within the cluster. A derivative of aminoglycoside, acarbose was isolated from Streptomyces diastaticus as an amylase inhibitor [70]. It is now widely used for the treatment of patients with type 2 diabetes mellitus [71]. However, nothing has been reported on its antimicrobial activity. The biosynthetic gene cluster was cloned [72] (GB No. AM409314). Acarbose kinase, GacK, and three transporters, GacX, GacY, and Gac W, are present within the cluster. GacK was reported to be implicated in the intracellular inactivation of acarbose [72]. Acarbose is conceived to have a dual role for the producer, that is, that it inhibits $\alpha$-glucosidic enzymes of competitors and functions as a carbophor for the uptake of glucose or starch molecules in the producer. Although the streptothricin class antibiotics, streptothricin and nourseothricin, show a broad antimicrobial activity, their characteristic delayed toxicity interrupts their clinical application. The cloned biosynthetic gene cluster comprises genes for an acetyltransferase (orfE) and two transporters ( orfW and orfX). These proteins are supposed to be involved in the self-resistance [73-75] (GB Nos. AB684619 and AB684620). Nourseothricin acetyltransferase gene (natI), which is involved in the self-resistance, was cloned [76,77].

The drug resistance in the antibiotic-producing bacteria is limited, so to speak, to their own territories. In contrast, that in pathogenic bacteria not only affects their own existence, but also 
affords threatening effects on human and livestock. The resistance mechanism of pathogenic bacteria to aminoglycoside antibiotics includes aminoglycoside-modifying enzymes, the mutation and the modification of the ribosomal target, and efflux pumps [78,79]. However, the most widely disseminated means of resistance to aminoglycoside antibiotics is the inactivation by their modifying enzymes. Among the aminoglycoside modifying enzymes, acetyltransferases, phosphotransferases and nucleotidyltransferases especially adenylyl transferases are clinically important, resistance-related enzymes. Aminoglycoside N-acetyltransferases (AACs) are divided into four major groups based on the position of acetylation: $\mathrm{AAC}(1), \mathrm{AAC}\left(2^{\prime}\right), \mathrm{AAC}(3)$, and $\mathrm{AAC}\left(6^{\prime}\right)[26,80]$. Another novel type of aminoglycoside modifying enzyme, the enhanced intracellular survival (Eis) protein, was identified in Mycobacterium tuberculosis [81]. Unlike other AACs, Eis and its homologues acetylate multiple amino groups of aminoglycosides and are distributed in Mycobacterium and other Actinobacteria [82]. Moreover, Eis proteins are composed of more than 400 amino acid residues and, their amino acid sequences and the crystal structures are completely different from those of other AACs [83]. It is hypothesized that the antibiotic modifying enzymes in pathogenic bacteria were evolved from those in antibiotic-producing bacteria [7-9]. Here this hypothesis is re-evaluated from the point of amino acid sequence similarities of AACs, revealing that it is not necessarily true (Table S2 and Figure S1). The amino acid sequences of AAC(3)s in pathogenic bacteria such as AAC(3)-IIa (GB Nos. are in the parentheses; CAA31895), AAC(3)-IIIb (AAA25682), AAC(3)-IVa (CAA25642), AAC(3)-Ilb (AAA26548), AAC(3)-IIc (CAA38525), AAC(3)-IIIa (CAA39184), AAC(3)-IIIc (AAA25683), and AAC(3)-VIa (AAA16194) are closely similar to those of aminoglycoside-producers (AAA88552, AAA26685, AAA25334, and BAA78619). For example, E values between AAA88552 (type VII AAC(3) from S. rimosus subsp. paromomycinus, a paromomycin-producer) and CAA31895, AAA25682, CAA25642, AAA26548, CAA38525, CAA39184, AAA25683, and AAA16194 are 2.9e-31, 1.4e-31, 1.8e-09, 1.2e-26, 1.1e-34, 1.3e-36, 6.8e-32, and 3.8e-24, respectively (Table S2 and Figure S1A). However, the nucleotide sequence similarities (E values) between sequence of an aminoglycoside producer (AAA88552) and those of pathogenic bacteria (CAA31895 and AAA25682) are 11 and 0.42 (identities are $56.0 \%$ and $57.4 \%$, and similarities are $66.1 \%$ and $66.9 \%)$, respectively, reflecting the different guanine+cytosine contents of these bacteria. On the other hand, those of the producers and of AAC(3)-Ia (AAO49599), AAC(3)-Ib (AAA88422), and AAC(3)-IC (CAD53575) and AAC(3)-Id (AAR21614) are dissimilar (Table S2 and Figure S1C). Instead, AAC(3)-Ia (AAO49599) shows a slight similarity to glucosamine-6-phosphate acetyltransferases from Aspergillus fumigatus (2VEZ-A, E = 5.4e-02) and Trypanosoma brucei (3I3G-B, E = 2.0e-02) (Table S2); AAC(3)-Ib (AAA88422) shows a slight similarity to ribosomal protein S18-alanine N-acetyltransferase of E. coli (NP_418790, E value $=0.039$ ), and $\mathrm{N}$ - $\alpha$-acetyltransferase 20 isoform a of $H$. sapiens (NP_057184, E value $=0.098)$; and AAC(3)-Ic (CAD53575) shows a slightly similarity to acyl-CoA N-acyltransferase (NAT) superfamily protein of Arabidopsis thaliana (NP_001190321, E value $=2 \mathrm{e}-05)$, and N-acetyltransferase 8 of Mus musculus (NP_075944, E value $=0.010$ ), suggesting that AAC(3)s in the pathogenic bacteria are evolutionally related not only to acetyltransferases of aminoglycoside-producing bacteria but also to other types of acetyltransferases of bacteria, fungi, plants and animals. Even between AAA88552 (AAC3 of a paromomycin-producer) and CAA31895 (AAC3 of plasmid pWP113a), similarity value E is 7.1 at their nucleotide sequence level instead of $2.9 \mathrm{e}-31$ at their amino acid sequence level. As described above, the paromomycin-producer $S$. rimosus possesses two aminoglycoside acetyltransferase genes located far outside the biosynthetic gene cluster. One of them AAA88552/CAG44462 is AAC (3) and the amino acid sequence is very similar to other AAC enzymes from aminoglycoside producers, indicating that the amino acid sequence is not influenced by the location (Figure S1A).

AAC(6)s in pathogenic bacteria form three clusters (B, D and E in Figure S1) in the phylogenetic tree constructed on the basis of their amino acid sequence homology. This result is in accord with that of Salipante and Hall [84]. While each member in the same cluster shows high sequence homology, that in the different clusters shows almost no homology at all. Furthermore, amino acid sequences in cluster B show relatively high homology to aminoglycoside $\mathrm{N}$-acetyltransferase AAC(6')-Ii from various species of Enterococcus; those in cluster D exhibit relatively high homology to acyl-CoA 
N-acyltransferase from Arabidopsis thaliana $\left(\mathrm{NP} \_201544\right.$, E value $\left.=0.003\right)$, diamine acetyltransferase 2 isoform 3 from $H$. sapiens (NP_597998, E value = 3e-04), and GNAT family N-acetyltransferase from Microcystis aeruginosa (WP_012265151, E value = 2e-04); and those in cluster E exhibit relatively high homology to those of acyl-CoA N-acetyltransferase from Clostridioides difficile (YP_001087683, E value $=0.018)$, spermidine/spermine acetyltransferase from B. subtilis $\left(\mathrm{NP} \_390537\right.$, E value $\left.=0.006\right)$, and lysine N-acetyltransferase from M. tuberculosis (YP_009358719, E value = 1e-06); suggesting again that the aminoglycoside acetyltransferases, $\mathrm{AAC}(6) \mathrm{s}$, in the pathogenic bacteria are evolutionally related not only to acetyltransferases of aminoglycoside-producing bacteria but also to other types of acetyltransferases of bacteria, plants and mammals. In other words, pathogenic bacteria had evolved the resistance genes from their divergent original proto-resistance genes and/or resistance-related and resistance-unrelated genes acquired through horizontal gene transfer $[84,85]$. The arrangement of the genes near AAC(3)-IId in Pseudomonas aeruginosa strain PA34 (WP_000557454) is completely different from that (CAH58703) in S. fradiae, a neomycin-producer (Figure S2A,B). However, the identity (E value) of the amino acid sequences between WP_000557454 and CAH58703 is 3.1e-31, suggesting that these two are highly similar at their amino acid sequence level (Figure S1 and Table S2), although these two species are completely different in taxonomical classification. On the other hand, acetyltransferases from Actinobacterial species are divided into four groups: aminoglycoside 3-acetyltransferases, streptothricin-acetyltransferases, aminoglycoside 6-acetyltransferases, and Eis proteins. However, no amino acid sequence homology is observed between the members of each group (e.g., AAA88552, CAA51674, CAF60525, and NP_628362 in Table S2, respectively).

Aminoglycoside phosphotransferases (APHs) catalyze the regiospecific transfer of the $\gamma$-phosphoryl group of ATP to one of the hydroxyl groups on aminoglycosides. They are divided into several groups: $\mathrm{APH}(4), \mathrm{APH}(6), \mathrm{APH}(9), \mathrm{APH}\left(3^{\prime}\right), \mathrm{APH}\left(2^{\prime \prime}\right), \mathrm{APH}\left(3^{\prime \prime}\right)$, and $\mathrm{APH}\left(7^{\prime \prime}\right)[80]$. They form several clusters in the phylogenetic tree constructed on the basis of their amino acid sequences (Figure S3). Streptomycin phosphotransferase (BAG22761), spectinomycin phosphotransferases (ABW87797, AAB66655, and U70376_3) belong to cluster A. Although two spectinomycin phosphotransferases (ABW87797 and AAB66655) give high similarity with each other, these two give almost no similarity to another phosphotransferase (U70376_3) and streptomycin phosphotransferase (BAG22761) (Table S3). In addition, these two show almost no similarity to the phosphotransferases from pathogenic bacteria (AAA26443, AE004612_1, and CAA25854). SmartBlast analyses suggest that SpcN from S. spectabilis (ABW87797) shows high similarities to phosphotransferases of S. hygroscopicus (WP_06628960, $\mathrm{E}=1 \mathrm{e}-172)$, S. aureocirculans (WP_030559002, $\mathrm{E}=3 \mathrm{e}-170)$, S. silvensis (WP_107450217, $\mathrm{E}=1 \mathrm{e}-155)$, and Thermobifida halotolerans (WP_068692512, E = 5e-127), indicating that these phosphotransferases form one group in Actinobacteria. In contrast, the phosphotransferase from S. netropsis (U70376_3) shows similarity to hydroxyurea phosphotransferase from S. pharetrae (WP_086170844, E = 2-174), streptomycin 3"-phosphotransferase from P. aeruginosa PAO1 (NP_250549, E = 4.0e-15), and streptomycin 3-kinase from Deinococcus radiodurans R1 (NP_294178, E = 2.0e-08), indicating that these phosphotransferases form another group. On the other hand, the phosphotransferases of pathogenic bacteria in cluster $B$ such as CAA23892, AE004828_7, and CAA24789 show high similarity scores not only to those of other pathogenic bacteria such as AAA2641, CAA23656, and AAA26442 but also to those from aminoglycoside-producing bacteria such as WP_063841674 (butirosin), CAN38351 (sisomicin), CAF34039 (gentamicin), CAG44623 (paromomycin), CAG34043 (ribostamycin), CAH58684 (neomycin), and others (Table S3). They are aminoglycoside 3' or 3"-phosphotransferases and are derived both from Gram-positive and Gram-negative bacteria. The phosphotransferases in cluster $\mathrm{C}$ exhibit the high similarity to members within the cluster, but not to those in other clusters (Table S3), supporting the concept that at least some resistance-involved phosphotransferases in pathogenic bacteria are only far distantly related to those in aminoglycoside-producing bacteria. The members in cluster $\mathrm{C}$ are aminoglycoside 2"-phosphotransferases and stem from Gram-positive bacteria. No report has been published on the involvement of nucleotidyltransferase in the self-resistance in Streptomyces [80,86], although lincosaminide and muraymycin nucleotidyltransferases have been reported $[87,88]$. 
The modification of the ribosomal target is another mechanism of resistance, that is, the methylation of $16 S$ ribosomal RNA by methyltransferases. Depending on the modified nucleotide position at the A-site of 16S rRNA, the methyltransferases involved in aminoglycoside resistance are classified into two groups: N7-G1405 (methylation of N7 position of guanine-1405) 16S rRNA methyltransferases and N1-A1408 (methylation of N1 position of adenine-1408) 16S rRNA methyltransferases [89]. A phylogenetic tree constructed on the basis of their amino acid sequences is shown in Figure S4. It is composed of three clusters: clusters A, B, and C. Members in cluster A belong to N1-A1408 methyltransferases, and those in clusters B and C are comprised of N7-G1405 methyltransferases. It should be pointed out that the members in cluster B from aminoglycoside-producers and those in cluster $C$ from plasmids in pathogenic bacteria are closely related phylogenetically, while those in cluster A are dissimilar (Table S4). The genes for rRNA methyltransferases in cluster C are present on plasmids isolated from Gram-negative bacteria. Cluster A includes rRNA methyltransferases both from Actinobacteria and a plasmid in Gram-negative bacteria (Figure S4). SpcM from S. spectabilis (spectinomycin-producer, ABW87807) was proposed to be an rRNA methyltransferase [57]. However the amino acid sequence is completely different from those of other rRNA methyltransferases (Table S4). Instead, it shows high similarity scores with N6-cytosine_N4-adenine site-specific DNA methyltransferases from Streptoalloteichus hindustanus (WP_073483148, E = 1e-103), Photorhabdus laumondii (WP_113024414, E = 3e-97), and from Erwinia toletana (WP_017800138, 2e-95). VldO from S. hygroscopicus subsp. limoneus (ABC67279, validamycin-producer) was predicted to be an O-methyltransferase [69]. The amino acid sequence is completely different from other rRNA methyltransferases (Table S4). Alternately, it is more similar to predicted O-methyltransferase YrrMs from S. corchorusii (WP_079082699), S. leeuwenhoekii (CQR66120), and Amycolatopsis sulphurea (WP_098513546). So, it is doubtful whether it functions as a self-defender. Summarizing these data, it is concluded that the heterogeneity of $16 \mathrm{~S}$ rRNA methyltransferases involved in the drug resistance is less than those of the acetyltransferases and phosphotransferases. These are the results of analyses at their amino acid sequence level. However, it should reevaluate the evolutional relation of the resistance genes in the antibiotic producers and the pathogens at the nucleotide sequence level. For example, even between CAE46946 (Kmr of a kanamycin producer) and AAN87711 (methyltransferase NbrB of Citrobacter freundii), similarity value $\mathrm{E}$ is 0.79 at their nucleotide sequence level instead of $9.0 \mathrm{e}-21$ at their amino acid sequence level.

To accomplish high-level resistance, pathogenic bacteria should accumulate a small but distinct increase in environmental adaptation by sequential mutations. Before achievement of such level of resistance, bacterial cells use efflux pumps or efflux transporters as the first line of defense against antibiotics. The antibiotic transporters are divided into five families: the small multidrug resistance (SMR) family, the multidrug and toxic compound extrusion (MATE) family, the major facilitator superfamily (MFS), the ATP-binding cassette (ABC) family and the resistance-nodulation-cell division (RND) family $[90,91]$. These transporters function as a network, that is, more than one transporters are involved in the exclusion of one xenobiotic such as antibiotics and pollutants [92,93]. Therefore, the antibiotic efflux transporters are only a part of an overall detoxifying system consisting of a large range of coordinated membrane proteins. This is reflected in the diversity of the transporters implicated in the aminoglycoside self-resistance. Figure S5 shows a phylogenetic tree constructed on the basis of the amino acid sequences of the transporters implicated in the aminoglycoside self-resistance (Table S1). The tree is divided into four clusters: cluster A, cluster B, cluster C, and cluster D. The cluster C is further divided into four sub-clusters: C1, C2, C3, and C4. The sub-cluster C4 contains most of the aminoglycoside-related transporters constituting of 16 members. The similarity values Es between SAV1866 in Staphylococcus aureus (WP_124781844) and one of those in sub-cluster C4 range from 4.6e-06 (S. hygroscopicus Hyg28, ABC42565) to 4.5e-70 (S. tenebrasius AprW, CAF33030). The other sub-clusters contain ABC permeases such as S. glaucescens GacX, S. kasugaensis KasL, and S. kasugaensis KasM, EamA-like MFS proteins such as S. tenebrarius TobU. The cluster B are ABC transporter components with low similarity to SAV1866 in S. aureus (WP_124781844) (Figure S5). The cluster D includes 9 
MFS members. The nine members in the cluster D and 2 members in the cluster A (M. olivasterospora ForV, CAF31538 and M. inyonensis Sis26, ACN38360) are clearly divided into two groups (Figure S6). The members of the group A belong to drug: $\mathrm{H}^{+}$antiporter 14-spanner (DHA14) or drug: $\mathrm{H}^{+}$antiporter 12-spanner (DHA12) drug efflux family and those of the group B belong to cyanate permease (CP) family [94]. Together with the fact that the cluster A includes FHA-domain containing proteins (S. tenjimariensis SteF24.27c, CAH60152 and M. inyonensis Sis27, ACN38361), it is suggested that the aminoglycoside-related transporters in the producing and pathogenic bacteria are composed of tremendously various proteins. Whereas the sequence similarities between transporters in the aminoglycoside producing and pathogenic bacteria are very high in $\mathrm{ABC}$ transporters described above, those among MFS members are very low (Figures S5 and S6). Hence, the similarity values Es between E. coli CynX (AAB18065) and one member in group B in Figure S6 span from 1.5 (S. tenebrarius TobT, CAH18551) to over $1 \mathrm{e}+03$ at the amino acid sequence level. Recently, the alteration of ribosomal targets by $16 \mathrm{~S}$ rRNA methyltransferases was reported to confer resistance to most aminoglycosides in pathogenic bacteria. This type of resistance was not previously thought to be a clinically relevant mechanism of resistance $[95,96]$.

\subsection{Macrolide and Related Antibiotics}

Macrolide antibiotics also belong to the protein synthesis inhibitors, and are divided into 12-, 14-, 15-, 16-, and 18-membered ring groups based on the chemical structures of the number of atoms in the macrocyclic lactone ring [97,98]. However, 14-membered (erythromycin, oleandomycin, narbomycin, and others) and 16-membered (tylosin, carbomycin, spiramycin, and others) ring macrolide antibiotics are major antimicrobials. The macrolide antibiotics bind to the ribosomal nascent peptide exit tunnel (PNET) adjacent to the peptidyl transferase center (PTC), and prevent protein biosynthesis. However, the binding mode is controlled discretely in the molecular-species-specific manner $[19,22]$. The macrolide antibiotics show antimicrobial activity against both Gram-positive and some Gram-negative bacteria. In addition, they are active against Mycoplasma, Chlamydia, Legionella, and Coxiella. Moreover, some macrolide antibiotics function as motilin receptor agonists [99].

Methymycin is a 12-membered ring macrolide antibiotic produced by S. venezuelae. The methymycin biosynthetic gene cluster was cloned and sequenced [100,101]. It contains genes for two rRNA methyltransferases (pikR1 and pikR2) and $\beta$-glycosyltransferase $(\operatorname{des} R)$ which are involved in the self-resistance. These genes are also implicated in the self-resistance against pikromycin and narbomycin, 14-membered ring macrolide antibiotics coproduced by S. venezuelae. The parts of the biosyntheses share a common route in these three antibiotics. Interestingly, the presence of macrolide glycosyltransferases has been reported in a number of macrolide non-producers such as S. vendargensis and S. lividans [102,103]. However, the detailed function of these glycosyltransferases has not been defined. Erythromycin is the best known member of the 14-membered group and was isolated from Saccharopolyspora erythraea. The biosynthetic gene clusters were cloned from S. erythraea [104-106]. The $23 \mathrm{~S}$ rRNA methyltransferase gene (ermE, SACE_0733) is present within the cluster. In addition, 11 further rRNA methyltransferases are present in the genome. Furthermore, two putative macrolide glycosyltransferases (SACE_1884, and SACE_3599), and a number of efflux proteins for antibiotics exist outside of the cluster (Table S1) [105]. These genes may be involved in the self-resistance. Oleandomycin is a 14-membered ring macrolide antibiotic isolated from S. antibioticus. Glycosyltransferases (OleD, Oleg1, OleG2, and OleI) and ABC transporters (OleB and OleC) were proposed to be implicated in the self-resistance [107-110]. As described above, pikromycin and narbomycin are 14-membered macrolide antibiotics produced by $S$. venezuelae, and the parts of the biosynthetic routes and the resistance genes share with those of methymycin [111]. Lankamycin is a 14-membered macrolide antibiotic. Interestingly, the biosynthetic genes are located on the giant linear plasmid pSLA2-L in S. rochei together with those of lankacidin, a 17-membered carbocyclic polyketide compound [112]. Two ABC transporter genes $(l k c I$ and $l k c J)$ are present within the biosynthetic gene cluster, and another $\mathrm{ABC}$ transporter gene $(l \mathrm{kmN})$ is present outside of the cluster. In addition, two efflux transporter genes (ST1928_p012 and 
ST1928_p024) exist outside of the cluster. These transporters are involved in the self-resistance (GB No.NC_004808). Tylosin is a 16-membered ring macrolide antibiotic developed for veterinary use [98]. Four self-resistance determinants are defined. Among them, three $(t \operatorname{lr} B, t \operatorname{lr} D$, and $t \operatorname{lr} C)$ are within the biosynthetic gene cluster, and one $(t y l A)$ exists outside of the cluster. $\operatorname{tr} A, t \operatorname{lr} B$, and $t \operatorname{lr} D$ code for rRNA methyltransferases, and $t l r C$ encodes an efflux protein [113-116]. The spiramycin biosynthetic gene cluster was cloned and sequenced [117] (GB No.CP012382). Two ABC transporters (SrmB and DrrA), two rRNA methyltransferase (SrmD and SrmA), and one macrolide glycosyltransferase (MgtA/GimA) are involved in the self-resistance. $m g t A / g i m A$ gene is present immediately downstream of $\operatorname{srm} A$ (GB No.SAM23877_5808) outside of the biosynthetic gene cluster [118]. Carbomycin is a 16-membered macrolide antibiotic isolated originally from $S$. halstedii and the biosynthetic gene cluster was cloned from S. thermotolerans (GB No.KR818745). Two transporter genes (carA/cbm25 and cbm26) and rRNA methyltransferase gene $(c a r B / c b m 7)$ were identified as resistance determinants $[119,120]$. Interestingly, amino acid sequences of CarA from $S$. thermotolerans, TlrC from S. fradiae and SrmB from S. ambofaciens are closely similar (similarity values Es $=3.4 \mathrm{e}-85 \sim 1.1 \mathrm{e}-115$ ). Mycinamicins are 16-membered macrolides constituting the mycinamicin subgroup produced by Micromonospora griseorubida. The biosynthetic gene cluster was cloned [121] (GB No.AB089954). MyrB, an rRNA methyltransferase, was reported to be implicated in the self-resistance [122]. Tiacumicin B is an 18-membered ring macrolide produced by Dactylosporangium aurantiacum. The gene cluster was cloned, and four transporter genes were reported within the cluster [123] (GB No.HQ011923).

Lincomycin is a member of lincosamide group antibiotics consisting of amino acid and sugar moieties. It is a protein synthesis inhibitor [124,125]. Three resistance-related genes, $\operatorname{lm} A$ and $\operatorname{lm} r \mathrm{C}$ encoding efflux pumps and $\operatorname{lm} r B$ encoding rRNA methyltransferase were identified within the biosynthetic gene cluster [126-128]. A lincosamide resistance determinant clr, a 23S rRNA methyltransferase gene, was also isolated from S. caelestis, a celesticetin-producer [129]. Hormaomycin is a bacterial signaling metabolite with narrow-spectrum antibiotic activity produced by S. griseoflavus. Pyrrolobenzodiazepine derivatives, tomaymycin, anthramycin and siberomycin, are sequence-selective DNA alkylating agents. Lincomycin, hormaomycin, tomaymycin, anthramycin and siberomycin are known to be derived from a common intermediate (3-vinyl-2,3-pyrroline-5-carboxylic acid), and to constitute similar biosynthetic gene clusters [130]. The biosynthetic gene cluster for hormaomycin in S. griseoflavus contains two transporter genes, hrmU and hrmV [131]. The tomaymycin biosynthetic gene cluster was cloned as 26kb DNA fragment, and one transporter gene, tomM, was identified within the cluster [132] (GB No. FJ768957). The biosynthetic gene cluster of anthramycin was cloned and sequenced. Adjacent genes orf9 and orf10 were proposed to encode transporters. From the amino acid sequence similarity of Orf8 to UvrA and DrrC, it is suggested a role as a transporter or the excision nucleotide repair system in the resistance [133] (GB No. EU195114). The siberomycin biosynthetic gene cluster was cloned as $32.7 \mathrm{~kb}$ DNA fragment. One transporter gene $s i b F$ was identified within the cluster [134] (GB No. FJ768674).

Streptogramins/pristinamycins are a family of antibiotics that are composed of a mixture of two chemically different compounds: group A streptogramins/pristinamycin II constituting of poly-saturated macrolactones, and group B streptogramins/pristinamycin I constituting of cyclic hexadepsipeptides. Both group A and group B streptogramins are protein biosynthesis inhibitors, and function synergistically to provide greatly enhanced levels of antimicrobial activity. Pristinamycin I and pristinamycin II biosynthetic gene clusters were cloned as a 210kb DNA fragment interspersed to two segments by the insertion of $90 \mathrm{~kb}$ cryptic secondary metabolite cluster [135]. Two transporter resistance genes, $s n b R$ and $p t r$, were identified, one within the cluster and another outside of the cluster [136]. Virginiamycin M and virginiamycin S belong to group A and group B streptogramin families, respectively. A part of the biosynthetic gene cluster was cloned [137]. Three transporter genes are present within the cluster. In addition, virginiamycin $\mathrm{M}$ was reported to be stereospecifically reduced to an inactive derivative in S. virginiae [138]. Griseoviridin and viridogrisein/etamycin belong to group A and group B streptogramin antibiotics produced by S. griseoviridis, respectively. Three 
transporter genes (sgvT1, sgvT2, and sgvT3) are found within the biosynthetic gene cluster [139] (JX508597). Evernimicin and avilamycin are orthosomycin group antibiotics inhibiting protein biosynthesis. However, cryo-electron microscopical analyses of the complexes of orthosomycins and E. coli ribosome revealed that the binding site on the large subunit is different from that of other antibiotics such as macrolides and thiostrepton [140]. The biosynthetic gene cluster for evernimicin was cloned. Two $23 \mathrm{~S}$ rRNA methyltransferase genes (evrH and orf6) and two efflux pump genes (evrE and $e v b B$ ) were identified within the cluster [141]. These may be involved in the self-resistance. Avilamycin biosynthetic gene cluster was cloned as $60 \mathrm{~kb}$ fragment from S. viridochromogenes. Two rRNA methyltransferases (AviRa and AviRb) and two antibiotic transporters (AviABC1 and AviABC2) were clarified [142] (GB No. AF333038). Viomycin and capreomycin are tuberactinomycin group antibiotics used for the treatment of multi-resistant tuberculosis. They inhibit bacterial protein biosynthesis by blocking translocation of the mRNA-tRNA complex. The biosynthetic gene cluster for viomycin was cloned. Viomycin phospho-transferase (Vph) and a permease (VioE) are assumed to be involved in the self-resistance [143] (GB No. AY263398). The capreomycin biosynthetic gene cluster was cloned. Within the cluster, rRNA methyltransferase gene ( $\mathrm{cmnU}$ ) and capreomycin phosphotransferase gene (cph) were detected [144] (EF472579). In addition, capreomycin acetyltransferase (Cac) was proposed to be implicated in the self-resistance [145].

In summary, in contrast to the cases of aminoglycosides the major resistance mechanisms to macrolide and related antibiotics in producing bacteria are efflux of the drugs and methylation of rRNA. As described above, the use of transporters/efflux pumps is the first line of defense against antibiotics by decreasing the intracellular level of antibiotics before the cell activates the various other tools of defense [146]. This is true not only in pathogenic bacteria but also in antibiotic-producing bacteria, so there are many genes encoding transporters/efflux pumps in the genomes, although the genes for drug transporters/efflux pumps have not been detected within the biosynthetic gene clusters of macrolide antibiotics methymycin and mycinamicin. These transporters/efflux pumps may be involved in the first line of defense in the producing bacteria. On the other hand, there are some questions. What is the real role of the assumed resistance-related proteins such as the glycosyltransferase (DesR) in methymycin-producer [101], the glycosyltransferases (OleG1, OleG2) in oleandomycin-producer [109,110], the phosphotransferase (Vph) in viomycin-producer [143], the phosphotransferase (Cph) and the acetyltransferase (Cac) in capreomycin-producer [144,145]? Cac is supposed to be an aminotransferase, as the amino acid sequences are highly similar to many aminotransferases from Actinobacteria. How did rRNA methyltransferases become resistance tools in antibiotic producers? How were the resistance-related these proteins evolved? Blast analyses revealed that amino acid sequence of DesR is similar not only to glycosyltransferases from various Streptomyces species but also to the glycosyl hydrolase from Schizosaccharomyces pombe (NP_595060, E value = 6e-78), and $\beta$-xylosidase from Arabidopsis thaliana (NP_196535, E value = 1e-38); that of Vph is similar not only to viomycin phosphotransferases from various species but also to aminoglycoside phosphotransferases from Seinonella peptonophila $($ WP_073150348, E value = 8e-24) and other Firmicutes bacteria; and that of Cac is similar not only to aminotransferases from various Actinobacteria but also to SufS family cysteine desulfurases from Microcystis aeruginosa $($ WP_002796790, E value $=2 \mathrm{e}-19)$ and other bacteria and plants. Together with the fact that similar functional proteins distribute in a wide range of phyla/biosphere irrespective of the large difference of GC contents in genomes, e.g., Erm-like protein is present in Yuhushiella deserti (GB No. SFO87742, E value $=3 \mathrm{e}-130$ ) as well as Homo sapiens (GB No.NP_001335005, E value $=4 \mathrm{e}-19)$, these results indicate that the antibiotic producing bacteria have evolved the resistant systems from the accidentally acquired related genes within the biosynthetic gene clusters. This has happened in a long evolutional history of life by overcoming the high barrier of GC contents in the genomes [147].

The resistance mechanism to macrolide and related antibiotics in pathogenic bacteria, on the other hand, is divided into mutations and modifications of $23 \mathrm{~S}$ rRNA, macrolide efflux systems, macrolide inactivation by phosphotransferases and esterases, and others. Macrolides interact 
primarily with A2058 and A2059 of the 23S rRNA, and the mutations in these nucleotides have been found in many macrolide-resistant pathogenic bacteria, such as Mycobacterium, and Helicobacter. Mutations at G2057 and C2611, sometimes in combination with A2058 or A2059, have been detected in Streptococcus, and Staphylococcus. In addition, mutations in genes encoding ribosomal proteins L4 and L22, which contact macrolides in the ribosome-macrolide complexes [148], confer resistance to macrolides in various pathogenic bacteria [149]. This type of mutations includes not only amino acid exchange, but also deletion and insertion. The resistance mechanisms of these types have not been observed in the macrolide-related antibiotic producers. The second type of resistant mechanism is the rRNA modification by rRNA methyltransferases encoded by erm genes. erm genes encode the methyltransferases which methylate A2058 located in the peptide exit tunnel of rRNA. This type of mechanism confers resistance to 14-, 15-, and 16-membered macrolides and ketolides, as well as to lincosamides and streptogramin B. Now, over $40 \mathrm{erm}$ genes have been reported [149]. Interestingly, the amino acid sequence of Erm in Stretococcus pneumoniae (GB No.BBG37057) is very similar to that in CarB in S. thermotolerans (GB No.AAC32026, E value $=1.8 \mathrm{e}-14$ ) and PikR2 in S. venezuelae (GB No. AAC69327, E value $=1.1 \mathrm{e}-19)$ and methyltransferases in other macrolide producers. The third type of mechanism is related to macrolide efflux systems encoded by $\mathrm{mef}, \mathrm{msr} / \mathrm{mel}$ and $l \mathrm{ls}$ genes. E values at nucleotide sequence level are 0.05 ( $\mathrm{erm} / \mathrm{carB}$ ), and 3.8e-3 (erm/pikR2), respectively. Coexpression of mef and $m s r$ is required for high level macrolide efflux, and these proteins interact synergistically to increase macrolide resistance. However, the detailed mechanism remains to be clarified, although it was reported that these proteins form a composite efflux pump [150]. While the amino acid sequence of Msr (GB No.WP_053875754) in S. aureus is similar to that of Hyg28 in S. hygroscopicus (E value = 8.9e-30), that of MefS in S. pneumoniae is not similar to any sequences in macrolide producers analyzed. It is possible that some other transporters outside of the biosynthetic gene clusters in producers are similar to those in the pathogenic bacteria. The fourth mechanism is macrolide inactivation by phosphoesterases and esterases that are encoded by $m p h$ and ere genes, respectively. Macrolide phosphotransferases are macrolide-inactivating enzymes widespread in Gram-positive and Gram-negative bacteria, and belong to the same family as aminoglycoside phosphotransferases and protein kinases [151]. Macrolide phosphotransferases confer resistance to a wide variety of macrolide antibiotics. However, details remain to be elucidated [152]. As for macrolide esterases that inhibit the antimicrobial activity of macrolides, five families are reported [152]. These enzymes are thought to be originally diverse, although they provide macrolide resistance to pathogenic bacteria [153]. This type of resistance has not been reported in macrolide producing bacteria. In summary, rRNA methyltransferases and phosphotransferases in pathogenic bacteria are closely related to those in macrolide-producing bacteria, whereas rRNA mutations and efflux pumps are scarcely related with each other. These resistance characters may have been transferred from other sources.

\subsection{Tetracycline and Chloramphenicol}

Tetracyclines have been used for the treatment of a wide variety of Gram-positive and Gram-negative bacterial infections and for animal feeds and aquaculture since the 1940s. Now, third and fourth generation compounds have rejuvenated clinical prospects for this drug class. Tetracyclines inhibit bacterial protein biosynthesis by binding to the $16 \mathrm{~S}$ rRNA, preventing the delivery of tRNA to the A-site $[19,23]$. The therapeutic potential in cardiovascular diseases was also reported, as tetracyclines inhibits matrix metalloproteinases [154]. The oxytetracycline biosynthetic gene cluster was cloned $[155,156]$. A total of $21 \mathrm{ORFs}$ were clustered between two resistance genes $\operatorname{otr} A$ and $\operatorname{tr} B$, encoding a ribosomal protection protein (RPP) [157] and a transporter, respectively [158]. The chlortetracycline biosynthetic gene cluster was cloned from Kitasatospora aureofaciens $[159,160]$ (HM627755). Within the cluster, one ribosomal protection protein gene $(c t c C)$, and three transporter genes ( $c t c R, c t c Y$ and $c t c 2)$ are detected. Recently, Forsberg et al. reported a novel family of tetracycline-inactivating enzymes by soil functional metagenomic selections, although the exact function in the drug resistance of pathogenic bacteria is not clear [161]. 
Chloramphenicol is an antibiotic produced by S. venezuelae and other Streptomyces species. It inhibits protein biosynthesis by interacting with the bacterial $50 \mathrm{~S}$ subunit of ribosome and blocking amino acyl-tRNA binding at the A-site, and is used for the treatment of Gram-positive and Gram-negative bacterial infection. However, the side effects such as bone marrow suppression, nausea and diarrhea hamper its common use. The chloramphenicol biosynthetic gene cluster was cloned and sequenced [162,163] (NC_018750). One gene for MFS efflux pump (cmlF,SVEN_RS04435) is present within the cluster, and another gene for MFS transporter (cmlV,SVEN_RS20160) is present outside of the cluster. Interestingly, chloramphenicol phosphotransferase gene (cpt, SVEN_RS20155) is present just adjacent to $\mathrm{cmlV}$. Acetylchloramphenicol was proposed to be an intermediate in chloramphenicol biosynthesis [164], although the exact role of acetylation of chloramphenicol in the self-resistance has not been elucidated. Chloramphenicol hydrolase was also proposed to be involved in the self-resistance [165].

As for the resistance to tetracyclines in pathogenic bacteria, at least four mechanisms have been reported, that is, binding site mutations, ribosomal protection proteins, efflux pumps, and enzymatic inactivation [166,167]. Because most bacteria have multiple rRNA copies, mutations in rRNA conferring tetracycline resistance are usually found in bacteria with low rRNA copy numbers, such as Propionibacterium acnes, Helicobacter pylori, Mycoplasma bovis, and S. pneumoniae. For example, $S$. pneumoniae with mutations C1054T and T1062G/A in 16S RNA is resistant to tigecycline when four genomic copies of $16 S$ rRNA are mutated. Mutations in the rpsJ encoding the $30 \mathrm{~S}$ ribosomal subunit protein S10 are also reported to confer resistance to tetracyclines in S. pneumoniae [168]. Mutations in rpsJ are described in various clinical isolates of Gram-negative bacteria. Furthermore, the same authors described nonsense mutations in spr1784 encoding a 16S rRNA methyltransferase resulting in tetracycline resistance in S. pneumoniae [168]. Tetracycline ribosomal protection proteins (RPPs) are GTPases with significant sequence and structural similarity to elongation factors EF-G and EF-Tu. They are found both in Gram-positive and Gram-negative bacteria. The most common RPPs are TetO and TetM. The sequence similarity values between OtrA from tetracycline producer S. rimosus (GB No.ALS03934) and TetM from E. faecalis (GB No.CAA63530), and TetO from Campylobacter jejuni (AAA23033) are 5e-79 and 2.2e-80 at the amino acid sequence level, and 2.1e-38 and 3.7e-47 at the nucleotide sequence level, respectively, indicating that these proteins are closely related each other. It is assumed that RPPs like TetM and TetO have originated in the tetracycline producers. The most common tetracycline-specific efflux pumps are members of the major facilitator superfamily transporters. They are classified in seven groups. The group 1 pumps such as TetA and TetB possess 12 transmembrane segments and distribute mostly in Gram-negative bacteria. The group 2 pumps like TetK and TetL contain 14 transmembrane segments and are present mostly in Gram-positive bacteria [91]. The amino acids of TetK and TetL from Gram-positive bacteria have some sequence similarity to those of OtrB, CtcR, and Ctc2 from tetracycline producers, showing that the similarity values Es are in the range of 1e-05 to 1e-09. Enzymes capable of inactivating tetracyclines are rare compared with enzymes that inactivate other antibiotics. Three enzymes are known to be implicated in the tetracycline inactivation: flavin-dependent monooxygenases encoded by tet $X$ family genes, NADP-requiring tetracycline modifying enzymes, and xanthine-guanine phosphoribosyltransferases [161]. These enzymes have not been described in tetracycline producing bacteria, although they may possess their dissemination potential into the clinic near future.

The resistance mechanisms to chloramphenicol in pathogenic bacteria are due to the enzymatic modification of chloramphenicol, efflux pumps, and target modifications. The amino acid sequence of the acetyltransferase from Streptomyces acrimycini (GB No.CAT_STRAC) is extremely similar to that from Haemophilus influenzae (GB No. CAA37806, E =9.5e-40), to that from Shigella flexneri plasmid (GB No. CAA30695, E = 3e-40), and that from S. aureus plasmid (GB No. CAA26367, E = 2.3e-35). However, whether the gene for this type of acetyltransferase is present in chloramphenicol producing Streptomyces species is not clear, although acetylchloramphenicol was detected in chloramphenicol producing S. venezuelae [164]. Whereas a chloramphenicol phosphotransferase is detected in chloramphenicol 
producing $S$. venezuelae, this type of phosphotransferase has not been reported in pathogenic bacteria. Similarly, a chloramphenicol hydrolase gene is found in the chloramphenicol producer $S$. venezuelae, but not in pathogenic bacteria [169]. Related to the chloramphenicol resistance, a number of efflux pumps have been reported [24]. The amino acid sequence of CmlV (GB No.AAB36568) from chloramphenicol producing $S$. venezuelae is similar to $\mathrm{CmxB}$ from Corynebacterium striatum plasmid (GB No. AAG03380, $\mathrm{E}=1.4 \mathrm{e}-23$ ), and to FexA from Staphylococcus lentus plasmid (GB No. CAD70268, E = 9.6e-02), but not to CmlA from Salmonella typhimurium plasmid (GB No. CAD31707, E = 2.2) and to Cml from $E$. coli plasmid (GB No. AAA26079, $\mathrm{E}=4.3 \mathrm{e}+02$ ). On the other hand, the $c f r$ gene encoding an rRNA methyltransferase that targets A2503 in the domain V of the 23S RNA has been identified on a number of plasmids in S. aureus and other Gram-positive bacteria. Furthermore, the cfr gene was also found in chromosomal DNAs or on plasmids in some Gram-negative bacteria [170]. This type of rRNA methyltransferase-mediated chloramphenicol-resistance has not been described in chloramphenicol producing S. venezuelae.

\subsection{Other Protein Synthesis Inhibitors}

Kirromycin is a complex linear polyketide peptide-bonded to sugar-like moiety produced by $S$. collinus, S. ramocissimus, S. cinnamoneus, and Nocardia lactamdurans. Among the kirromycin-producers, S. collinus Tue365 and S. ramocissimus express kirromycin-sensitive elongation factors even during the kirromycin producing period, whereas S. cinnamoneus and N. lactamdurans encode kirromycin-resistant elongation factor [171,172]. EF-Tu3 from S. coelicolor A3(2), a kirromycin-non-producer, is also resistant to kirromycin [172]. The kirromycin biosynthetic gene cluster was isolated as 130kb DNA fragment containing 57 ORFs. Two MFS type transporters are detected within the cluster [173,174] (GB No.AM746336). Kirromycin shows strong antibacterial activity against Streptococci, some Enterococci, Neisseria, and Haemophilus, but not to S. aureus. The narrow antibiotic spectrum of kirromycin is explained by the sophisticated structural difference of EF-Tus in bacteria $[175,176]$. The role of kirromycin has not been clarified in pathogenic bacteria.

Bicyclomycin is a 2,5-diketopiperazine derivative and a selective inhibitor of the transcription termination factor Rho. It is isolated from S. cinnamoneus and shows a broad-spectrum antibiotic activity against Gram-negative bacteria. The biosynthetic gene cluster was cloned from S. cinnamoneus, but putative bicyclomycin gene clusters are bound to at least seven spanning Actinobacteria and Proteobacteria. The MFS type transporter gene $b c m T$ is present within the cluster [177,178]. In a pandemic $P$. aeruginosa clone, the integrative and conjugative element carrying the metallo- $\beta$-lactamase gene and bicyclomycin resistance gene bcr1 was reported [179]. bcr1 encodes a efflux pump for bicyclomycin [180].

Thiostrepton is a thiopeptide group antibiotic isolated from S. azureus more than 50 years ago. This type of antibiotics inhibits protein synthesis by targeting the ribosome or ribosome-associated factors. They are active against clinically relevant methicillin-resistant S. aureus (MRSA), E. faecium (MREF), penicillin-resistant S. pneumoniae (PRSP) and vancomycin-resistant Enterococci (VRE). However, it is only limitedly applied clinically due to its poor solubility and toxicity. The biosynthetic gene clusters for thiostrepton and related antibiotics GE2270 and thiomuracin were cloned from S. laurentii and Nonomuraea, respectively [181,182] (GB Nos. FJ652572; FJ461359; FJ461360). An rRNA methyltransferase gene, that imparts self-resistance to thiostrepton in S. laurentii, is not linked to the biosynthetic gene cluster but instead it is located within a cluster of ribosomal protein operons [183]. Spontaneous thiostrepton-resistant mutants were isolated from Thermus thermophilus. The mutations were found in the L11-binding site of 23S rRNA [184]. Microccin P1 is a thiopeptide group antibiotic having a 26-membered macrocycle like thiostrepton. The microccin P1 biosynthetic gene cluster was isolated from S. epidermidis and compared with that of thiocillin from B. cereus [185-187]. The cluster for microccin P1 contains $t c l Q$ that encodes TclQ protein incorporating into the ribosome in place of L11 and conferring the self-resistance to microccin P1 [185]. The cluster for thiocillin contains two L11-like proteins TclQ and TclT that may be involved in the self-resistance [187]. The resistance mechanisms in 
this class of antibiotics are generally similar between producers and pathogens, although the details have not been elucidated yet.

\section{Cell Wall/Membrane Synthesis Inhibitors}

\section{1. $\beta$-Lactams}

$\beta$-Lactam group antibiotics including semi-synthetic penicillins and cephalosporins are the most commonly used antibiotics in the clinic for the treatment of Gram-positive as well as Gram-negative bacterial infections, although they have been used for almost one century. They are classified into five groups according to their chemical structures: penicillins, cephalosporins/cephamycins, clavulanic acid, thienamycin, nocardicin A and sulfazecin. Penicillin was isolated in 1929 as the first antibiotic by Fleming [188], and rediscovered in 1940 by Chain et al. [189] and in 1941 by Abraham et al. [190]. Penicillins and cephalosporins/cephamycins are produced by bacteria as well as fungi, whereas other $\beta$-lactam antibiotics are produced by bacteria [191-193]. The gene clusters for the biosyntheses of penicillins/cephalosporins/cephamycins were cloned from Streptomyces clavuligerus [194,195] (GB No. CM000913, SCLAV_4179 SCLAV_4214), S. cattleya [196] (GB No. NC_016111, SCAT_5676 SCAT_5692), Nocardia lactamdurans [197,198], Lysobacter lactamgenus [199] (GB No. X56660), Penicillium chrysogenum [200] (GB No.CM002799, EN45_082610 EN45_082630), and Aspergillus (Emericella) nidulans [201]. Interestingly, whereas the genes for penicillin-binding proteins and $\beta$-lactamases, which are involved in the self-resistance in bacteria $[5,202,203]$, are present within these clusters of bacteria, they are absent in those of the fungi, indicating strongly that penicillin-binding proteins and $\beta$-lactamases especially the formers are involved in the self-resistance [5]. Clavulanic acid is a potent inhibitor of a various kind of $\beta$-lactamases from pathogenic bacteria with antibacterial activity and was isolated from S. clavuligerus $[204,205]$. It has been used in combination with $\beta$-lactam antibiotics [206]. The gene cluster for the biosynthesis of clavulanic acid is located between cephamycin gene cluster and penicillin-binding protein and $\beta$-lactamase genes $[195,207,208]$. Comparison of the gene clusters for the biosynthesis of cephamycin in S. clavuligerus and S. cattleya, a clavulanic acid-non-producer, indicates that the clavulanic acid gene cluster is inserted between the cephamycin gene cluster and penicillin-binding protein/ $\beta$-lactamase genes without affecting the presence of penicillin-binding protein and $\beta$-lactamase genes, suggesting that the penicillin-binding proteins and the $\beta$-lactamases play important roles in the protection from cephamycin but not from clavulanic acid in the producers [209]. However, precise role of penicillin-binding protein and $\beta$-lactamase genes in clavulanic acid biosynthesis remains to be elucidated [210].

Thienamycin displays antimicrobial activity against Gram-negative, Gram-positive as well as anaerobic bacteria. Unfortunately, however, it is extremely unstable in aqueous solution [211]. Consequently, using thienamycin as a progenitor natural product a various carbapenem compounds such as imipenem, meropenem and others with broad antibacterial activity have been synthesized and introduced to clinic [212]. The gene cluster for the biosynthesis of thienamycin is located on the plasmid of S. cattleya [213,214](GB No. AJ421798). Three genes, thnF, thnJ, and thnS, encoding $\mathrm{N}$-acetyltransferase, transporter protein and $\beta$-lactamase, respectively, may be involved in the self-resistance [213]. In addition, thnC encoding efflux pump may be implicated in the resistance. Like other $\beta$-lactam antibiotics, thienamycin binds to penicillin-binding proteins (PBPs) of E. coli, especially to PBP2 [215], although the genes for the PBPs are not detectable within the thienamycin biosynthetic gene cluster. Alternatively, two PBP genes are present within the cephamycin biosynthetic gene cluster as described above. Nocardicin A is a monocyclic $\beta$-lactam antibiotic monobactam, and was isolated from Nocardia uniformis [216] and other actinomycetes. It shows moderate antimicrobial activity against Gram-negative bacteria and exhibits some $\beta$-lactamase resistance [217]. The monobactam antibiotic was later developed to clinically important aztreonam. The biosynthetic gene cluster of nocardicin A was cloned [218] (GB No. AY541063). Acetyltransferase (NocD) and transporter protein (NocH) were proposed to be involved in the self-resistance. Another monobactam antibiotic sulfazecin was isolated 
from Pseudomonas acidophila. It is active against Gram-negative bacteria [219] and is not inactivated by metallo- $\beta$-lactamases that make bacteria resistant to extended-spectrum $\beta$-lactam antibiotics. The gene cluster contains several transporter genes, a $\beta$-lactamase gene, and the multidrug transporter gene $m d t B$ which may be involved in the self-resistance [220] (GB No. KX757706). However, the exact role of $\beta$-lactamase remains to be clarified.

In pathogenic bacteria, the predominant resistance mechanism of Gram-positive bacteria to $\beta$-lactam antibiotics is different from that of Gram-negative bacteria. Whereas the primary mechanism of Gram-positive bacteria is due to the mutation of the targets, penicillin-binding proteins (PBPs), that of Gram-negative bacteria is caused by the expression of $\beta$-lactamases [221,222]. The former mechanism of Gram-positive bacteria is similar to the Gram-positive bacterial $\beta$-lactam producers [223]. Among Gram-positive bacteria, S. pneumoniae, Enterococcus faecium, and S. aureus are clinically important, $\beta$-lactam targeting pathogenic bacteria. S. pneumoniae contains six PBPs for the construction of its peptidoglycan. Three PBPs (PBP1a, PBP1b and PBP2a) are bifunctional class A PBPs, having both transglycosylase and transpeptidase activities, two PBPs (PBP2b and PBP2x) are class B transpeptidases, and the sixth PBP (PBP3) is a class C DD-carboxypeptidase. Resistance to $\beta$-lactam antibiotics by $S$. pneumoniae is the consequence of extensive and complementary mosaic mutations of two key $\beta$-lactam target enzymes, PBP2b and/or PBP2x, and compensatory PBP1a [224,225]. In addition, single nucleotide polymorphisms are also associated with $\beta$-lactam resistance within pneumococcal genes connected with a couple of the pathways including the peptidoglycan synthesis pathway [226]. Interestingly, unlike in many bacterial pathogens the expression of $\beta$-lactamases has not been reported in S. pneumoniae, although genes for four enzymes (GB Nos. NP_357719, NP_358132, NP359083, and NP_358185) belonging to the metallo- $\beta$-lactamase superfamily are detectable in its genome. NP_358185 is an RNase Z/an arylsulfatase, NP_359083 is related to glyoxalase II, while NP_358132 and NP_357719 are distantly related to metallo- $\beta$-lactamases from B. cereus (GB No.AAA22276 and AAA22562) and Bacteroides fragilis (GB No.AAA22904) [227].

Enterococci are resident bacterial flora isolated from the ileum, oral cavity and vulval region and usually asymptomatic. Recently, however, multidrug-resistant E. faecium emerged as a major threat to human health. The main mechanism of resistance of multidrug-resistant E. faecium to $\beta$-lactams is the mutation and overexpression of PBP5 belonging to class B PBPs like S. pneumoniae PBP2b and PBP2x and S. aureus PBP2a. Mutations I499T, E629V, and the introduction of an additional Ser466 to the PBP5 gene, and the combinations of these mutations increase the minimum inhibitory concentrations (MICs) of $\beta$-lactams to different $\beta$-lactams [221]. Additionally, D,L-peptidoglycan transpeptidases may be involved in the resistance. They are implicated in the formation of second type of cross-links, the $3 \rightarrow 3$ cross-links, and by-pass the classical PBP pathway. These enzymes are detected in in vitro selected $E$. faecium, wild type M. tuberculosis, M. abscessus, and C. difficile. They have a cysteine residue as an active site instead of a serine residue in PBPs, and are sensitive to carbapenem group $\beta$-lactams, but resistant to ampicillin and cephem group $\beta$-lactams [228].

$S$. aureus is a human commensal, Gram-positive bacteria. Two mechanisms confer resistance in S. aureus. The first is the production of PC1 $\beta$-lactamase encoded by blaZ, which inactivates $\beta$-lactams by hydrolysis of its $\beta$-lactam ring [229]. blaZ products are classified into four groups, A, B, C and D on the basis of their serotype and substrate specificity. blaZ is mostly located on plasmids. However, the leading role in the resistance has been replaced by PBPs at the present time, although $\beta$-lactamases emerged as the initial resistance mechanism in S. aureus. Methicillin-resistant Staphylococcus aureus (MRSA), which is resistant to virtually all $\beta$-lactam antibiotics, has also acquired the mecA gene encoding PBP2a. Additional genes such as fem and aux have been identified to be necessary for methicillin resistance [230]. Clinical isolates of S. aureus with methicillin-resistant and high-level ceftaroline resistant phenotype have PBP2a carrying two contiguous substitutions Y446N and E447K in the cephalosporin-binding pocket of the transpeptidase domain [231].

In contrast to Gram-positive bacteria, Gram-negative bacteria have a thin peptidoglycan cell wall sandwiched between their inner and outer membranes. In Gram-negative bacteria, the primary 
resistance mechanism to $\beta$-lactams is the degradation of $\beta$-lactams by $\beta$-lactamases especially carbapenem-hydrolysing $\beta$-lactamases called as carbapenemases. These enzymes possessing a variety of properties belong to Ambler class A, B, and D. The class A carbapenemases consist primarily of the Klebsiella pneumoniae carbapenemase (KPC), Serratia marcescens enzyme (SME), and imipenem carbapenemase (IMP). The class B carbapenemases are referred to metallo- $\beta$-lactamases (MBLs), and include Verona integron-encoded metallo- $\beta$-lactamase (VIM), and New Delhi metallo- $\beta$-lactamase (NDM). The class D enzymes consist of the OXA $\beta$-lactamases such as OXA23, OXA24, OXA48 and OXA58, which are able to hydrolyze carbapenems [232]. In addition, these carbapenemases exist together with at least one other $\beta$-lactamase, and are able to hydrolyze substantially all $\beta$-lactam antibiotics. Furthermore, most of the genes for the carbapenemases are located on transferrable plasmids flanked by transposable elements, permitting endless transfer and dissemination between bacteria of different species in different environments, sometimes crossing over between Gram-positive and Gram-negative bacteria [233]. The amino acid sequence of Tcur2040 $\beta$-lactamase (GB No.WP_012852391) from Thermomonospora curvata, a thermophilic Gram-positive Actinobacterial species, is also closely related to that of class D $\beta$-lactamases such as OXA5 (GB No.X58272) and OXA27 (GB No.AAC15074, partial) from Gram-negative bacteria [234]. Similarity values are $1.1 \mathrm{e}-46$ and $1.8 \mathrm{e}-43$ at amino acid sequence level, and 1.1e-14 and 2.8e-15 at nucleotide sequence level, respectively. Consequently, bacterial species usually susceptible to carbapenems such as Enterobacteriaceae, Acinetobacter baumannii, $P$. aeruginosa, and K. pneumoniae have acquired the ability to hydrolyze $\beta$-lactams and make them highly resistant to most $\beta$-lactam antibiotics. Moreover, efflux pumps of the RND superfamily such as AcrB of E. coli and MexB of P. aeruginosa are reported to play an important role in producing intrinsic multidrug resistance including $\beta$-lactam antibiotics in Gram-negative bacteria [235].

In summary, the resistance mechanism in $\beta$-lactam producers is primarily due to the intrinsic resistant PBPs. In contrast, the resistance mechanism in Gram-positive pathogenic bacteria is mainly attributed to the mutation of PBPs, while that in Gram-negative bacteria resides in the acquisition of $\beta$-lactamases. Intriguingly, the amino acid sequence of PBP2x of S. pneumoniae (GB No.AFC91889) is more closely related to those of group VIII-5 Streptomyces PBPs such as SCO2090, SCATT_12070, SCLAV_1301, and SSHG_01149 [223] than to those of PBP1a (GB No.AFC91821) and PBP2b (GB No.AAC95433) of S. pneumoniae, to PBP5 of E. faecium (GB No.AIG13035), and to PBP2a of S. aureus (GB No.AVI00630). E values in the former cases are in the order of 1e-20, but those in the latter cases are in the order of 1e-10, suggesting that group VIII-5 PBPs are somehow related to self-resistance in Streptomyces species besides group VIII-6 PBPs [223]. On the other hand, the amino acid sequences of class A carbapenemases in Gram-negative bacteria such as SME3, IMI3, NMC-A, KPC1 and GES2 are closely related to those of actinobacterial $\beta$-lactamases such as SCAB_38731, SAV_4452, SACE_1374, and Amir_2178 (Figure S7). For example, E values between KPC1 (GB No.AF297554_1) and these sequences are 5.9e-35, 6.1e-34, 2.8e-40 and 4.0e-33 at amino acid sequence level, and 2.0e-28, 7.6e-31, 8.3e-43 and $1.8 \mathrm{e}-28$ at nucleotide sequence level, respectively. However, sequence similarities between class $\mathrm{B}$ carbapenemases and actinobacterial $\beta$-lactamases are not so high. For example, E values between IMP1 (GB No.AXQ85786) and Tcur_2765 and Ppa_0914 are 2.2e-08 and 3e-07, respectively. In any case, it is quite surprising that the sequences in Gram-positive pathogenic PBPs are considerably homologous to those in actinobacterial PBPs and, in addition, the Gram-negative pathogenic $\beta$-lactamases have some similarity to actinobacterial $\beta$-lactamases [234].

\subsection{Glycopeptides, Lipopeptides and Related Antibiotics}

The glycopeptide and lipoglycopeptide antibiotics such as vancomycin and teicoplanin show antibacterial activity against Gram-positive bacteria through binding to the D-alanyl-D-alanine terminus of the lipid II bacterial cell wall precursor and sequestrating the lipid II substrate, resulting in the inhibition of peptidoglycan biosynthesis. They are supposed to be the last resort for the treatment of infections caused by methicillin-resistant S. aureus (MRSA) and Enterococcus species. Recently, however, the resistance to these antibiotics is emerging and conferring a terrible threat to human health [236]. In 
contrast, Gram-negative bacteria are intrinsically resistant to these antibiotics because the presence of the outer membrane prevents these molecules from reaching the target. They are biosynthesized by non-ribosomal peptide synthetases $[237,238]$. The biosynthetic gene cluster of vancomycin was cloned from Amycolatopsis orientalis [239] (GB Nos. HE589771 and HQ679900). The ABC transporter (GB No, CCD33134) and VanHAX resistance cassette genes are present within and at the end of the cluster. VanH is a dehydrogenase that converts pyruvate into D-lactate, VanA is a D-Ala-D-Lac ligase, and VanX is a D-Ala-D-Ala dipeptidase that cleaves residual D-Ala-D-Ala dipeptide. Moreover, vanHAX genes are detectable not only in vancomycin-related glycopeptide producing Actinoplanes teichomyceticus [240] and Streptomyces toyokaensis [241] but also in non-producing Streptomyces coelicolor (GB No. AL939117, SCO3594 SCO3596). The biosynthetic gene clusters for vancomycin-related glycopeptide or lipoglycopeptide antibiotics such as balhimycin, chloroeremomycin, teicoplanin, A47934, complestatin, A40926, and pekiskomycin were also cloned [240-250]. The ABC transporters are present in all these clusters. Intriguingly, however, glycopeptide antibiotic A40926 producer Nonomuraea species does not possess the canonical vanHAX genes, instead it possesses vanY gene encoding a novel D,D-peptidase/D,D-carboxypeptidase involved in the self-resistance and peptidoglycan maturation [248,249]. VanHAX enzymes together with two component regulatory system VanSR are implicated in the resistance and regulatory mechanisms in VRE by redirecting a portion of the peptidoglycan biosynthetic pathway, whereas vanSR genes are missing in the DNA flanking the vanHAX cluster in balhimycin producer, and vanHAX genes are constitutively expressed [251,252]. It is speculated, therefore, that vanHAX and their regulatory systems have sophisticatedly evolved depending on the divergent environment surrounding glycopeptide antibiotic producers and related soil-dwelling Actinobacteria [237,253].

On the contrary, in the pathogenic bacteria the first VRE were reported in 1988 [254], and now they are ubiquitously distributed in hospitals as well as in the environment throughout the world. The major resistance mechanism is due to two causes: the first is the substitution of the target D-Ala-D-Ala residues in the peptidoglycan by low affinity termini (D-Ala-D-Lac or D-Ala-D-Ser) and the second is the removal of D-Ala-D-Ala precursors [255]. Ten types of glycopeptide resistance determinants have been reported. Among them, VanA and VanB genotypes predominate worldwide. The VanA type resistance element was originally detected on a plasmid in an E. faecium clinical isolate, and its prevalence has occurred not only in enterococci but also in MRSA, resulting in almost no therapeutic avenues to treat these pathogenic bacteria now. The second type of resistance is mediated by the cooperative function of $\operatorname{VanX}$ and $\operatorname{Van} Y$ which is located adjacent to vanHAX gene cluster. However, this type of resistance is rare comparing to $\operatorname{Van} A$ and $\operatorname{Van} B$ types. It is interesting that the resistance gene organization in enterococci is very similar to that in the glycopeptide producers [256] and, in addition, the amino acid sequences of these proteins in enterococci are extremely similar to those in glycopeptide producers and the related Actinobacteria. For example, E values between VanA of E. faecium (GB No.APC57471) and that of A. orientalis (GB No.CCD33129), A. mediterranei (GB No.WP_013230018), A. balhimycina (GB No.RSM46375), A. teichomyceticus (GB No.CAE53344), S. toyocaensis (GB No.AAC23582), Streptomyces sp. WAC1420 (GB No.AGF91737), S. coelicolor A3(2) (GB No.NP_627790), and VanB of E. faecalis (GB No.AKJ75209) and VanC of E. casseliflavus (GB No.WP_12847813) are 1.3e-105, 6.7e-92, 3.6e-103, 2.8e-90, $7.8 \mathrm{e}-99,6.4 \mathrm{e}-102,2.6 \mathrm{e}-101,5.4 \mathrm{e}-117$, and $1.6 \mathrm{e}-45$ at the amino acid sequence level, respectively. More surprisingly, the sequence similarity at the nucleotide sequence level is exceedingly high: the $E$ values in the above pairs are 1.9e-107, 4e-115, 2.5e-102, 4.9e-127, 5.4e-96, 3.3e-98, 1.2e-116, 9e-200, and 1.8e-24, respectively, although the GC contents between enterococci and Actinobacteria are quite different. E. coli and other Gram-negative bacteria show intrinsic resistance to vancomycin which results from the permeability barrier imposed by the outer membrane as described above [257].

Moenomycin group antibiotics belong to phosphoglycolipids produced by $S$. ghanaensis and inhibit peptidoglycan glycosyltransferases involved in the penultimate step of bacterial cell wall biosynthesis. Although they have been used as animal growth promoters for a couple of decades, no report has been published on significant resistance to moenomycins. The moenomycin A biosynthetic 
gene cluster was cloned as two separate clusters: one cluster contains three genes involved in A ring assembly and the other cluster contains the genes involved in the assembly of the phosphoglycolipid pentasaccharide scaffold [258] (GB No.DQ988994). Four transporter genes are present within the cluster. In addition, most actinomycetes including moenomycin non-producers are reported to be intrinsically resistant to moenomycin A [259]. Furthermore, genome mining revealed that presumed moenomycin gene clusters are present in S. clavuligerus, and $\gamma$-proteobacteria Photorhabdus luminescens and P. asymbiotica. Teichomycin $\mathrm{A}_{1}$ is a phosphoglycolipid antibiotic related to moenomycin, and was isolated from A. teichomyceticus, teicoplanin-producer, although its exact chemical structure has not been determined yet. The biosynthetic gene cluster was cloned from A. teichomyceticus [260] (GB No.KU726098). Although the overall architectures of teichomycin and moenomycin gene clusters are quite different, out of 18 identified teichomycin genes 16 teichomycin genes are orthologous in the moenomycin gene cluster. Within the cluster four transporter genes are present that may be involved in the self-resistance.

Daptomycin is a cyclic lipodepsipeptide produced by S. roseosporus that is clinically used for the treatment of severe infections with Gram-positive bacteria. It was reported that the effect of daptomycin is due to the alteration of the permeabilization and depolarization of the bacterial cell membrane by interacting with $\mathrm{Ca}^{2+}$ ion and phosphatidylglycerol in the membrane [261]. However, the detailed mechanism of action has not been understood. The biosynthetic gene clusters were cloned from S. roseosporus and Saccharomonospora viridis $[262,263]$. Adjacent to the core biosynthetic region, two transporters and a membrane protein genes ( $d p t M, d p t N$ and $d p t P ; d p t N-s v, d p t M-s v$ and $d p t P-s v)$, that may be involved in the self-resistance, are present in S. roseosporus and S. viridis genomes, respectively. Daptomycin non-susceptible $S$. aureus clinical isolates have been obtained very rarely at the present time. They are ascribed to the mutation of the genes involved in cell membrane homeostasis, such as mprF encoding lysyl-phosphatidyl glycerol synthetase; $y y c G / w a l K$ encoding the synthesis of a histidine kinase sensor and a regulator; $r p o B$ and $r p o C$ encoding RNA polymerase $\beta$ and $\beta^{\prime}$ subunits respectively, and others [264,265]. Daptomycin resistance associated with host defense cationic peptides, that related to cardiolipin synthase mutation, and that associated with the mutations within the genes encoding the LiaFSR regulatory system and YycFGHIJ were reported in clinical isolates of S. aureus, and enterococci [266-268].

Friulimicin and laspartomycin are cyclic lipopeptide antibiotics isolated from Actinoplanes friuliensis and S. viridochromogenes, and show antimicrobial activity against broad spectrum of Gram-positive pathogenic bacteria including MRSA and VRE. While friulimicin B inhibits the cell wall precursor cycle, the exact mechanism of action of laspartomycin remains to be clarified [269]. The biosynthetic gene cluster for friulimicin was cloned from $A$. friuliensis [270]. Three transporter genes are present within the cluster. The biosynthetic gene cluster for laspartomycin was cloned and compared with that of friulimicin [271]. Three transporter genes are present within the cluster. Surfactin is a cyclic lipopeptide that is biosynthesized by non-ribosome peptide synthetases (NRPS) in Bacillus species. The whole genome sequencing of B. amyloliquefaciens FZB42 and B. subtilis 916 revealed that the genomes contain three NRPS gene clusters encoding surfactin, bacillomycin D, and fengycin, and four NRPS gene clusters encoding surfactin, bacillomycin L, fengycin, and locillomycin, respectively [272-274]. Many transporter genes exist in the genomes. At least some of them may be implicated in the self-resistance. Tsuge et al. reported that YerP protein was involved in the self-resistance to surfactin in B. subtilis [275]. The amino acid sequence analysis indicates that YerP may correspond to KO64_03555 protein in B. subtilis 916 , which is assumed to be the swarming motility protein SwrC or the multidrug efflux pump subunit AcrB [274].

\subsection{Polyene Macrolides}

Amphotericin B belongs to a group of polyene macrolide antibiotics and has been used as a medically important antifungal antibiotic for several decades. It exerts the antibiotic activity by disruption of fungal cell wall synthesis through its binding to sterols, primarily ergosterol in fungal cell 
wall, resulting in the formation of trans-membrane channels and disturbing the barrier function of the membrane. However, it also binds to cholesterol in mammalian cell membranes to a lesser extent and shows many side effects, especially nephrotoxicity [276]. Moreover, it induces oxidative damage in the cells and modulates the immune system [276,277]. The biosynthetic gene cluster was cloned from S. nodosus [278]. Two ABC transporter genes ( $a m p h G$ and $a m p h H$ ) are detected at the end of the cluster. It is speculated that AmphG and AmphH excrete the drug by forming a heterodimer. Amphotericin B was also produced by Penicillium nalgiovense Laxa [279]. Nystatin is a polyene macrolide antibiotic produced by $S$. noursei and an important antifungal agent used for the treatment of superficial mycosis. Dos Santos et al. revealed that the mechanism of nystatin action is, in addition to the action on membrane sterols, dependent on the membrane biophysical properties and lipid composition [280]. The biosynthetic gene cluster for nystatin was cloned from S. noursei ATCC11455 [281]. It contains six genes including two transporter genes nys $G$ and $n y s H$ within the cluster that may be involved in ATP-dependent nystatin efflux. Candicidin is an aromatic polyene macrolide antibiotic isolated from several Actinomycetes. The biosynthetic gene clusters were cloned [282,283]. They contain two ABC transporter genes at the end of the clusters. Natamycin, also called pimaricin, tennecetin and natacyn, is a polyene macrolide antibiotic and widely used in pharmacotherapy for topical treatment and in the food industry as a natural food preservative. However, it does not exert its antifungal activity by forming pores and permeabilizing the plasma membrane, as other polyene macrolide antibiotics do. Instead, it inhibits a wide range of essential membrane transporters in an ergosterol-dependent manner [284]. The biosynthetic gene clusters were cloned from S. natalensis and S. chattanoogensis $[285,286]$. In the former, two genes for ABC transporters (pimA and pimB) and, in addition, one gene for an efflux pump $(\operatorname{pimH})$ are present within the cluster, whereas pimH is absent in the cluster from $S$. chattanoogensis and other polyene macrolide gene clusters [287]. Although natamycin does not have any antimicrobial activity, the overproduction of the drug is thought to be harmful to the producer organisms. The efflux pumps may function in such situation.

Some clinical isolates of Candida glabrata show the reduced susceptibility to amphotericin B and nystatin, although polyene macrolides in general show a remarkably low rate of antifungal resistance. The isolates have lower ergosterol contents in their membrane than the wild type due to nonsense or missense mutations in the genes which are involved in the biosynthesis of ergosterol. However, ergosterol levels of clinical isolates of Aspergillus terreus are almost identical. On the other hand, there are several reports demonstrating that resistant mutants with similar ergosterol contents convert cell wall composition significantly, especially $\beta-1,3-$ glucan contents. The other mechanisms such as adaptation to oxidative stress and a decrease in mitochondrial activity are also implicated in the resistance of pathogenic fungi $[288,289]$.

\subsection{Lantibiotics and Cyclic Peptides}

Lantibiotics are members of bacteriocins and belong to a group of ribosomally synthesized, post-translationally modified peptides containing unusual amino acids including the thioether amino acids such as lanthionine. They are produced by certain Gram-positive bacteria, and in general have a desirable feature of low likelihood of promoting the development of bacterial resistance and low cytotoxicity at antimicrobial concentration [290-292]. The first lantibiotic, nisin, was discovered in the 1920s and has been used as a food preservative for several decades. Lantibiotics are classified into type A and type B peptides based on their chemical structures and functional properties. Type A lantibiotics are elongated, cationic peptides up to 34 residues in length, whereas type B lantibiotics are globular peptides up to 19 residues in length. Type A lantibiotic nisin binds to and forms a complex with lipid II, a precursor of cell wall peptidoglycan, resulting in the inhibition of peptidoglycan synthesis. Moreover, nisin increases the membrane permeability to lead to the pore formation and the release of ions and small molecules from the target bacteria [293]. Nisin is shown to have antimicrobial activity against both Gram-positive and some Gram-negative pathogens. In addition, nisin is suggested to influence multisets of host immune cells [294]. Type A lantibiotics such as nisin, subtilin, and 
sublancin, also inhibit the germination of spores from Bacillus and Clostridium species. Type B lantibiotic mersacidin inhibits cell wall biosynthesis by forming a complex with lipid II but does not form pores in the cytoplasmic membrane [295]. The biosynthetic gene cluster for nisin was cloned [296] (GB No.HM219853). The eleven genes required for nisin biosynthesis are located in the gene cluster on Tn7276. nisFEG located at the end of the cluster encode putative transporter proteins and nisI within the cluster encodes a nisin-binding lipoprotein that is involved in immunity. The gene cluster for type AI lantibiotic subtilin was cloned from Bacillus subtilis subsp. spizizenii ATCC 6633 [297]. Compared to nisin, the subtilin gene cluster lacks the gene corresponding to nis $P$, which codes for an extracellular subtilisin-like protease involved in precursor processing. Four genes spaIFEG located within the cluster are implicated in the immunity. spaT encoding a transporter is also within the cluster. Type AI lantibiotic microbisporicin produced by actinomycetes Microbispora corallina contains chlorinated tryptophan and dihydroproline residues. It shows antimicrobial activity against a wide range of Gram-positive pathogenic bacteria, and inhibits peptidoglycan biosynthesis by binding to lipid II, and some activity against Gram-negative bacteria such as E. coli, Moraxella catarrhalis, and H. influenza, although the exact mechanism remains to be clarified. The biosynthetic gene cluster was cloned and characterized [298] (GB No.HM536998). Four transporter/immunity genes (mibT, mibU, mibE, mibF) are identified within the cluster. Type AII lantibiotic lacticin 481 forms a complex with lipid II and inhibits PBP1b-catalyzed peptidoglycan biosynthesis [299]. The biosynthetic gene cluster for lacticin 481 was cloned and characterized [300]. Four genes lctTFEG within the cluster are involved in drug transporter or immunity. Among them, at least three genes lctFEG are necessary to provide immunity to lacticin 481. The gene corresponding to nisI is missing in the cluster. The type AII bacteriocin sublancin 168 differs from other lantibiotics of this group due to the presence of two disulfide linkages [301]. The mechanism of action of sublancin is also different from other lantibiotics, that is, that sublancin negatively affects DNA replication, transcription and translation without affecting cell wall biosynthesis [302]. The gene cluster was cloned from B. subtilis 168 [301]. The ABC transporter gene (sunT) and immunity protein gene (sunI) are located within the cluster. The phosphoenolpyruvate: sugar phosphotransferase system is involved in the sensitivity to the glucosylated sublancin [303]. Cinnamycin isolated from S. cinnamoneus belongs to the type B lantibiotics, and binds to phosphatidylethanolamine in the inner layer of the plasma membrane, inducing membrane reorganization such as membrane fusion and the alteration of morphology of the membrane [304]. The gene cluster was cloned and characterized [305]. Two component transporter genes $\operatorname{cinT}$ and $\operatorname{cinH}$ are located in the middle of the cluster. Another actinomycete lantibiotic actagardine is a tetracyclic, type B lantibiotic. It was reported that actagardine inhibits the peptidoglycan transglycosylase, but the details remain to be elucidated [306]. The biosynthetic gene cluster for actagardine was cloned and characterized [307]. Two transporter genes, garH and garT, are present within the cluster and three genes, orf16, orf17, and orf18, are present adjacent to the cluster. The bacteriocin enterocin F4-9 is not a lantibiotic but an O-linked glycopeptide isolated from Enterococcus faecalis [308]. However, the organization of gene cluster is analogous to that of sublancin [301].

Although nisin has been used for decades as a natural preservative in the food industry, there are only few cases of naturally occurring lantibiotic resistance. However, human pathogenic bacteria such as S. aureus and Streptococcus agalactiae confer inherent resistance against lantibiotics such as nisin. There are several mechanisms for the intrinsic resistance: First, nisin resistance protein (NSR), a membrane-associated protease, is detected in S. lactis, S. aureus, S. agalactiae and other pathogenic bacteria $[309,310]$. The genes for these proteins are regulated by specific two-component systems. Second, ABC transporter is involved in the drug excretion from inside the cells. The expression of the ABC transporters is also regulated by two-component systems [291,311]. Third is the modifications of cell wall and membrane. The D-alanylation of teichoic acids alters the net charge distribution in cell wall, making cationic lantibiotics be repelled from the cell envelope of target bacteria such as S. aureus, S. pneumoniae, Clostridium difficile, and B. cereus [312]. The overexpression of the penicillin-binding proteins makes Listeria monocytogenes and S. aureus resistant to nisin and cell 
wall-targeting compounds [313]. The changes of the lipid composition and lysine esterification of the hydroxyl groups of phosphatidylglycerol in cell membranes were also reported to be implicated in the resistance of pathogens against lantibiotics [314]. Summarizing these results, the mechanisms of action of lantibiotics in pathogenic bacteria are little different from those in producing bacteria. In producing bacteria the main players are $A B C$ transporters and immunity protein, while in pathogenic bacteria the nisin resistance protein and the modification of cell wall are additional players.

The polymyxins are the cyclic lipopeptide antibiotic family and were first isolated in 1947 from Bacillus polymyxa (Paenibacillus polymyxa) as antibiotics specifically active against Gram-negative bacteria such as the majority of Enterobacteriaceae as well as Acinetobacter baumannii and P. aeruginosa. Although their clinical use were once gradually decreased by the nephrotoxicity and neurological effects, they have resurged as the last-line drugs against extremely resistant Gram-negative bacteria, due to the global dissemination of these bacteria. The positively charged polymyxins bind to the negatively charged lipid A part of lipopolysaccharide (LPS), exclusively present in Gram-negative bacteria and located in the outer membrane [315]. The polymyxin biosynthetic gene cluster was cloned from P. polymyxa and characterized [316]. Two transporter genes $p m x C$ and $p m x D$ are present in the middle of the cluster. A number of Gram-negative bacteria such as Brucella spp., Edwardsiella spp., and Serratia spp. are naturally resistant to polymyxins. The mechanism is hypothesized to be due to the addition of cationic molecules to LPS. Recently, the acquired resistant strains to polymyxins are increasing in clinical isolates. The mechanisms of the resistance are various modifications of LPS and the use of efflux pumps, some of which are encoded by genes located on plasmids [317,318]. Bacitracin is a cyclic peptide antibiotic produced by several B. licheniformis strains. It is synthesized non-ribosomally by the large multienzyme complex BacABC. It is used as a single ointment or in combination as a triple therapy ointment with neomycin and polymyxin $\mathrm{B}$, and is active against Gram-positive bacteria including Staphylococcus, Streptococcus, Corynebacterium, and Clostridium species. Bacitracin interferes with bacterial cell-wall synthesis by binding undecaprenyl pyrophosphate, a lipid carrier that serves as a critical intermediate in cell wall biosynthesis [319]. The biosynthetic gene cluster of bacitracin was cloned and characterized [320,321]. The transporter encoding genes $b c r A B C$ are located about $3 \mathrm{~kb}$ downstream of the bacitracin biosynthetic operon $b a c A B C$. The two-component regulatory system BacRS is present between these clusters and is implicated in the regulation of the self-resistance of B. licheniformis.

\subsection{Other Cell Wall/Membrane Synthesis Inhibitors}

Capuramycin-type nucleoside antibiotics such as A-500359s and A-102395 show antimicrobial activity against Gram-positive and Gram-negative bacteria and, in addition, M. tuberculosis. Recently, this type of antibiotics gains a considerable attention as potent anti-tuberculosis drugs, because multidrug resistant $M$. tuberculosis strains pose significant threats to human health [322]. These antibiotics inhibit bacterial translocase I, a ubiquitous and essential enzyme that acts in peptidoglycan cell wall biosynthesis. The biosynthetic gene clusters for A-500359s and A-102395 were cloned from S. griseus and Amycolatopsis sp., respectively [323,324]. The former contains genes encoding aminoglycoside phosphotransferase (orf21) and four transporters (orf19, orf20, orf30 and orf35), and the latter contains genes for phosphotransferase (cpr17), but three transporter genes are replaced by three genes for transposases. Instead, four transporter genes (orf58, orf59, orf60 and orf61) exit near the end of the cluster [324]. The phosphotransferase (ORF21) phosphorylates the unsaturated hexuronic acid, a component of A-500359s. These genes are supposed to be implicated in the self-resistance. The biosynthetic gene cluster for A-503083s was also cloned from Streptomyces sp. SANK 62, 799 [325].

D-Cycloserine is a natural metabolite of $S$. lavendulae and S. garyphalus and is a structural analog of D-alanine. It inhibits two sequential enzymes in the cell wall peptidoglycan biosynthetic pathway, alanine racemase and D-Ala-D-Ala ligase [326]. It is used clinically for the treatment of tuberculosis as a second-line drug. The biosynthetic gene cluster for D-cycloserine was cloned [327]. D-Ala-D-Ala ligase and a putative membrane protein (transporter) are proposed to be involved in the 
self-resistance [327]. Fosfomycin is a revival antibiotic and is a phosphoenolpyruvate analogue produced by Streptomyces species. It is active against both Gram-positive and Gram-negative drug-resistant pathogens. Fosfomycin interferes with and inhibits the first step enzyme, UDP-N-acetylglucosamine enolpyruvyl transferase (MurA), of bacterial peptidoglycan biosynthesis [328]. The biosynthetic gene cluster for fosfomycin was cloned from $S$. fradiae and characterized $[329,330]$. fom $A$ and fom $B$ within the cluster are proposed to be involved in the self-resistance in S. wedmorensis [329]. Mutations of $\operatorname{murA}$, a salvage pathway in peptidoglycan biosynthesis, mutations in the uptake systems, and fosfomycin-modifying enzymes are described to function in the fosfomycin resistance in pathogenic bacteria [331]. In $M$. tuberculosis, mutations of alanine racemase, L-alanine dehydrogenase are reported to be implicated in the resistance [332,333]. On the other hand, fosfomycin resistance is very rare in pathogenic bacteria [334].

\section{DNA Synthesis Inhibitors and Related Antibiotics}

\subsection{Bleomycin and Related Antitumor Antibiotics}

Bleomycins are glycopeptide-derived antibiotics produced non-ribosomally by S. verticillus and are clinically valuable natural products used for the treatment of several types of tumors [335]. Bleomycins exert their biological activity though metal-dependent oxidative cleavage of DNA and RNA, but are not cell wall inhibitors such as vancomycin and teicoplanin. The biosynthetic gene cluster for bleomycin was cloned from S. verticillus ATCC15003 as 77kb DNA fragment [336] (GB No.AF210249). The three self-resistance-related genes, $b \operatorname{lm} A, b \operatorname{lm} B$ and orf7 encoding the bleomycin-binding protein, the bleomycin acetyltransferase, and $A B C$ transporter respectively, are present at the end of the cluster [337-339] (GB No. L26955). orf29, which is located at another end of the cluster, may also be involved in the self-resistance by transporting the drug [336]. Tallysomycin and zorbamycin are members of bleomycin family antitumor antibiotics. Their biosynthetic gene clusters were cloned from Streptoalloteichus hindustanus and S. flavoviridis, respectively [340,341]. The gene cluster for tallysomycin contains one each of the genes for $\mathrm{ABC}$ transporter $(\operatorname{tlm} T)$, the tallysomycin-binding protein $(t \operatorname{lm} A)$ and an $\mathrm{N}$-acetyltransferase $(\operatorname{tm} B)$, whereas that for zorbamycin contains three genes for $\mathrm{ABC}$ transporters (orf36, orf37 and orf38) and the zorbamycin-binding protein $(z \mathrm{bmA})$ within the clusters but lacks the zorbamycin acetyltransferase gene. Interestingly, BlmB and TlmB acetylate the metal-free forms of four bleomycin family members, that is, bleomycin, phleomycin, tallysomycin and zorbamycin, and BlmB can provide resistance to zorbamycin in S. flavoviridis, a zorbamycin-producer [342]. Bleomycin can be metabolically inactivated in normal and tumor cells by bleomycin hydolases. These hydrolases are widely distributed in mammals, yeast, and bacteria [343]. DNA strand breaks caused by oxidative damage can be repaired by polynucleotide kinase $3^{\prime}$-phosphatase, the pnkp gene product [344]. PNKP and its homologs are detectable in mammalian cells, yeast as well as bacteria. In addition, the bleomycin-binding proteins are found in MRSA and some pathogenic bacteria [345]. These three mechanisms may function as the major role in the bleomycin resistance in the clinical field.

\subsection{Quinone and Related Antitumor and Antimicrobial Antibiotics}

The angucycline group antibiotics are referred to the characteristic four-ring frame of the aglycone moiety, including tetracycline group antibiotics and anthracycline group antibiotics [346,347]. Daunorubicin, aclacinomycin, and nogalamycin belong to the anthracycline group antitumor antibiotics. Their chemotherapy maintains a prominent role in the treatment of many forms of tumors, as they are listed among the World Health Organization (WHO) model list of essential medicines [348]. However, their clinical use is limited because of the cardiotoxic side effect. The basic mechanisms of cardiotoxicity involve direct pathways for reactive oxygen species generation and the inhibition of topoisomerase 2B [349]. On the other hand, as anthracyclines mediate diverse molecular effects, the mechanism of their cytotoxicity includes multiple pathways: intercalation into DNA, generation of free radicals, DNA binding and alkylation, inhibition of helicase, inhibition of topoisomerases, and so 
on [350]. The doxorubicin (14-hydroxydaunorubicin, adriamycin) and daunorubicin biosynthetic gene cluster were cloned from S. peucetius and characterized [351,352]. Interestingly, S. peucetius ATCC 29, 050 produces daunorubicin but not doxorubicin, whereas $S$. peucetius ATCC 29, 052 produces both daunorubicin and doxorubicin. DrrA and DrrB form a transporter of the antibiotic [353], and DrrC is a UvrS-like DNA repair protein [354]. These are involved in the self-resistance. Daunorubicin forms a specific complex with a secreted serine protease and the protease sequesters daunorubicin to prevent its entry into the cells [355]. DrrD was reported to be implicated in the resistance. However, the detailed mechanism has not been analyzed so far. Aclacinomycin A (aclarubicin), a trisaccharide anthracycline, is shown to be active in patients with acute myeloblastic leukemia, but induces late cardiac toxicity. Aclacinomycin A inhibits topoisomerase I and topoisomerase II. The biosynthetic gene cluster for aclacinomycin was cloned from S. galilaeus [356,357]. AcrV (ABC transporter ATP binding component) and AcrW (ABC transporter transmembrane protein) are present at the end of the cluster. Nogalamycin is an anthracycline group antibiotic produced by $S$. nogalater. The chemical structure is unique in that one of the carbohydrate units of the molecule, nogalamine, is attached both via a carbon-carbon bond and a classical O-glycosidic linkage to the aglycone. It is an antitumor antibiotic and belongs to a threading intercalator, in contrast to daunorubicin which belongs to a non-threading classical intercalators. The biosynthetic gene cluster for nogalamycin was cloned from S. nogalater as a $20 \mathrm{~kb}$ DNA fragment [358]. The genes encoding SnoO (a nuclear transport factor 2 superfamily member, a polyketide cyclase?) and SnorO (an UvrA-like excinuclease) are identified within the cluster. These may be involved in the self-resistance.

Landomycin, urdamycin and jadomycin belong to angucycline group antibiotics. Landomycin E is produced by S. globisporus, and shows antitumor activity which is only mildly affected by multidrug resistance-mediated drug efflux. It is reported that landomycin E arrests tumor cell cycle progression, and induces apoptosis by activation of initiator procaspase-16 [359]. The biosynthetic gene cluster for landomycin E was cloned from S. globisporus [360], and that for landomycin A was cloned from S. cyanogenus [361]. Three genes $\ln d J$, $\ln d W$, and $\ln d W 2$ encoding a transporter, an ABC transporter, and an ATPase of ABC transporter were detected within and the end of the cluster, respectively. Urdamycin is an angucycline-type antibiotic and biologically active against Gram-positive bacteria and stem cells of murine L1210 leukemia. The biosynthetic gene cluster was cloned from S. fradiae [362]. Two transporter genes, $u r d J$ and $u r d J 2$, are detected within the cluster. Aquayamycin and rabelomycin have similar chemical skeleton as urdamycins. Jadomycins are angucycline-type antibiotics and inhibit topoisomerases and promote apoptosis [363]. The biosynthetic gene cluster for jadomycin was cloned from S. venezuelae [364]. A MFS type transporter gene jadL is located within the cluster.

Actinorhodin, granaticin, and medermycin are the benzoisochromanequinone-type antibiotics. Actinorhodin is a blue-pigmented, $\mathrm{pH}$-responsive antibiotic. It shows a weak antibacterial activity against Gram-positive bacteria and causes oxidative damage of multiple cellular targets including DNA, proteins and cell envelope [365]. The biosynthetic gene cluster for actinorhodin was cloned from S. coelicolor and characterized [366,367]. Three transporter genes actII-orf2, actII-orf3 and actVA-orf1, corresponding to SCO5083, SCO5084 and SCO5076, respectively, are detected within the cluster. Granaticin is an antibiotic produced by Streptomyces species and shows an antibacterial activity against Gram-positive bacteria and antitumor activity against P-388 lymphocytic leukemia in mice and human oral epidermoid carcinoma cells [368]. It inhibits rRNA maturation and cell cycle specificity. The biosynthetic gene cluster was cloned from S. violaceoruber $[369,370]$. One transporter gene orf15, which is corresponding to actII-orf2 in S. coelicolor, is detectable within the cluster. Medermycin is an antibiotic active against Gram-positive bacteria. It inhibits platelet aggregation. The biosynthetic gene cluster was cloned from Streptomyces sp. AM-7161 [371]. One transporter gene orf25 is detected within the cluster. Mitomycins were isolated from $S$. lavendulae as antitumor antibiotics more than 60 years ago. They are comprised of aziridine, quinone, and carbamate moieties arranged in a compact pyrroloindole structures. They cross-link DNA with high efficiency and specificity for the sequence $\mathrm{CG}$, and function as alkylating agents only after reductive conversion to highly reactive quinone 
methides [372]. The biosynthetic gene cluster for mitomycin C was cloned from S. lavendulae [373]. Three genes $m c r A, m r d$, and $m c t$ encoding a flavoprotein oxidoreductase, mitomycin-binding protein, and translocase/transporter, respectively, were reported to be involved in the self-resistance [374-376]. Two of them are located within the cluster, but mcrA is outside of the cluster. Interestingly, two homologous genes to $m c r A$, mitR and $m m c M$, are present within the cluster. Yatakemycin is an extraordinarily toxic and DNA alkylating agent with potent antimicrobial and antitumor activity. Together with CC-1065 and duocarmycins, it forms a cyclopropapyrroloindole antibiotic group. The biosynthetic gene cluster for yatakemycin was cloned from Streptomyces sp. TP-A2060 [377,378]. Two transporters and one DNA repair enzyme (YtkR6, DNA glycosylase) were reported to be involved in the self-resistance.

Rebeccamycin and staurosporine are the indolocarbazole type antibiotics produced by Actinobacteria. Rebeccamycin, a halogen-containing natural product, shows antibacterial and antitumor activities. It inhibits DNA topoisomerase I, suppresses myosin light chain kinase production and induces claudin-5 expression [379]. The biosynthetic gene cluster was cloned from Saccharothrix (Lechevalieria) aerocolonigenes [380,381]. RebT and RebU were reported to be involved in the self-resistance/secretion. The indolocarbazole staurosporine is a potent inhibitor of a variety of protein kinases such as protein kinase $C$ and cyclin-dependent protein kinase. It induces cell cycle arrest, apoptosis, and activation of caspase-3. The biosynthetic gene clusters were cloned from Streptomyces sp. TP-A0274 [382] and S. clavuligerus ATCC27064. No gene related to the resistance/transporter has been detectable within and adjacent to the gene cluster in both Streptomyces sp. TP-A0274 and S. clavuligerus ATCC27064. Moreover, no gene related to the resistance/transporter is present within and adjacent to the gene cluster (DDQ41_30655 DDQ41_30725 in GB No. CP029254) in S. spongiicola HNM0071, that produces staurosporine. The fact that no gene related to the self-resistance is detectable in these species suggests that these genes were deleted or missing at the beginning from the genome due to the unnecessity for their existence because of the lack of antimicrobial activity. However, details remain to be clarified. Indolmycin is an antibiotic produced by S. griseus and Pseudoalteromonas luteoviolacea, a marine $\gamma$-proteobacterium $[383,384]$, and shows an antimicrobial activity against human pathogens, including MRSA and H. pylori. It competes with tryptophan for binding to tryptophanyl-tRNA synthetase as a natural tryptophan analog. The biosynthetic gene cluster for indolmycin was cloned from S. griseus ATCC12648 [385]. However, no resistance-related gene is detectable. Interestingly, S. griseus NBRS13350 has two genes encoding tryptophanyl-tRNA synthetases (SGR_2702 and SGR_3809). Among them, the SGR_3809 gene encodes an indolmycin-resistant enzyme. Moreover, a cDNA 93\% identical in sequence to SGR_3809 was detected in S. griseus ATCC12648, the indolmycin producer, indicating that an auxiliary tryptophanyl-tRNA synthetase has a role in the self-resistance [386].

Chromomycin $\mathrm{A}_{3}$ and mithramycin are aureolic acid-type antitumor antibiotics. Chromomycin $\mathrm{A}_{3}$ forms dimeric complexes with divalent cations and binds to the GC rich sequence of DNA to inhibit DNA replication and transcription [387]. It shows antimicrobial activity against Gram-positive bacteria and inhibits the growth of several lines of tumor cells. The biosynthetic gene cluster was cloned from S. griseus [388]. It contains three genes at the end of the cluster that are involved in the self-resistance. The $c m r A$ and $c m r B$ genes encode the $A B C$ transporters, and $c m r X$ encodes an UvrA-like UV repair nuclease. The $\mathrm{CmrAB} A B C$ transporter confers a high level resistance to the biosynthetic intermediate [389]. The aureolic acid group compound mithramycin is an antitumor antibiotic produced by $S$. argillaceus. The biosynthetic genes for mithramycin were cloned from S. argillaceus [390,391]. Three genes $m \operatorname{tr} A, m \operatorname{tr} B$, and $m \operatorname{tr} X$, supposed to be involved in the self-resistance are located at the end of the cluster. $m \operatorname{tr} A$ and $m \operatorname{tr} B$ encode a transporter and $m \operatorname{tr} X$ encodes the UV-repair system.

Thiocoraline, echinomycin and triostin are thiodepsipeptide antibiotics produced by several species of actinomycetes. This group of compounds belongs to a large family of bisintercalators based on their nonribosomally biosynthesized peptide cores [392]. These compounds intercalate with high affinity into the minor groove of DNA and show their potent activity on various tumors, viruses and 
bacteria. Thiocoraline is a member of the two-fold symmetric bicyclic bisintercalators produced by two marine Micromonospora species. This compound shows antibacterial activity against Gram-positive bacteria and antitumor activity against various human cancer cell lines. It inhibits DNA polymerase $\alpha$ and promotes cell cycle arrest. The biosynthetic gene cluster was cloned from Micromonospora sp. ML1 as 65kb DNA fragment [393]. Within the cluster, there are two transporter genes (tioC and tioD), uvrA-like gene (tioU) and tioX encoding a protein that could be involved in the sequestration of thiocoraline $[393,394]$. Echinomycin/quinomycin A is a pseudosymmetric bicyclic bisintercalator produced by several Streptomyces species. This compound was reported to specifically inhibit binding of hypoxia-inducible factor-1 (HIF-1) to the hypoxia-responsive element (HRE) sequence contained in the vascular endotherial growth factor (VEGF) promoter. The biosynthetic gene clusters were cloned from S. lasaliensis [395], and S. griseovariabilis [396]. While the cluster in S. lasaliensi contains uvrA-like gene (ecm16), but not two transporter genes, that in S. griseovariabilis contains uvrA-like gene (qui10) as well as two transporter genes (quil and qui2). Recent whole genome sequencing of S. spongiicola HNM0071 (GB No. CP029254) indicates that six ABC transporters within the cluster might regulate the biosynthesis of echinomycin [397]. Triostin A is the direct precursor of echinomycin, and the ecm18 gene product $S$-adenosyl-L-methionine (SAM)-dependent methyltransferase is thought to catalyze this transformation [395]. This compound prefers to bind AT-rich DNA sequences over the GC-rich DNA sequences. The biosynthetic gene cluster for triostin A was cloned from S. triostinicus [398]. Two transporter genes ( $t r s D$ and $\operatorname{trs} E$ ) and one DNA repair gene (trs $M)$ are present within the cluster.

Azinomycin and ficellomycin are hybrid polyketide/nonribosomal peptide natural products possessing an azabicyclohexane ring system, and show antitumor activity by interacting covalently with duplex DNA in the major groove and inducing interstrand crosslinking. The biosynthetic gene cluster for azinomycin B was cloned from S. sahachiroi [399]. One transporter gene (aziE) is detected within the cluster. The DNA glycosylase (AlkZ), which functions in the reduction and repair of azinomycin B induced DNA damage, and the azinomycin-binding protein (AziR) are involved in the self-resistance in $S$. sahachiroi $[400,401]$. Ficellomycin exhibits potent in vitro activity against $S$. aureus including MRSA. It was reported that ficellomycin selectively impairs semiconservative DNA replication in DNA polymerase I-deficient E. coli [402]. The biosynthetic gene cluster for ficellomycin was cloned from S. ficellus [403]. It was proposed that Fic11, Fic12 and Fic42 function as the ABC transporters and Fic14 and Fic45 are MFS transporters.

Novobiocin, coumermycin $\mathrm{A}_{1}$ and clorobiocin constitute the aminocoumarin antibiotics. These compounds are potent inhibitors of gyrase, bind to the B subunit of bacterial DNA gyrase, and inhibit the ATP-dependent DNA supercoiling catalyzed by gyrase. DNA gyrase is a type II topoisomerase. The fluoroquinolones are good examples of very successful gyrase-targeted drugs, although they are not antibiotics. The clinical use of aminocoumarin antibiotics are limited due to their poor pharmacological properties, limited solubility in water, and moderate toxicity to human. The biosynthetic gene cluster for novobiocin was cloned from S. sphaeroids NCIB11891 as 25.6kb DNA fragment [404]. The cluster contains transporter gene $(n o v A)$ and the novobiocin-resistant gyrase gene $\left(g y r B^{R}\right)$. The novobiocin-producing $S$. sphaeroides possesses two $g y r B$ genes, $g y r B^{S}$ and $g y r B^{R}$ [405], encoding novobiocin-sensitive predominant form of the enzyme and novobicin-resistant form, respectively. Coumermycin $\mathrm{A}_{1}$ has the most complex chemical structure among the three aminocoumarins described above. The coumermycin $\mathrm{A}_{1}$ biosynthetic gene cluster was cloned from S. rishiriensis DSM40489 [406]. The cluster contains two aminocoumarin-resistant topoisomerase genes, $g y r B^{R}$ and $\operatorname{par} Y^{R}$. The $\operatorname{par} Y^{R}$ gene, located immediately downstream of $g y B^{R}$ gene, encodes an aminocoumarin-resistant topoisomerase IV subunit. Gyrase as well as topoisomerase IV belong to type II topoisomerases. Clorobiocin is a halogen-containing aminocoumarin antibiotic produced by a various Streptomyces species. The clorobiocin biosynthetic gene cluster was cloned from S. roseochromogenes DS 12.976 [407]. No transporter gene was detected in the cloned cluster. Interestingly, the clorobiocin gene cluster possesses two aminocoumarin-resistant topoisomerase genes, $g y r B^{R}$ and $\operatorname{par} Y^{R} \operatorname{similar}$ to that of coumermycin $A_{1}$. However, par $Y^{R}$ is missing in the cluster of novobiocin [408]. 


\subsection{Enediyne Antitumor Antibiotics}

The enediyne antitumor antibiotics are a growing family of natural products with novel molecular architecture with triple bonds, and unique biological activity. The clinical usage of the natural compounds of this family are limited mainly because of their toxicity. However, the improvement of the delivery systems and antibody-drug conjugates have paved the way to great clinical success in antitumor chemotherapy [409]. These compounds are classified roughly into two categories. The first category is comprised of the chromoprotein enediyne, possessing a novel nine-membered enediyne chromophore core with a specific associated protein for stabilization. The second category is constituted of the ten-membered ring system and lacks any additional stabilization factor. The nine-membered as well as the ten-membered enediyne compounds bind DNA with high affinity and induce the oxidative DNA strand cleavage. Neocarzinostatin, C-1027, macromomycin, kedarcidin, maduropeptin, and actinoxanthin belong to the first category, whereas calicheamicin and dynemicin belong to the second category. Cyanosporasides are supposed to be degradation products of enediyne compounds [410]. Neocarzinostatin, produced by S. carzinostaticus, is composed of a protein moiety and an enediyne chromophore in the molar ratio of 1:1. The amino acid sequence of the protein moiety was determined [411]. The biosynthetic gene cluster for the enediyne chromophore was cloned from S. carzinostaticus as 92kb DNA fragment [412]. There are two self-resistance-related genes, $n c s A$ encoding apoprotein for the sequestration of the enediyne chromophore, and ncs $A 1$ encoding efflux pump transporter within the cluster [412]. In addition, mycothiol-dependent detoxication may be involved in the self-resistance [413]. C-1027 is a chromoprotein antitumor antibiotic produced by $S$. globisporus and composed of an apoprotein and the enediyne chromophore. The amino acid sequence of the apoprotein was determined [414]. The biosynthetic gene cluster was cloned from S. globisporus [415]. Four genes are implicated in the self-resistance; $c a g A, \operatorname{sgcB}, \operatorname{sgcB} 4$, and $\operatorname{sgcB} 2 / \operatorname{orf}$ (-1) encoding the apoprotein, a transporter, a transporter, and the UvrA-like protein, respectively. Macromomycin/auromomycin isolated from $S$. macromomyceticus is supposed to contain an enediyne chromophore, but the complete structure of the chromophore has not been elucidated yet. The amino acid sequence of the apoprotein (McmA) was determined, which is essential for the maintenance of the stability of the chromophore [416,417]. Kedarcidin with antitumor activity was isolated as a noncovalent complex consisting of an apoprotein and a reactive enediyne chromophore from Streptoalloteichus species. The amino acid sequence of the apoprotein was determined [418]. The biosynthetic gene cluster for the kedarcidin chromophore was cloned [419]. The genes for apoprotein $(k e d A)$ and two transporters (kedX2 and kedX) are present within the cluster. Maduropeptin was isolated from Actinomadura madurea ATCC 39144, consisting of an enediyne chromophore embedded in a highly acidic protein. The cloned biosynthetic gene cluster contains genes for the apoprotein $(m d p A)$, a transporter $(m d p R 3)$, and the DNA repair protein $(m d p R 4)$ [420]. The antitumor protein actinoxanthin was isolated from Actinomyces globisporus. The amino acid sequence of the apoprotein (AxnA) was determined [421,422]. The genes for actinoxanthin apoprotein (DIJ69_34170), transporters, and the UvrA-like protein are located on S. globisporus TFH56 plasmid pTFSG1 (GB No. CP029362).

Calicheamicin and dynemicin are ten-membered enediyne compounds. A semisynthetic derivative of calicheamicin covalently coupled to a humanized monoclonal antibody specific for the antigen CD33 was approved by FDA as the first antibody-targeted cytotoxic antitumor drug (Mylotarg) for clinical use [409]. The biosynthetic gene cluster was cloned from Micromonospora echinospora [423]. The cluster contains genes for putative transporters (calT1 calT7) and the self-sacrifice proteins (CalC, CalU16, and CalU19) [424]. The self-sacrifice proteins form the complex with calicheamicin, induce the proteolysis of the complex, and inactivate both the highly reactive calicheamicin and the self-sacrifice protein. Dynemicin is a hybrid compound constituted of anthraquinone and enediyne core, which contribute to binding and cleavage of DNA, respectively. The dynemicin biosynthetic gene cluster was cloned from Micromonospora chersina [425]. The cluster contains genes for transporters (DynU6, DynT8, and DynT10), dioxygenase (DynE11) which is similar to bleomycin-resistance protein, and a self-sacrifice protein (DynU16). Tiancimycin is a hybrid compound containing anthraquinone and enediyne core. 
The tiancimycin biosynthetic gene cluster was cloned [426]. Two transporters (TnmT1, TnmT2), one self-sacrifice protein (TnmB), and three dioxygenase/bleomycin-resistance-like proteins (TnmS1, TnmS2, and TnmS3) are detectable within the cluster. The dioxygenase/bleomycin-resistance-like proteins may function in the sequestration of tiancimycin in the producer [427]. Cyanosporasides were isolated from marine actinomycetes genus Salinispora. These compounds are speculated to be spontaneous enediyne degradation products [428]. The cyanosporacide biosynthetic gene clusters were cloned from Salinispora pacifica CNS-143 and Streptomyces sp. CNT-179 [429]. There are three transporter genes (orf $(-6)$, orf (-5), and cyaR3) and resistance gene (cyaR2) in S. pacifica, and four transporter genes (orf (-5), orf (-3), cynR4 and orfR5) in Streptomyces sp. CNT-179, respectively, within or adjacent to the clusters.

\section{Other Antibiotics}

The polyketide tetronate compounds bear a tetronate moiety within the structure. These compounds are divided into two classes: tetronates and spirotetronates, and show a vast structural and functional diversity. Some compounds show antimicrobial activity against Gram-positive bacteria, whereas some show antitumor and anti-retroviral activity [430,431]. Tetronomycin is a linear polyether type tetronate inhibiting the growth of Gram-positive bacteria. The tetronomycin biosynthetic gene cluster was cloned from Streptomyces sp. NRRL 11, 266 [432]. No self-resistance-related gene is detectable within the cluster. Maklamicin is a small-sized spirotetronate class antibiotic possessing antimicrobial activity against Gram-positive bacteria and moderate cytotoxicity against some human tumor cell lines. The maklamicin biosynthetic gene cluster was cloned from Micromonospora sp. NBRC 110, 955 [433]. Three transporter genes are detected within the cluster. Abyssomicins belong to the small-sized spirotetronate class of antibiotics and inhibit the chorismate pathway and folate biosynthesis [434]. Abyssomicin analogs A88696C, D, and F are gastric ATPase inhibitors. The abyssomicin biosynthetic gene cluster was cloned from deep-sea-derived S. koyangensis SCSIO 5802 [435]. Five transporter genes $(a b m F 1, a b m F 2, a b m F 3, a b m F 4, a b m D)$ are present within the cluster. $a b m F 1, a b m F 2, a b m F 3$, and $a b m F 4$ constitute a four-component ABC transporter-based import system. Chlorothricin is a medium-sized spirotetronate class antibiotic, and inhibits pyruvate carboxylases from rat liver and Azotobacter vinelandii and cholesterol biosynthesis. The chlorothricin biosynthetic gene cluster was cloned from S. antibioticus DSM 40, 725 [436]. One transporter gene (chlG) is located within the cluster. However, the author suggests that ChlG may not be efficient to transport the synthesized product out of the cells. Lobophorins are medium-sized spirotetronate antibiotics, and show antimicrobial and antitumor activity. The biosynthetic gene cluster for lobophorin was cloned from the deep-sea derived Streptomyces sp. [437]. The genes related to a transporter (lobT1) and the resistance (lobT2) are present within the cluster.

Platensimycin and platensin are novel class of antibiotics isolated from older microbial screening library [438,439]. These compounds show strong, Gram-positive antibacterial activity by selectively inhibiting cellular lipid biosynthesis [440]. The former inhibits $\beta$-ketoacyl carrier protein synthases (KAS) I/II (FabB/F), whereas the latter inhibits acyl carrier protein II/III (FabF/H). The biosynthetic gene clusters for platensimycin (PTM) and platencin (PTN) were cloned from S. platensis MA 7327, and S. platensis MA7339, respectively [441]. Four genes (ptmP1/ptnP1, ptmP2/ptnP2, ptmP3/ptnP3, and $p t n P 4 / p t n P 4)$ were proposed to be involved in the self-resistance. $p t m P 4 / p t n P 4$ codes for an efflux pump. PtmP3 is homologous to the FabB/F enzymes and can functionally replace both FabF and FabH enzymes of the housekeeping type II bacterial fatty acid synthase (FAS II) in Streptomyces species. In addition, FabF is resistant to platensimycin. Kalimantacins, linear polyketides, were isolated from Alcaligenes sp. YL-02632S and show strong antimicrobial activity against S. aureus and S. epidemidis including multi-resistant strains by using FabI, enoyl-acyl carrier protein reductase, as the target [442]. The kalimantacin biosynthetic gene cluster was cloned from Pseudomonas fluorescens [443]. The kalimantacin-producer strain possesses an isoform of FabI, BatG, within the biosynthetic gene cluster which confers full resistance to the producer and functionally complements the E. coli fabI mutation [444]. In addition, the author proposed the involvement of BatM, an alcohol dehydrogenase, 
in the self-resistance, where inactive 17-hydroxyl kalimantacin is exported out of the cells and then the inactive intermediate is activated to kalimantacin by the secreted BatM.

The rifamycins belong to the ansamycin group antibiotics produced by Amycolatopsis mediterranei. Rifampicin, a semisynthetic derivative of rifamycin, has been used as an anti-tuberculosis drug for over several decades. These compounds inhibit DNA-dependent RNA synthesis by binding to the DNA-dependent RNA polymerases of prokaryotes. The rifamycin biosynthetic gene cluster was cloned from Amycolatopsis mediterrane [445]. Three transporter genes (orf21, orf22 and orf23) are located at one end of the cluster, whereas rifP encoding an efflux transporter is present in the middle of the cluster. However, the predominant cause for the self-resistance is due to the intrinsically resistant RNA polymerase encoded by rpoB located at the other end of the cluster. Three amino acid residues in RpoB were reported to be sufficient to confer rifampicin resistance to the producer (GB No.AF040570). The clinical isolates of rifamycin-resistant M. tuberculosis and S. aureus also possess mutant RNA polymerases, although multidrug transporters function as the resistance mechanism in minor parts of clinical resistant isolates [446]. Rifamycin phosphotransferase is also involved in the resistance in clinical isolates [447]. Holomycin is a member of the dithiopyrrolone class antibiotic produced by several Streptomyces species as well as Gram-negative bacteria such as Yersinia ruckeri. It possesses a broad spectrum of antimicrobial activity against Gram-positive and Gram-negative bacteria and inhibits RNA polymerases [448]. The holomycin biosynthetic gene clusters were cloned from S. clavuligerus, Yersinia ruckeri and marine bacterium Pseudoalteromonas sp. [449-451]. In S. clavuligerus, two MFS transporters (SSCG_03491/hlmH and SSCG_03542), flavin-dependent dihydroholomycin oxidase/disulfide reductase (SSCG_03492/hlmI), and S-methylation were proposed to be involved in the self-resistance $[449,452]$. In contrast, rRNA methyltransferase gene (hom12) is present within the gene cluster of Y. ruckeri besides MFS transporter gene (hom8) [450].

Salinosporamide A is a natural proteasome inhibitor isolated from the marine actinobacterium Salinispora tropica and is a promising clinical agent for the treatment of multiple myeloma. The salinosporamide A biosynthetic gene cluster was cloned from S. tropica CNB-440 [453]. The 20S proteasome machinery of $S$. tropica possesses a redundant proteasome $\beta$-subunit (SalI) within the salinosporamide A biosynthetic gene cluster, which confers 30 -fold resistance to salinosporamide A in the producer species [454]. Up-regulation of proteasome subunits and the mutations of the $\beta 5$-subunit encoding gene PSMB5 have been observed in tumor cell lines with acquired resistance. Edeines are a group of closely related linear peptides produced by the soil bacterium Brevibacillus brevis and show an antibacterial activity against Gram-positive and Gram-negative bacteria. The mode of action of edeines was reported to inhibit DNA synthesis at low concentration, and translation at high concentration, and also inhibit cell division [455]. The edeine biosynthetic gene cluster was cloned from B. brevis $\mathrm{Vm} 4$ [456]. The transporter gene (edeA) is present at one end, whereas $\mathrm{N}$-acetyltransferase gene (edeQ) is located at another end of the cluster, which acetylates the $\alpha$-amino group of the 2,3-diaminopropionic acid residue of edeines. Zwittermicin A is the linear aminopolyol antibiotic produced by Bacillus species having the ability to suppress plant diseases and moderate activity against Gram-positive and Gram-negative bacteria. The biosynthetic gene cluster for zwittermicin A was cloned from B. cereus and B. thuringiensis $[457,458]$. zmaR encoding the $\mathrm{N}$-acetyltransferase was reported to be involved in the self-resistance in B. cereus and B. thuringiensis, and zmaWXY encoding three transporters are located at the end of the cluster of $B$. thuringiensis.

Griseofulvin has been used for many years for the oral treatment of Tinea capitis and other dermatophyte infections [459]. Recent studies have paid attention to its antiviral and anticancer effects. The compound inhibits mitosis by affecting mitotic spindle microtubule functions. The griseofulvin biosynthetic gene cluster was cloned from Penicillium aethiopicum [460]. The cluster contains the chlorinase gene $(g s f l)$ involved in the biosynthesis of griseofulvin, and the transporter gene $(g s f)$ ). Mycophenolic acid is a fungal metabolite isolated as early as 1893. It was reported to possess antiviral, antifungal, antibacterial, antitumor, and immunosuppressive activity [461]. The target of mycophenolic acid is inosine- $5^{\prime}$-monoposphate (IMP) dehydrogenase, which catalyzes the rate limiting step in the 
guanine nucleotide biosynthesis. The biosynthetic gene cluster for mycophenolic acid was cloned from Penicillium brevicompactum [462]. The gene cluster contains extra copy of IMP dehydrogenase gene (mpaF), which is resistant to mycophenolic acid. Interestingly, subgenus Penicillium species of both mycophenolic acid producers and non-producers possess two copies of IMP dehydrogenases [463].

\section{Conclusions}

The environment surrounding multidrug resistant pathogenic bacteria is getting worse and worse. The antibiotic resistance genes are complex mixtures of the genes of intrinsic antibiotic resistance [464,465], acquired resistance [466], and adaptive resistance [4]. These genes constitute the resistome [467-469]. This paper compares the resistance mechanisms in antibiotic producers and those in pathogenic bacteria. As a result, some points should be emphasized as follows. First, whereas some of the amino acid sequences of aminoglycoside acetyltransferases and phosphotransferases in pathogenic bacteria show high similarity E values, some others show no similarity at all (Tables S2 and S3, Figures S1 and S3). The similar phenomena are observed at their nucleotide sequence levels. The aminoglycoside acetyltransferase Eis, which is expressed in extensively drug-resistant strains of M. tuberculosis, is an exception, although they are present in other Actinobacteria as well as Anabaena variabilis, B. anthracis, and E. faecalis $[81,82,470]$. However, no report has been published on the involvement of these enzymes in self-resistance of the producers. As for $\beta$-lactamases, sequence similarities are observed between those from Gram-negative bacteria and Actinobacteria at amino acid and nucleotide levels (Figure S7) [5,209,234].

Second, some resistance mechanisms are observed in pathogenic bacteria, but not in antibiotic-producers. For example, the following mechanisms are recognized in pathogenic bacteria: mutations of nucleotides in 23S rRNA and ribosomal proteins in macrolide antibiotics [471-473], and macrolide esterases [152,153]; xanthine-guanine phosphoribosyltransferases and flavin-dependent mono-oxygenases in tetracyclines [161,474,475]; and nisin resistance protein/membrane-associated protease, modification of cell wall/membrane components in lantibiotics [310-314].

Third, according to the antibiotic classes, the bacteria exert their characteristic resistance mechanisms; antibiotic modifications such as acetylation and phosphorylation in aminoglycoside antibiotics; antibiotic modification by glycosylation and target-modification by rRNA methylation in macrolide antibiotics; antibiotic destruction by $\beta$-lactamases and target-modification of penicillin-binding proteins in $\beta$-lactam antibiotics; sequestration by binding to specific proteins in DNA interacting antitumor antibiotics such as bleomycin group of antibiotics [338,340,341], mitomycin [375], thiocoraline [393], and enediyne antibiotics [476]; DNA repair in DNA interacting antitumor antibiotics such as nogalamycin, yatakemycin, chromomycin $\mathrm{A}_{3}$, mithramycin, echinomycin, and enediyne antibiotics.

Fourth, some antibiotic producing bacteria possess two target enzymes, and at least one of them is resistant to their own antibiotics. For example, the indolmycin-producer strain possesses two tryptophanyl-tRNA synthetase genes, and one of them is resistant to indolmycin [386]; the novobiocin-producer strain possesses topoisomerase (DNA gyrase)-sensitive and resistant genes, $g y r B^{S}$ and $g y r B^{R}$ [405]; courmermycin $\mathrm{A}_{1}$-producer strain has two coumermycin- and clorobiocin-resistant topoisomerase genes, $g y r B^{R}$ and $\operatorname{par} Y^{R}$ [408]; salinosporamide A-producer strain holds a salinosporamide-resistant redundant proteasome $\beta$-subunit salI gene within the biosynthetic gene cluster [454]; and the mycophenolic acid-producer strain possesses mycophenolic acid-resistant extra copy of IMP dehydrogenase gene mpaF within the biosynthetic gene cluster [462].

Fifth, in accordance with the dissemination of multidrug resistant pathogenic bacteria, the acquisition of multidrug resistant determinants in opportunistic and/or resident pathogens, and the discovery and introduction of new types of antibiotics such as enediyne compounds, new types of resistance mechanisms such as the self-sacrifice proteins $[424,427,477]$, aminoglycoside acetyltransferases 'Eis' [81,82], and adaptive antibiotic resistance [4] have emerged, and in addition the transfer of the resistance mechanism in producers to new fields of pathogenic bacteria such as $16 \mathrm{~S}$ 
rRNA methyltransferases were reported $[95,96]$. I am worrying that these types of mechanisms will be prevailing in the whole environments near future.

Antibiotic resistance can develop through three distinct mechanisms: intrinsic resistance, acquired resistance and adaptive resistance [2-4]. Adaptive resistance can emerge as a result of concentration gradient and contact with sub-inhibitory concentrations of antibiotics [4]. Among three mechanisms, antibiotic resistances acquired by horizontal gene transfer poses a major threat to human and livestock $[478,479]$. To establish the successful transfer from donor bacteria to recipient bacteria, that reside in various environments, by transformation, transduction or conjugation [7-9], it is necessary to overcome the barrier of GC-content between bacterial species [480-484]. These authors described that a large excess of synonymous GC $\rightarrow$ AT mutation over AT $\rightarrow$ GC mutations arises across a broad range of phylogenetically diverse species, that in a wide variety of bacterial species, the evolution of GC-content by recombination tends to increase the probability of fixation of $\mathrm{AT} \rightarrow \mathrm{GC}$ mutations, and homologous recombination via GC-biased gene conversion ( $\mathrm{gBGC}$ ) is a crucial factor universally influencing the nucleotide content of genes and genomes, and that genes capable of conferring antibiotic resistance are not easily transferred to human pathogens, especially if selection is absent. That is that the GC-content of the genome is a result of complex shuffling of various DNA fragments by mutation, recombination and selection. As a result of these phenomena, GC-contents in the genomes distribute broardly from $16.5 \%$ of Carsonella ruddii to $74.9 \%$ of Anaeromyxobacter dehalogenans in bacterial species $[485,486]$. However, recent analyses of gene transfer to $E$. coli using 200 genes in human pathogens varying widely in resistance mechanisms, targeted antibiotic classes, and phylogenetic dissemination revealed that sequence composition such as codon adaptation index (CAI), GC-content, N-terminal mRNA-folding energy, and gene length is not a major functional barrier, but resistance mechanism and phylogenetic origin are more important determinants deciding the functional compatibility and fitness of the antibiotic resistance genes in the recipient bacteria [147]. Furthermore, phylogenetic relatedness of the donor and the recipient species affects the functional compatibility and fitness cost of newly acquired genes. These results are supported by the analyses of the antibiotic resistance gene distribution in 17 important human pathogens [484]. Considering these results, it is possible to conclude that the environments surrounding the antibiotic resistance in human and livestock have changed from the early antibiotic phase to the newer antibiotic phase. At the early antibiotic phase, even though the transfer of antibiotic resistance genes happened among the antibiotic producing soil bacteria, non-producing environmental bacteria and the clinic pathogens, the frequency and the technique including mobile genetic elements are more restricted and regulated. Moreover, it sometimes is possible to predict the future environment encompassing the antibiotic resistance. However, as the usage and the classes of antibiotics have been enlarged and entered into a new generation, the resistome is getting more and more complex and sophisticated and, is also entering into a new generation [468,469]. In addition, it is going harder and harder to predict the future of antibiotic resistance $[487,488]$. So when we use antibiotics, we should follow the recommendation of WHO at least [1].

Supplementary Materials: The following are available online at http://www.mdpi.com/1420-3049/24/19/3430/s1, Figure S1: Phylogenetic tree of aminoglycoside acetyltransferases on the basis of amino acid sequences of those from antibiotic producers and pathogens; Figure S2: The gene arrangements around the aminoglycoside N-acetyltransferases in Pseudomonas aeruginosa PA34 (A) and Streptomyces fradiae (B); Figure S3: Phylogenetic tree of aminoglycoside phosphotransferases on the basis of amino acid sequences of those from antibiotic producers and pathogens; Figure S4: Phylogenetic tree of aminoglycoside rRNA methyltransferases on the basis of amino acid sequences of those from antibiotic producers and pathogens; Figure S5: Phylogenetic tree of aminoglycoside transporters on the basis of amino acid sequences of those from antibiotic producers and pathogens; Figure S6. Phylogenetic tree of aminoglycoside transporters on the basis of amino acid sequences of those from antibiotic producers and pathogens; Figure S7. Phylogenetic tree of carbapenemases from pathogens and some $\beta$-lactamases from Streptomyces species on the basis of their amino acid sequences; Table S1. Antibiotic resistance-related strategies in bacteria and fungi; Table S2. Amino acid sequence similarities of aminoglycoside acetyltransferases from antibiotic producers and pathogens; Table S3. Amino acid sequence similarities of aminoglycoside phosphotransferases from antibiotic producers and pathogens; Table S4. Amino acid sequence similarities of aminoglycoside $\mathrm{N}$-acetyltransferases from antibiotic producers and pathogens.

Funding: This research received no external funding. 
Acknowledgments: I should like to devote this review paper to the late Prof. Hamao Umezawa, the Former director, Department of Antibiotics, National Institute of Health of Japan (now, reorganized to National Institute of Infectious Diseases) for introducing me to the antibiotic field.

Conflicts of Interest: The author declares no conflict of interest.

\section{References}

1. Antibiotic Resistance. Available online: https://www.who.int/en/news-room/fact-sheets/detail/antibioticresistance (accessed on 11 August 2019).

2. Blair, J.M.; Webber, M.A.; Baylay, A.J.; Ogbolu, D.O.; Piddock, L.J. Molecular mechanisms of antibiotic resistance. Nat. Rev. Microbiol. 2015, 13, 42-51. [CrossRef] [PubMed]

3. Munita, J.M.; Arias, C.A. Mechanisms of antibiotic resistance. Microbiol. Spectr. 2016, 4. [CrossRef]

4. Sandoval-Motta, S.; Aldana, M. Adaptive resistance to antibiotics in bacteria: A systems biology perspective. Wiley Interdiscip. Rev. Syst. Biol. Med. 2016, 8, 253-267. [CrossRef] [PubMed]

5. Ogawara, H. Self-resistance in Streptomyces, with special reference to $\beta$-lactam antibiotics. Molecules 2016, 21, 605. [CrossRef] [PubMed]

6. D'Costa, V.M.; King, C.E.; Kalan, L.; Morar, M.; Sung, W.W.; Schwarz, C.; Froese, D.; Zazula, G.; Calmels, F.; Debruyne, R.; et al. Antibiotic resistance is ancient. Nature 2011, 477, 457-461. [CrossRef] [PubMed]

7. Walker, M.S.; Walker, J.B. Streptomycin biosynthesis and metabolism. Enzymatic phosphorylation of dihydrostreptobiosamine moieties of dihydrostreptomycin-(streptidino) phosphate and dihydrostreptomycin by Streptomyces extracts. J. Biol. Chem. 1970, 245, 6683-6689.

8. Ogawara, H. Antibiotic resistance in pathogenic and producing bacteria, with special reference to $\beta$-lactam antibiotics. Microbiol. Rev. 1981, 45, 591-619.

9. Benveniste, R.; Davies, J. Aminoglycoside antibiotic-inactivating enzymes in actinomycetes similar to those present in clinical isolates of antibiotic-resistant bacteria. Proc. Natl. Acad. Sci. USA 1973, 70, 2276-2280. [CrossRef]

10. Jiang, X.; Ellabaan, M.M.H.; Charusanti, P.; Munck, C.; Blin, K.; Tong, Y.; Weber, T.; Sommer, M.O.A.; Lee, S.Y. Dissemination of antibiotic resistance genes from antibiotic producers to pathogens. Nat. Commun. 2017, 8 , 15784. [CrossRef]

11. Martinez, J.L. Ecology and evolution of chromosomal gene transfer between environmental microorganisms and pathogens. Microbiol. Spectr. 2018, 6. [CrossRef]

12. Peterson, E.; Kaur, P. Antibiotic resistance mechanisms in bacteria: Relationships between resistance determinants of antibiotic producers, environmental bacteria, and clinical pathogens. Front. Microbiol. 2018, 9, 2928. [CrossRef] [PubMed]

13. Bengtsson-Palme, J.; Kristiansson, E.; Larsson, D.G.J. Environmental factors influencing the development and spread of antibiotic resistance. FEMS Microbiol. Rev. 2018, 42. [CrossRef] [PubMed]

14. Wencewicz, T.A. Crossroads of antibiotic resistance and biosynthesis. J. Mol. Biol. 2019, 431, 3370-3399. [CrossRef] [PubMed]

15. Arenz, S.; Wilson, D.N. Bacterial protein synthesis as a target for antibiotic inhibition. Cold Spring Harb. Perspect. Med. 2016, 6, a025361. [CrossRef] [PubMed]

16. Sohmen, D.; Harms, J.M.; Schlunzen, F.; Wilson, D.N. SnapShot: Antibiotic inhibition of protein synthesis I. Cell 2009, 138, 1248.e1. [CrossRef]

17. Voorhees, R.M.; Ramakrishnan, V. Structural basis of the translational elongation cycle. Annu. Rev. Biochem. 2013, 82, 203-236. [CrossRef]

18. Davis, B.D. Mechanism of bactericidal action of aminoglycosides. Microbiol. Rev. 1987, 51, 341-350.

19. Wilson, D.N. The A-Z of bacterial translation inhibitors. Crit. Rev. Biochem. Mol. Biol. 2009, 44, $393-433$. [CrossRef]

20. Takahashi, Y.; Igarashi, M. Destination of aminoglycoside antibiotics in the 'post-antibiotic era'. J. Antibiot. (Tokyo) 2017, 71, 4-14. [CrossRef]

21. Kohanski, M.A.; Dwyer, D.J.; Wierzbowski, J.; Cottarel, G.; Collins, J.J. Mistranslation of membrane proteins and two-component system activation trigger antibiotic-mediated cell death. Cell 2008, 135, 679-690. [CrossRef] 
22. Vazquez-Laslop, N.; Mankin, A.S. How Macrolide Antibiotics Work. Trends Biochem. Sci. 2018, 43, 668-684. [CrossRef] [PubMed]

23. Chopra, I.; Roberts, M. Tetracycline antibiotics: Mode of action, applications, molecular biology, and epidemiology of bacterial resistance. Microbiol. Mol. Biol. Rev. 2001, 65, 232-260. [CrossRef] [PubMed]

24. Schwarz, S.; Kehrenberg, C.; Doublet, B.; Cloeckaert, A. Molecular basis of bacterial resistance to chloramphenicol and florfenicol. FEMS Microbiol. Rev. 2004, 28, 519-542. [CrossRef] [PubMed]

25. Kotra, L.P.; Haddad, J.; Mobashery, S. Aminoglycosides: Perspectives on mechanisms of action and resistance and strategies to counter resistance. Antimicrob. Agents Chemother. 2000, 44, 3249-3256. [CrossRef] [PubMed]

26. Magnet, S.; Blanchard, J.S. Molecular insights into aminoglycoside action and resistance. Chem. Rev. 2005, 105, 477-498. [CrossRef] [PubMed]

27. Borovinskaya, M.A.; Pai, R.D.; Zhang, W.; Schuwirth, B.S.; Holton, J.M.; Hirokawa, G.; Kaji, H.; Kaji, A.; Cate, J.H. Structural basis for aminoglycoside inhibition of bacterial ribosome recycling. Nat. Struct. Mol. Biol. 2007, 14, 727-732. [CrossRef]

28. Trylska, J.; Kulik, M. Interactions of aminoglycoside antibiotics with rRNA. Biochem. Soc. Trans. 2016, 44, 987-993. [CrossRef] [PubMed]

29. Umezawa, H.; Ueda, M.; Maeda, K.; Yagishita, K.; Kondo, S.; Okami, Y.; Utahara, R.; Osato, Y.; Nitta, K.; Takeuchi, T. Production and isolation of a new antibiotic: Kanamycin. J. Antibiot (Tokyo) 1957, 10, 181-188.

30. Kharel, M.K.; Subba, B.; Basnet, D.B.; Woo, J.S.; Lee, H.C.; Liou, K.; Sohng, J.K. A gene cluster for biosynthesis of kanamycin from Streptomyces kanamyceticus: Comparison with gentamicin biosynthetic gene cluster. Arch. Biochem. Biophys. 2004, 429, 204-214. [CrossRef]

31. Yanai, K.; Murakami, T. The kanamycin biosynthetic gene cluster from Streptomyces kanamyceticus. J. Antibiot. (Tokyo) 2004, 57, 351-354. [CrossRef]

32. Hirayama, T.; Tamegai, H.; Kudo, F.; Kojima, K.; Kakinuma, K.; Eguchi, T. Biosynthesis of 2-deoxystreptamine-containing antibiotics in Streptoalloteichus hindustanus JCM 3268: Characterization of 2-deoxy-scyllo-inosose synthase. J. Antibiot. (Tokyo) 2006, 59, 358-361. [CrossRef] [PubMed]

33. Kharel, M.K.; Basnet, D.B.; Lee, H.C.; Liou, K.; Woo, J.S.; Kim, B.G.; Sohng, J.K. Isolation and characterization of the tobramycin biosynthetic gene cluster from Streptomyces tenebrarius. FEMS Microbiol. Lett. 2004, 230, 185-190. [CrossRef]

34. Yamamoto, H.; Hotta, K.; Okami, Y.; Umezawa, H. Mechanism of resistance to aminoglycoside antibiotics in nebramycin-producing Streptomyces tenebrarius. J. Antibiot. (Tokyo) 1982, 35, 1020-1025. [CrossRef] [PubMed]

35. Skeggs, P.A.; Holmes, D.J.; Cundliffe, E. Cloning of aminoglycoside-resistance determinants from Streptomyces tenebrarius and comparison with related genes from other actinomycetes. J. Gen. Microbiol. 1987, 133, 915-923. [CrossRef] [PubMed]

36. Kharel, M.K.; Basnet, D.B.; Lee, H.C.; Liou, K.; Moon, Y.H.; Kim, J.J.; Woo, J.S.; Sohng, J.K. Molecular cloning and characterization of a 2-deoxystreptamine biosynthetic gene cluster in gentamicin-producing Micromonospora echinospora ATCC15835. Mol. Cells 2004, 18, 71-78.

37. Unwin, J.; Standage, S.; Alexander, D.; Hosted, T. Jr.; Horan, A.C.; Wellington, E.M.H. Gene cluster in Micromonospora echinospora ATCC15835 for the biosynthesis of the gentamicin C complex. J. Antibiot. (Tokyo) 2004, 57, 436-445. [CrossRef]

38. Hong, W.R.; Ge, M.; Zeng, Z.H.; Zhu, L.; Luo, M.Y.; Shao, L.; Chen, D.J. Molecular cloning and sequence analysis of the sisomicin biosynthetic gene cluster from Micromonospora inyoensis. Biotechnol. Lett. 2009, 31, 449-455. [CrossRef]

39. Matkovic, B.; Piendl, W.; Bock, A. Ribosomal resistance as a wide-spread self-defence mechanism in aminoglycoside-producing Micromonospora species. FEMS Microbiol. Lett. 1984, 24, 273-276. [CrossRef]

40. Kojic, M.; Topisirovic, L.; Vasiljevic, B. Translational autoregulation of the sgm gene from Micromonospora zionensis. J. Bacteriol. 1996, 178, 5493-5498. [CrossRef]

41. Husain, N.; Tkaczuk, K.L.; Tulsidas, S.R.; Kaminska, K.H.; Cubrilo, S.; Maravic-Vlahovicek, G.; Bujnicki, J.M.; Sivaraman, J. Structural basis for the methylation of G1405 in 16S rRNA by aminoglycoside resistance methyltransferase Sgm from an antibiotic producer: A diversity of active sites in m7G methyltransferases. Nucleic Acids Res. 2010, 38, 4120-4132. [CrossRef]

42. Lee, B.K.; Condon, G.; Wagman, G.H.; Weinstein, M.J. Formation of methylated and phosphorylated metabolites during the fermentation process of verdamicin. Antimicrob. Agents Chemother. 1976, 10, 363-369. [CrossRef] [PubMed] 
43. Huang, F.; Haydock, S.F.; Mironenko, T.; Spiteller, D.; Li, Y.; Spencer, J.B. The neomycin biosynthetic gene cluster of Streptomyces fradiae NCIMB 8233: Characterisation of an aminotransferase involved in the formation of 2-deoxystreptamine. Org. Biomol. Chem. 2005, 3, 1410-1418. [CrossRef] [PubMed]

44. Kudo, F.; Yamamoto, Y.; Yokoyama, K.; Eguchi, T.; Kakinuma, K. Biosynthesis of 2-deoxystreptamine by three crucial enzymes in Streptomyces fradiae NBRC12773. J. Antibiot. (Tokyo) 2005, 58, 766-774. [CrossRef] [PubMed]

45. Hotta, K.; Ishikawa, J.; Ogata, T.; Mizuno, S. Secondary aminoglycoside resistance in aminoglycosideproducing strains of Streptomyces. Gene 1992, 115, 113-117. [CrossRef]

46. Lopez-Cabrera, M.; Perez-Gonzalez, J.A.; Heinzel, P.; Piepersberg, W.; Jimenez, A. Isolation and nucleotide sequencing of an aminocyclitol acetyltransferase gene from Streptomyces rimosus forma paromomycinus. J. Bacteriol. 1989, 171, 321-328. [CrossRef] [PubMed]

47. Subba, B.; Kharel, M.K.; Lee, H.C.; Liou, K.; Kim, B.G.; Sohng, J.K. The ribostamycin biosynthetic gene cluster in Streptomyces ribosidificus: Comparison with butirosin biosynthesis. Mol. Cells 2005, 20, 90-96. [PubMed]

48. Ota, Y.; Tamegai, H.; Kudo, F.; Kuriki, H.; Koike-Takeshita, A.; Eguchi, T.; Kakinuma, K. Butirosin-biosynthetic gene cluster from Bacillus circulans. J. Antibiot. (Tokyo) 2000, 53, 1158-1167. [CrossRef] [PubMed]

49. Kudo, F.; Numakura, M.; Tamegai, H.; Yamamoto, H.; Eguchi, T.; Kakinuma, K. Extended sequence and functional analysis of the butirosin biosynthetic gene cluster in Bacillus circulans SANK 72073. J. Antibiot. (Tokyo) 2005, 58, 373-379. [CrossRef]

50. Matsuhashi, Y.; Sawa, T.; Kondo, S.; Takeuchi, T. Aminoglycoside 3'-phosphotransferase in Bacillus circulans producing butirosins. J. Antibiot. (Tokyo) 1977, 30, 435-437. [CrossRef]

51. Pfister, P.; Hobbie, S.; Vicens, Q.; Bottger, E.C.; Westhof, E. The molecular basis for A-site mutations conferring aminoglycoside resistance: Relationship between ribosomal susceptibility and X-ray crystal structures. Chembiochem 2003, 4, 1078-1088. [CrossRef]

52. Schatz, A.E.; Bugie, E.; Waksman, S.A. Streptomycin, a substance exhibiting antibiotic activity against Gram-positive and Gram-negative bacteria. Proc. Soc. Exp. Biol. Med. 1944, 55, 66-69. [CrossRef]

53. Carter, A.P.; Clemons, W.M.; Brodersen, D.E.; Morgan-Warren, R.J.; Wimberly, B.T.; Ramakrishnan, V. Functional insights from the structure of the $30 \mathrm{~S}$ ribosomal subunit and its interactions with antibiotics. Nature 2000, 407, 340-348. [CrossRef]

54. Ohnuki, T.; Imanaka, T.; Aiba, S. Self-cloning in Streptomyces griseus of an str gene cluster for streptomycin biosynthesis and streptomycin resistance. J. Bacteriol. 1985, 164, 85-94.

55. Distler, J.; Mansouri, K.; Mayer, G.; Stockmann, M.; Piepersberg, W. Streptomycin biosynthesis and its regulation in Streptomycetes. Gene 1992, 115, 105-111. [CrossRef]

56. Ohnishi, Y.; Ishikawa, J.; Hara, H.; Suzuki, H.; Ikenoya, M.; Ikeda, H.; Yamashita, A.; Hattori, M.; Horinouchi, S. Genome sequence of the streptomycin-producing microorganism Streptomyces griseus IFO 13350. J. Bacteriol. 2008, 190, 4050-4060. [CrossRef]

57. Kim, K.R.; Kim, T.J.; Suh, J.W. The gene cluster for spectinomycin biosynthesis and the aminoglycosideresistance function of spcM in Streptomyces spectabilis. Curr. Microbiol. 2008, 57, 371-374. [CrossRef] [PubMed]

58. Lyutzkanova, D.; Distler, J.; Altenbuchner, J. A spectinomycin resistance determinant from the spectinomycin producer Streptomyces flavopersicus. Microbiology 1997, 143, 2135-2143. [CrossRef]

59. Brodersen, D.E.; Clemons, W.M.; Carter, A.P.; Morgan-Warren, R.J.; Wimberly, B.T.; Ramakrishnan, V. The structural basis for the action of the antibiotics tetracycline, pactamycin, and hygromycin B on the $30 \mathrm{~S}$ ribosomal subunit. Cell 2000, 103, 1143-1154. [CrossRef]

60. Pardo, J.M.; Malpartida, F.; Rico, M.; Jimenez, A. Biochemical basis of resistance to hygromycin B in Streptomyces hygroscopicus-the producing organism. J. Gen. Microbiol. 1985, 131, 1289-1298. [CrossRef]

61. Tang, W.; Guo, Z.; Cao, Z.; Wang, M.; Li, P.; Meng, X.; Zhao, X.; Xie, Z.; Wang, W.; Zhou, A.; et al. d-Sedoheptulose-7-phosphate is a common precursor for the heptoses of septacidin and hygromycin B. Proc. Natl. Acad. Sci. USA 2018, 115, 2818-2823. [CrossRef]

62. Palaniappan, N.; Ayers, S.; Gupta, S.; Habib, E.-S.; Reynolds, K.A. Production of hygromycin A analogs in Streptomyces hygroscopicus NRRL 2388 through identification and manipulation of the biosynthetic gene cluster. Chem. Biol. 2006, 13, 753-764. [CrossRef] [PubMed]

63. Dhote, V.; Gupta, S.; Reynolds, K.A. An O-phosphotransferase catalyzes phosphorylation of hygromycin A in the antibiotic-producing organism Streptomyces hygroscopicus. Antimicrob. Agents Chemother. 2008, 52, 3580-3588. [CrossRef] [PubMed] 
64. Ohta, T.; Hasegawa, M. Analysis of the nucleotide sequence of fmrT encoding the self-defense gene of the istamycin producer, Streptomyces tenjimariensis ATCC 31602; comparison with the squences of kamB of Streptomyces tenebrarius NCIB 11028 and kamC of Saccharopolyspora hirsuta CL102. J. Antibiot. (Tokyo) 1993, 46, 511-517. [PubMed]

65. Hotta, K.; Ogata, T.; Ishikawa, J.; Okanishi, M.; Mizuno, S.; Morioka, M.; Naganawa, H.; Okami, Y. Mechanism of multiple aminoglycoside resistance of kasugamycin-producing Streptomyces kasugaensis MB273: Involvement of two types of acetyltransferases in resistance to astromicin group antibiotics. J. Antibiot. (Tokyo) 1996, 49, 682-688. [CrossRef] [PubMed]

66. Schluenzen, F.; Takemoto, C.; Wilson, D.N.; Kaminishi, T.; Harms, J.M.; Hanawa-Suetsugu, K.; Szaflarski, W.; Kawazoe, M.; Shirouzu, M.; Nierhaus, K.H.; et al. The antibiotic kasugamycin mimics mRNA nucleotides to destabilize tRNA binding and inhibit canonical translation initiation. Nat. Struct. Mol. Biol. 2006, 13, 871-878. [CrossRef] [PubMed]

67. Ikeno, S.; Yamane, Y.; Ohishi, Y.; Kinoshita, N.; Hamada, M.; Tsuchiya, K.S.; Hori, M. ABC transporter genes, kasKLM, responsible for self-resistance of a kasugamycin producer strain. J. Antibiot. (Tokyo) 2000, 53, 373-384. [CrossRef] [PubMed]

68. Ohta, T.; Hasegawa, M. Analysis of the self-defense gene ( $m r O)$ of a fortimicin A (astromicin) producer, Micromonospora olivasterospora: Comparison with other aminoglycoside-resistance-encoding genes. Gene 1993, 127, 63-69. [PubMed]

69. Singh, D.; Seo, M.J.; Kwon, H.J.; Rajkarnikar, A.; Kim, K.R.; Kim, S.O.; Suh, J.W. Genetic localization and heterologous expression of validamycin biosynthetic gene cluster isolated from Streptomyces hygroscopicus var. limoneus KCCM 11405 (IFO 12704). Gene 2006, 376, 13-23. [PubMed]

70. Murao, S.; Ohyama, K. New amylase inhibitor (S-AI) from Streptomyces diastaticus var. amylostaticus no. 2476. Agric. Biol. Chem. 1975, 39, 2271-2273.

71. McIver, L.A.; Tripp, J. Acarbose; StatPearls: Treasure Island, FL, USA, 2018.

72. Rockser, Y.; Wehmeier, U.F. The gac-gene cluster for the production of acarbose from Streptomyces glaucescens GLA.O: Identification, isolation and characterization. J. Biotechnol. 2009, 140, 114-123. [CrossRef]

73. Kobayashi, T.; Uozumi, T.; Beppu, T. Cloning and characterization of the streptothricin-resistance gene which encodes streptothricin acetyltransferase from Streptomyces lavendulae. J. Antibiot. (Tokyo) 1986, 39, 688-693. [CrossRef] [PubMed]

74. Maruyama, C.; Toyoda, J.; Kato, Y.; Izumikawa, M.; Takagi, M.; Shin-ya, K.; Katano, H.; Utagawa, T.; Hamano, Y. A stand-alone adenylation domain forms amide bonds in streptothricin biosynthesis. Nat. Chem. Biol. 2012, 8, 791-797. [CrossRef]

75. Yu, Y.; Tang, B.; Dai, R.; Zhang, B.; Chen, L.; Yang, H.; Zhao, G.; Ding, X. Identification of the streptothricin and tunicamycin biosynthetic gene clusters by genome mining in Streptomyces sp. strain fd1-xmd. Appl. Microbiol. Biotechnol. 2018, 102, 2621-2633. [CrossRef] [PubMed]

76. Haupt, I.; Thrum, H.; Noack, D. Self-resistance of the nourseothricin-producing strain Streptomyces noursei. J. Basic Microbiol. 1986, 26, 323-328. [CrossRef] [PubMed]

77. Grammel, N.; Pankevych, K.; Demydchuk, J.; Lambrecht, K.; Saluz, H.P.; Krugel, H. A $\beta$-lysine adenylating enzyme and a $\beta$-lysine binding protein involved in poly $\beta$-lysine chain assembly in nourseothricin synthesis in Streptomyces noursei. Eur. J. Biochem. 2002, 269, 347-357. [CrossRef] [PubMed]

78. Garneau-Tsodikova, S.; Labby, K.J. Mechanisms of resistance to aminoglycoside antibiotics: Overview and perspectives. Medchemcomm. 2016, 7, 11-27. [CrossRef] [PubMed]

79. Costello, S.E.; Deshpande, L.M.; Davis, A.P.; Mendes, R.E.; Castanheira, M. Aminoglycoside-modifying enzymes and 16S ribosomal RNA methyltransferases-encoding genes among a global collection of Gram-negative isolates. J. Glob. Antimicrob. Resist. 2019, 16, 278-285. [CrossRef]

80. Ramirez, M.S.; Tolmasky, M.E. Aminoglycoside modifying enzymes. Drug Resist. Updat. 2010, 13, $151-171$. [CrossRef]

81. Zaunbrecher, M.A.; Sikes, R.D., Jr.; Metchock, B.; Shinnick, T.M.; Posey, J.E. Overexpression of the chromosomally encoded aminoglycoside acetyltransferase eis confers kanamycin resistance in Mycobacterium tuberculosis. Proc. Natl. Acad. Sci. USA 2009, 106, 20004-20009. [CrossRef]

82. Pricer, R.E.; Houghton, J.L.; Green, K.D.; Mayhoub, A.S.; Garneau-Tsodikova, S. Biochemical and structural analysis of aminoglycoside acetyltransferase Eis from Anabaena variabilis. Mol. Biosyst. 2012, 8, 3305-3313. [CrossRef] [PubMed] 
83. Green, K.D.; Biswas, T.; Chang, C.; Wu, R.; Chen, W.; Janes, B.K.; Chalupska, D.; Gornicki, P.; Hanna, P.C.; Tsodikov, O.V.; et al. Biochemical and structural analysis of an Eis family aminoglycoside acetyltransferase from Bacillus anthracis. Biochemistry 2015, 54, 3197-3206. [CrossRef] [PubMed]

84. Salipante, S.J.; Hall, B.G. Determining the limits of the evolutionary potential of an antibiotic resistance gene. Mol. Biol. Evol. 2003, 20, 653-659. [CrossRef] [PubMed]

85. Perry, J.A.; Westman, E.L.; Wright, G.D. The antibiotic resistome: what's new? Curr. Opin. Microbiol. 2014, 21, 45-50. [CrossRef] [PubMed]

86. Vakulenko, S.B.; Mobashery, S. Versatility of aminoglycosides and prospects for their future. Clin. Microbiol. Rev. 2003, 16, 430-450. [CrossRef] [PubMed]

87. Marshall, V.P.; McGee, J.E.; Cialdella, J.I.; Baczynskyj, L.; Chirby, D.G.; Yurek, D.A.; Liggett, W.F.; Kuo, M.S. Purification of lincosaminide O-nucleotidyltransferase from Streptomyces coelicolor Mueller. J. Antibiot. (Tokyo) 1991, 44, 895-900. [CrossRef] [PubMed]

88. Cui, Z.; Wang, X.C.; Liu, X.; Lemke, A.; Koppermann, S.; Ducho, C.; Rohr, J.; Thorson, J.S.; Van Lanen, S.G. Self-resistance during muraymycin biosynthesis: A complementary nucleotidyltransferase and phosphotransferase with identical modification sites and distinct temporal order. Antimicrob. Agents Chemother. 2018, 62. [CrossRef] [PubMed]

89. Doi, Y.; Wachino, J.I.; Arakawa, Y. Aminoglycoside resistance: The emergence of acquired $16 \mathrm{~S}$ ribosomal RNA methyltransferases. Infect. Dis. Clin. N. Am. 2016, 30, 523-537. [CrossRef] [PubMed]

90. Li, X.Z.; Plesiat, P.; Nikaido, H. The challenge of efflux-mediated antibiotic resistance in Gram-negative bacteria. Clin. Microbiol. Rev. 2015, 28, 337-418. [CrossRef] [PubMed]

91. Schindler, B.D.; Kaatz, G.W. Multidrug efflux pumps of Gram-positive bacteria. Drug Resist. Updat. 2016, 27, 1-13. [CrossRef]

92. Shuster, Y.; Steiner-Mordoch, S.; Alon Cudkowicz, N.; Schuldiner, S. A transporter interactome is essential for the acquisition of antimicrobial resistance to antibiotics. PLoS ONE 2016, 11, e0152917. [CrossRef] [PubMed]

93. Tal, N.; Schuldiner, S. A coordinated network of transporters with overlapping specificities provides a robust survival strategy. Proc. Natl. Acad. Sci. USA 2009, 106, 9051-9056. [CrossRef] [PubMed]

94. Pao, S.S.; Paulsen, I.T.; Saier, M.H., Jr. Major facilitator superfamily. Microbiol. Mol. Biol. Rev. 1998, 62, 1-34. [PubMed]

95. Fritsche, T.R.; Castanheira, M.; Miller, G.H.; Jones, R.N.; Armstrong, E.S. Detection of methyltransferases conferring high-level resistance to aminoglycosides in enterobacteriaceae from Europe, North America, and Latin America. Antimicrob. Agents Chemother. 2008, 52, 1843-1845. [CrossRef] [PubMed]

96. Taylor, E.; Sriskandan, S.; Woodford, N.; Hopkins, K.L. High prevalence of $16 \mathrm{~S}$ rRNA methyltransferases among carbapenemase-producing Enterobacteriaceae in the UK and Ireland. Int. J. Antimicrob. Agents 2018, 52, 278-282. [CrossRef] [PubMed]

97. Katz, L.; Mankin, A.S. Macrolides. In Encyclopedia of Microbiology, 3rd ed.; Academic Press: New York, NY, USA, 2009; pp. 529-558.

98. Arsic, B.; Barber, J.; Ckos, A.; Mladenovic, M.; Stankovic, N.; Novak, P. 16-membered macrolide antibiotics: A review. Int. J. Antimicrob. Agents 2018, 51, 283-298. [CrossRef] [PubMed]

99. Xu, L.; Depoortere, I.; Vertongen, P.; Waelbroeck, M.; Robberecht, P.; Peeters, T.L. Motilin and erythromycin-A share a common binding site in the third transmembrane segment of the motilin receptor. Biochem. Pharmacol. 2005, 70, 879-887. [CrossRef] [PubMed]

100. Xue, Y.; Zhao, L.; Liu, H.W.; Sherman, D.H. A gene cluster for macrolide antibiotic biosynthesis in Streptomyces venezuelae: Architecture of metabolic diversity. Proc. Natl. Acad. Sci. USA 1998, 95, 12111-12116. [CrossRef]

101. Zhao, L.; Beyer, N.J.; Borisova, S.A.; Liu, H.W. $\beta$-Glucosylation as a part of self-resistance mechanism in methymycin/pikromycin producing strain Streptomyces venezuelae. Biochemistry 2003, 42, 14794-14804. [CrossRef]

102. Cundliffe, E. Glycosylation of macrolide antibiotics in extracts of Streptomyces lividans. Antimicrob. Agents Chemother. 1992, 36, 348-352. [CrossRef]

103. Skinner, R.; Cundliffe, E.; Schmidt, F.J. Site of action of a ribosomal RNA methylase responsible for resistance to erythromycin and other antibiotics. J. Biol. Chem. 1983, 258, 12702-12706.

104. Weber, J.M.; Leung, J.O.; Maine, G.T.; Potenz, R.H.; Paulus, T.J.; DeWitt, J.P. Organization of a cluster of erythromycin genes in Saccharopolyspora erythraea. J. Bacteriol. 1990, 172, 2372-2383. [CrossRef] 
105. Oliynyk, M.; Samborskyy, M.; Lester, J.B.; Mironenko, T.; Scott, N.; Dickens, S.; Haydock, S.F.; Leadlay, P.F. Complete genome sequence of the erythromycin-producing bacterium Saccharopolyspora erythraea NRRL23338. Nat. Biotechnol. 2007, 25, 447-453. [CrossRef]

106. Chen, D.; Feng, J.; Huang, L.; Zhang, Q.; Wu, J.; Zhu, X.; Duan, Y.; Xu, Z. Identification and characterization of a new erythromycin biosynthetic gene cluster in Actinopolyspora erythraea YIM90600, a novel erythronolide-producing halophilic actinomycete isolated from salt field. PLoS ONE 2014, 9, e108129. [CrossRef]

107. Rodriguez, A.M.; Olano, C.; Vilches, C.; Mendez, C.; Salas, J.A. Streptomyces antibioticus contains at least three oleandomycin-resistance determinants, one of which shows similarity with proteins of the ABC-transporter superfamily. Mol. Microbiol. 1993, 8, 571-582. [CrossRef]

108. Olano, C.; Rodriguez, A.M.; Mendez, C.; Salas, J.A. A second ABC transporter is involved in oleandomycin resistance and its secretion by Streptomyces antibioticus. Mol. Microbiol. 1995, 16, 333-343. [CrossRef]

109. Olano, C.; Rodriguez, A.M.; Michel, J.M.; Mendez, C.; Raynal, M.C.; Salas, J.A. Analysis of a Streptomyces antibioticus chromosomal region involved in oleandomycin biosynthesis, which encodes two glycosyltransferases responsible for glycosylation of the macrolactone ring. Mol. Gen. Genet. 1998, 259, 299-308. [CrossRef]

110. Quiros, L.M.; Aguirrezabalaga, I.; Olano, C.; Mendez, C.; Salas, J.A. Two glycosyltransferases and a glycosidase are involved in oleandomycin modification during its biosynthesis by Streptomyces antibioticus. Mol. Microbiol. 1998, 28, 1177-1185. [CrossRef]

111. Xue, Y.; Sherman, D.H. Biosynthesis and combinatorial biosynthesis of pikromycin-related macrolides in Streptomyces venezuelae. Metab. Eng. 2001, 3, 15-26. [CrossRef]

112. Mochizuki, S.; Hiratsu, K.; Suwa, M.; Ishii, T.; Sugino, F.; Yamada, K.; Kinashi, H. The large linear plasmid pSLA2-L of Streptomyces rochei has an unusually condensed gene organization for secondary metabolism. Mol. Microbiol. 2003, 48, 1501-1510. [CrossRef]

113. Birmingham, V.A.; Cox, K.L.; Larson, J.L.; Fishman, S.E.; Hershberger, C.L.; Seno, E.T. Cloning and expression of a tylosin resistance gene from a tylosin-producing strain of Streptomyces fradiae. Mol. Gen. Genet. 1986, 204, 532-539. [CrossRef]

114. Fouces, R.; Mellado, E.; Díez, B.; Barredo, J.L. The tylosin biosynthetic cluster from Streptomyces fradiae: Genetic organization of the left region. Microbiology 1999, 145, 855-868. [CrossRef]

115. Cundliffe, E. Organization and control of the tylosin-biosynthetic genes of Streptomyces fradiae. Actinomycetologica 1999, 13, 68-75. [CrossRef]

116. Liu, M.; Douthwaite, S. Resistance to the macrolide antibiotic tylosin is conferred by single methylations at $23 S$ rRNA nucleotides G748 and A2058 acting in synergy. Proc. Natl. Acad. Sci. USA 2002, 99, 14658-14663. [CrossRef]

117. Karray, F.; Darbon, E.; Oestreicher, N.; Dominguez, H.; Tuphile, K.; Gagnat, J.; Blondelet-Rouault, M.H.; Gerbaud, C.; Pernodet, J.L. Organization of the biosynthetic gene cluster for the macrolide antibiotic spiramycin in Streptomyces ambofaciens. Microbiology 2007, 153, 4111-4122. [CrossRef]

118. Gourmelen, A.; Blondelet-Rouault, M.H.; Pernodet, J.L. Characterization of a glycosyl transferase inactivating macrolides, encoded by gimA from Streptomyces ambofaciens. Antimicrob. Agents Chemother. 1998, 42, 2612-2619. [CrossRef]

119. Zalacain, M.; Cundliffe, E. Methylation of 23 S ribosomal RNA due to carB, an antibiotic-resistance determinant from the carbomycin producer, Streptomyces thermotolerans. Eur. J. Biochem. 1990, 189, 67-72. [CrossRef]

120. Schoner, B.; Geistlich, M.; Rosteck, P. Jr.; Rao, R.N.; Seno, E.; Reynolds, P.; Cox, K.; Burgett, S.; Hershberger, C. Sequence similarity between macrolide-resistance determinants and ATP-binding transport proteins. Gene 1992, 115, 93-96. [CrossRef]

121. Anzai, Y.; Saito, N.; Tanaka, M.; Kinoshita, K.; Koyama, Y.; Kato, F. Organization of the biosynthetic gene cluster for the polyketide macrolide mycinamicin in Micromonospora griseorubida. FEMS Microbiol. Lett. 2003, 218, 135-141. [CrossRef]

122. Inouye, M.; Morohoshi, T.; Horinouchi, S.; Beppu, T. Cloning and sequences of two macrolide-resistance-encoding genes from mycinamicin-producing Micromonospora griseorubida. Gene 1994, 141, 39-46. 
123. Xiao, Y.; Li, S.; Niu, S.; Ma, L.; Zhang, G.; Zhang, H.; Zhang, G.; Ju, J.; Zhang, C. Characterization of tiacumicin $B$ biosynthetic gene cluster affording diversified tiacumicin analogues and revealing a tailoring dihalogenase. J. Am. Chem. Soc. 2011, 133, 1092-1105. [CrossRef]

124. Spizek, J.; Rezanka, T. Lincosamides: Chemical structure, biosynthesis, mechanism of action, resistance, and applications. Biochem. Pharmacol. 2017, 133, 20-28. [CrossRef]

125. Tenson, T.; Lovmar, M.; Ehrenberg, M. The mechanism of action of macrolides, lincosamides and streptogramin $B$ reveals the nascent peptide exit path in the ribosome. J. Mol. Biol. 2003, 330, 1005-1014. [CrossRef]

126. Zhang, H.Z.; Schmidt, H.; Piepersberg, W. Molecular cloning and characterization of two lincomycin-resistance genes, $\operatorname{lm} r A$ and $\operatorname{lmrB}$, from Streptomyces lincolnensis 78-11. Mol. Microbiol. 1992, 6, 2147-2157. [CrossRef]

127. Peschke, U.; Schmidt, H.; Zhang, H.Z.; Piepersberg, W. Molecular characterization of the lincomycin-production gene cluster of Streptomyces lincolnensis 78-11. Mol. Microbiol. 1995, 16, 1137-1156. [CrossRef]

128. Koberska, M.; Kopecky, J.; Olsovska, J.; Jelinkova, M.; Ulanova, D.; Man, P.; Flieger, M.; Janata, J. Sequence analysis and heterologous expression of the lincomycin biosynthetic cluster of the type strain Streptomyces lincolnensis ATCC 25466. Folia Microbiol. (Praha) 2008, 53, 395-401. [CrossRef]

129. Calcutt, M.J.; Cundliffe, E. Cloning of a lincosamide resistance determinant from Streptomyces caelestis, the producer of celesticetin, and characterization of the resistance mechanism. J. Bacteriol. 1990, 172, 4710-4714. [CrossRef]

130. Colabroy, K.L. Tearing down to build up: Metalloenzymes in the biosynthesis lincomycin, hormaomycin and the pyrrolo [1,4]benzodiazepin. Biochim. Biophys. Acta 2016, 1864, 724-737. [CrossRef]

131. Hoefer, I.; Cruesemann, M.; Radzom, M.; Geers, B.; Flachshaar, D.; Cai, X.; Zeeck, A.; Piel, J. Insights into the biosynthesis of hormaomycin, an exceptionally complex bacterial signaling metabolite. Chem. Biol. 2011, 18, 381-391. [CrossRef]

132. Li, W.; Chou, S.; Khullar, A.; Gerratana, B. Cloning and characterization of the biosynthetic gene cluster for tomaymycin, an SJG-136 monomeric analog. Appl. Environ. Microbiol. 2009, 75, 2958-2963. [CrossRef]

133. Hu, Y.; Phelan, V.; Ntai, I.; Farnet, C.M.; Zazopoulos, E.; Bachmann, B.O. Benzodiazepine biosynthesis in Streptomyces refuineus. Chem. Biol. 2007, 14, 691-701. [CrossRef]

134. Li, W.; Khullar, A.; Chou, S.; Sacramo, A.; Gerratana, B. Biosynthesis of sibiromycin, a potent antitumor antibiotic. Appl. Environ. Microbiol. 2009, 75, 2869-2878. [CrossRef]

135. Mast, Y.; Weber, T.; Goelz, M.; Ort-Winklbauer, R.; Gondran, A.; Wohlleben, W.; Schinko, E. Characterization of the 'pristinamycin supercluster' of Streptomyces pristinaespiralis. Microb. Biotechnol. 2011, 4, 192-206. [CrossRef]

136. Bamas-Jacques, N.; Lorenzon, S.; Lacroix, P.; De Swetschin, C.; Crouzet, J. Cluster organization of the genes of Streptomyces pristinaespiralis involved in pristinamycin biosynthesis and resistance elucidated by pulsed-field gel electrophoresis. J. Appl. Microbiol. 1999, 87, 939-948. [CrossRef]

137. Pulsawat, N.; Kitani, S.; Nihira, T. Characterization of biosynthetic gene cluster for the production of virginiamycin M, a streptogramin type A antibiotic, in Streptomyces virginiae. Gene 2007, 393, 31-42. [CrossRef]

138. Lee, C.K.; Minami, M.; Sakuda, S.; Nihira, T.; Yamada, Y. Stereospecific reduction of virginiamycin M1 as the virginiamycin resistance pathway in Streptomyces virginiae. Antimicrob. Agents Chemother. 1996, 40, 595-601. [CrossRef]

139. Xie, Y.; Wang, B.; Liu, J.; Zhou, J.; Ma, J.; Huang, H.; Ju, J. Identification of the biosynthetic gene cluster and regulatory cascade for the synergistic antibacterial antibiotics griseoviridin and viridogrisein in Streptomyces griseoviridis. Chembiochem 2012, 13, 2745-2757. [CrossRef]

140. Arenz, S.; Juette, M.F.; Graf, M.; Nguyen, F.; Huter, P.; Polikanov, Y.S.; Blanchard, S.C.; Wilson, D.N. Structures of the orthosomycin antibiotics avilamycin and evernimicin in complex with the bacterial $70 S$ ribosome. Proc. Natl. Acad. Sci. USA 2016, 113, 7527-7532. [CrossRef]

141. Hosted, T.J.; Wang, T.X.; Alexander, D.C.; Horan, A.C. Characterization of the biosynthetic gene cluster for the oligosaccharide antibiotic, evernimicin, in Micromonospora carbonacea var. africana ATCC39149. J. Ind. Microbiol. Biotechnol. 2001, 27, 386-392. [CrossRef] 
142. Weitnauer, G.; Muhlenweg, A.; Trefzer, A.; Hoffmeister, D.; Sussmuth, R.D.; Jung, G.; Welzel, K.; Vente, A.; Girreser, U.; Bechthold, A. Biosynthesis of the orthosomycin antibiotic avilamycin A: Deductions from the molecular analysis of the avi biosynthetic gene cluster of Streptomyces viridochromogenes Tu57 and production of new antibiotics. Chem. Biol. 2001, 8, 569-581. [CrossRef]

143. Thomas, M.G.; Chan, Y.A.; Ozanick, S.G. Deciphering tuberactinomycin biosynthesis: Isolation, sequencing, and annotation of the viomycin biosynthetic gene cluster. Antimicrob. Agents Chemother. 2003, 47, 2823-2830. [CrossRef]

144. Felnagle, E.A.; Rondon, M.R.; Berti, A.D.; Crosby, H.A.; Thomas, M.G. Identification of the biosynthetic gene cluster and an additional gene for resistance to the antituberculosis drug capreomycin. Appl. Environ. Microbiol. 2007, 73, 4162-4170. [CrossRef]

145. Thiara, A.S.; Cundliffe, E. Analysis of two capreomycin-resistance determinants from Streptomyces capreolus and characterization of the action of their products. Gene 1995, 167, 121-126. [CrossRef]

146. Rahman, T.; Yarnall, B.; Doyle, D.A. Efflux drug transporters at the forefront of antimicrobial resistance. Eur. Biophys. J. 2017, 46, 647-653. [CrossRef]

147. Porse, A.; Schou, T.S.; Munck, C.; Ellabaan, M.M.H.; Sommer, M.O.A. Biochemical mechanisms determine the functional compatibility of heterologous genes. Nat. Commun. 2018, 9, 522. [CrossRef]

148. Hansen, J.L.; Ippolito, J.A.; Ban, N.; Nissen, P.; Moore, P.B.; Steitz, TA. The structures of four macrolide antibiotics bound to the large ribosomal subunit. Mol. Cell 2002, 10, 117-128. [CrossRef]

149. Marilyn, C. Roberts, Ph.D. Thesis. Available online: https://faculty.washington.edu/marilynr/ (accessed on 21 July 2019).

150. Nunez-Samudio, V.; Chesneau, O. Functional interplay between the ATP binding cassette Msr(D) protein and the membrane facilitator superfamily $\operatorname{Mef}(\mathrm{E})$ transporter for macrolide resistance in Escherichia coli. Res. Microbiol. 2013, 164, 226-235. [CrossRef]

151. Fong, D.H.; Burk, D.L.; Blanchet, J.; Yan, A.Y.; Berghuis, A.M. Structural basis for kinase-mediated macrolide antibiotic resistance. Structure 2017, 25, 750-761. [CrossRef]

152. Golkar, T.; Zieliński, M.; Berghuis, A.M. Look and outlook on enzyme-mediated macrolide resistance. Front. Microbiol. 2018, 9, 1942. [CrossRef]

153. Morar, M.; Pengelly, K.; Koteva, K.; Wright, G.D. Mechanism and diversity of the erythromycin esterase family of enzymes. Biochemistry 2012, 51, 1740-1751. [CrossRef]

154. Castro, M.M.; Kandasamy, A.D.; Youssef, N.; Schulz, R. Matrix metalloproteinase inhibitor properties of tetracyclines: Therapeutic potential in cardiovascular diseases. Pharmacol. Res. 2011, 64, 551-560. [CrossRef]

155. Doyle, D.; McDowall, K.J.; Butler, M.J.; Hunter, I.S. Characterization of an oxytetracycline-resistance gene, otrA, of Streptomyces rimosus. Mol. Microbiol. 1991, 5, 2923-2933. [CrossRef]

156. Zhang, W.; Ames, B.D.; Tsai, S.C.; Tang, Y. Engineered biosynthesis of a novel amidated polyketide, using the malonamyl-specific initiation module from the oxytetracycline polyketide synthase. Appl. Environ. Microbiol. 2006, 72, 2573-2580. [CrossRef]

157. Connell, S.R.; Tracz, D.M.; Nierhaus, K.H.; Taylor, D.E. Ribosomal protection proteins and their mechanism of tetracycline resistance. Antimicrob. Agents Chemother. 2003, 47, 3675-3681. [CrossRef]

158. Yu, L.; Yan, X.; Wang, L.; Chu, J.; Zhuang, Y.; Zhang, S.; Guo, M. Molecular cloning and functional characterization of an ATP-binding cassette transporter OtrC from Streptomyces rimosus. BMC Biotechnol. 2012, 12, 52. [CrossRef]

159. Zhu, T.; Cheng, X.; Liu, Y.; Deng, Z.; You, D. Deciphering and engineering of the final step halogenase for improved chlortetracycline biosynthesis in industrial Streptomyces aureofaciens. Metab. Eng. 2013, 19, 69-78. [CrossRef]

160. Dairi, T.; Aisaka, K.; Katsumata, R.; Hasegawa, M. A self-defense gene homologous to tetracycline effluxing gene essential for antibiotic production in Streptomyces aureofaciens. Biosci. Biotechnol. Biochem. 1995, 59, 1835-1841. [CrossRef]

161. Forsberg, K.J.; Patel, S.; Wencewicz, T.A.; Dantas, G. The tetracycline destructases: A novel family of tetracycline-inactivating enzymes. Chem. Biol. 2015, 22, 888-897. [CrossRef]

162. He, J.; Magarvey, N.; Piraee, M.; Vining, L.C. The gene cluster for chloramphenicol biosynthesis in Streptomyces venezuelae ISP5230 includes novel shikimate pathway homologues and a monomodular non-ribosomal peptide synthetase gene. Microbiology 2001, 147, 2817-2829. [CrossRef] 
163. Fernandez-Martinez, L.T.; Borsetto, C.; Gomez-Escribano, J.P.; Bibb, M.J.; Al-Bassam, M.M.; Chandra, G.; Bibb, M.J. New insights into chloramphenicol biosynthesis in Streptomyces venezuelae ATCC 10712. Antimicrob. Agents Chemother. 2014, 58, 7441-7450. [CrossRef]

164. Gross, F.; Lewis, E.A.; Piraee, M.; van Pee, K.H.; Vining, L.C.; White, R.L. Isolation of $3^{\prime}$ -O-acetylchloramphenicol: A possible intermediate in chloramphenicol biosynthesis. Bioorg. Med. Chem. Lett. 2002, 12, 283-286. [CrossRef]

165. Mosher, R.H.; Ranade, N.P.; Schrempf, H.; Vining, L.C. Chloramphenicol resistance in Streptomyces: Cloning and characterization of a chloramphenicol hydrolase gene from Streptomyces venezuelae. J. Gen. Microbiol. 1990, 136, 293-301. [CrossRef] [PubMed]

166. Thaker, M.; Spanogiannopoulos, P.; Wright, G.D. The tetracycline resistome. Cell. Mol. Life Sci. 2010, 67, 419-431. [CrossRef] [PubMed]

167. Nguyen, F.; Starosta, A.L.; Arenz, S.; Sohmen, D.; Donhofer, A.; Wilson, D.N. Tetracycline antibiotics and resistance mechanisms. Biol. Chem. 2014, 395, 559-575. [CrossRef] [PubMed]

168. Lupien, A.; Gingras, H.; Leprohon, P.; Ouellette, M. Induced tigecycline resistance in Streptococcus pneumoniae mutants reveals mutations in ribosomal proteins and rRNA. J. Antimicrob. Chemother. 2015, 70, 2973-2980. [CrossRef] [PubMed]

169. Tao, W.; Lee, M.H.; Wu, J.; Kim, N.H.; Kim, J.C.; Chung, E.; Hwang, E.C.; Lee, S.W. Inactivation of chloramphenicol and florfenicol by a novel chloramphenicol hydrolase. Appl. Environ. Microbiol. 2012, 78, 6295-6301. [CrossRef] [PubMed]

170. Zhang, W.J.; Wang, X.M.; Dai, L.; Hua, X.; Dong, Z.; Schwarz, S.; Liu, S. Novel conjugative plasmid from Escherichia coli of swine origin that coharbors the multiresistance gene cfr and the

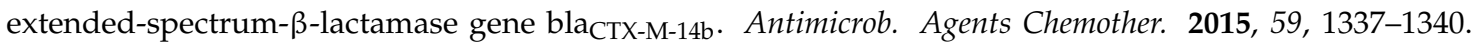
[CrossRef] [PubMed]

171. Cappellano, C.; Monti, F.; Sosio, M.; Donadio, S.; Sarubbi, E. Natural kirromycin resistance of elongation factor Tu from the kirrothricin producer Streptomyces cinnamoneus. Microbiology 1997, 143, 617-624. [CrossRef] [PubMed]

172. Olsthoorn-Tieleman, L.N.; Palstra, R.J.; van Wezel, G.P.; Bibb, M.J.; Pleij, C.W. Elongation factor Tu3 (EF-Tu3) from the kirromycin producer Streptomyces ramocissimus is resistant to three classes of EF-Tu-specific inhibitors. J. Bacteriol. 2007, 189, 3581-3590. [CrossRef]

173. Weber, T.; Laiple, K.J.; Pross, E.K.; Textor, A.; Grond, S.; Welzel, K.; Pelzer, S.; Vente, A.; Wohlleben, W. Molecular analysis of the kirromycin biosynthetic gene cluster revealed $\beta$-alanine as precursor of the pyridone moiety. Chem. Biol. 2008, 15, 175-188. [CrossRef]

174. Robertsen, H.L.; Musiol-Kroll, E.M.; Ding, L.; Laiple, K.J.; Hofeditz, T.; Wohlleben, W.; Lee, S.Y.; Grond, S.; Weber, T. Filling the gaps in the kirromycin biosynthesis: Deciphering the role of genes involved in ethylmalonyl-CoA supply and tailoring reactions. Sci. Rep. 2018, 8, 3230. [CrossRef]

175. Hall, C.C.; Watkins, J.D.; Georgopapadakou, N.H. Effects of elfamycins on elongation factor Tu from Escherichia coli and Staphylococcus aureus. Antimicrob. Agents Chemother. 1989, 33, 322-325. [CrossRef] [PubMed]

176. Prezioso, S.M.; Brown, N.E.; Goldberg, J.B. Elfamycins: Inhibitors of elongation factor-Tu. Mol. Microbiol. 2017, 106, 22-34. [CrossRef] [PubMed]

177. Vior, N.M.; Lacret, R.; Chandra, G.; Dorai-Raj, S.; Trick, M.; Truman, A.W. Discovery and biosynthesis of the antibiotic bicyclomycin in distantly related bacterial classes. Appl. Environ. Microbiol. 2018, 84. [CrossRef] [PubMed]

178. Patteson, J.B.; Cai, W.; Johnson, R.A.; Santa Maria, K.C.; Li, B. Identification of the biosynthetic pathway for the antibiotic bicyclomycin. Biochemistry 2018, 57, 61-65. [CrossRef] [PubMed]

179. Fonseca, E.L.; Marin, M.A.; Encinas, F.; Vicente, A.C. Full characterization of the integrative and conjugative element carrying the metallo- $\beta$-lactamase bla SPM-1 and bicyclomycin bcr 1 resistance genes found in the pandemic Pseudomonas aeruginosa clone SP/ST277. J. Antimicrob. Chemother. 2015, 70, 2547-2550. [CrossRef] [PubMed]

180. Malik, M.; Li, L.; Zhao, X.; Kerns, R.J.; Berger, J.M.; Drlica, K. Lethal synergy involving bicyclomycin: An approach for reviving old antibiotics. J. Antimicrob. Chemother. 2014, 69, 3227-3235. [CrossRef] [PubMed]

181. Kelly, W.L.; Pan, L.; Li, C. Thiostrepton biosynthesis: Prototype for a new family of bacteriocins. J. Am. Chem. Soc. 2009, 131, 4327-4334. [CrossRef] [PubMed] 
182. Morris, R.P.; Leeds, J.A.; Naegeli, H.U.; Oberer, L.; Memmert, K.; Weber, E.; LaMarche, M.J.; Parker, C.N.; Burrer, N.; Esterow, S.; et al. Ribosomally synthesized thiopeptide antibiotics targeting elongation factor Tu. J. Am. Chem. Soc. 2009, 131, 5946-5955. [CrossRef]

183. Smith, T.M.; Jiang, Y.F.; Shipley, P.; Floss, H.G. The thiostrepton-resistance-encoding gene in Streptomyces laurentii is located within a cluster of ribosomal protein operons. Gene 1995, 164, 137-142. [CrossRef]

184. Cameron, D.M.; Thompson, J.; Gregory, S.T.; March, P.E.; Dahlberg, A.E. Thiostrepton-resistant mutants of Thermus thermophilus. Nucleic Acids Res. 2004, 32, 3220-3227. [CrossRef]

185. Bennallack, P.R.; Burt, S.R.; Heder, M.J.; Robison, R.A.; Griffitts, J.S. Characterization of a novel plasmid-borne thiopeptide gene cluster in Staphylococcus epidermidis strain 115. J. Bacteriol. 2014, 196, 4344-4350. [CrossRef] [PubMed]

186. Bennallack, P.R.; Bewley, K.D.; Burlingame, M.A.; Robison, R.A.; Miller, S.M.; Griffitts, J.S. Reconstitution and Minimization of a Micrococcin Biosynthetic Pathway in Bacillus subtilis. J. Bacteriol. 2016, 198, 2431-2438. [CrossRef] [PubMed]

187. Wieland Brown, L.C.; Acker, M.G.; Clardy, J.; Walsh, C.T.; Fischbach, M.A. Thirteen posttranslational modifications convert a 14-residue peptide into the antibiotic thiocillin. Proc. Natl. Acad. Sci. USA 2009, 106, 2549-2553. [CrossRef] [PubMed]

188. Fleming, A. On the antibacterial action of cultures of Penicillium, with special reference to their use in the isolation of B. influenzae. Br. J. Exp. Pathol. 1929, 10, 226-236. [CrossRef]

189. Chain, E.; Florey, H.W.; Gardner, A.D.; Heatley, N.G.; Jennings, M.A.; Orr-Ewing, J.; Sanders, A.G. Penicillin as a chemotherapeutic agent. Lancet 1940, 236, 226-228. [CrossRef]

190. Abraham, E.P.; Chain, E.; Fletcher, C.M.; Florey, H.W.; Gardner, A.D.; Heatley, N.G.; Jennings, M.A. Further observations in penicillin. Lancet 1941, 238, 177-189. [CrossRef]

191. Brakhage, A.A.; Al-Abdallah, Q.; Tuncher, A.; Sprote, P. Evolution of beta-lactam biosynthesis genes and recruitment of trans-acting factors. Phytochemistry 2005, 66, 1200-1210. [CrossRef]

192. Townsend, C.A. Convergent biosynthetic pathways to $\beta$-lactam antibiotics. Curr. Opin. Chem. Biol. 2016, 35, 97-108. [CrossRef]

193. Hamed, R.B.; Gomez-Castellanos, J.R.; Henry, L.; Ducho, C.; McDonough, M.A.; Schofield, C.J. The enzymes of $\beta$-lactam biosynthesis. Nat. Prod. Rep. 2013, 30, 21-107. [CrossRef]

194. Ward, J.M.; Hodgson, J.E. The biosynthetic genes for clavulanic acid and cephamycin production occur as a 'super-cluster' in three Streptomyces. FEMS Microbiol. Lett. 1993, 110, 239-242. [CrossRef]

195. Medema, M.H.; Trefzer, A.; Kovalchuk, A.; van den Berg, M.; Mueller, U.; Heijne, W.; Wu, L.; Alam, M.T.; Ronning, C.M.; Nierman, W.C.; et al. The sequence of a 1.8-mb bacterial linear plasmid reveals a rich evolutionary reservoir of secondary metabolic pathways. Genome Biol. Evol. 2010, 2, 212-224. [CrossRef] [PubMed]

196. Barbe, V.; Bouzon, M.; Mangenot, S.; Badet, B.; Poulain, J.; Segurens, B.; Vallenet, D.; Marliere, P.; Weissenbach, J. Complete genome sequence of Streptomyces cattleya NRRL 8057, a producer of antibiotics and fluorometabolites. J. Bacteriol. 2011, 193, 5055-5056. [CrossRef] [PubMed]

197. Coque, J.J.; Liras, P.; Martin, J.F. Genes for a $\beta$-lactamase, a penicillin-binding protein and a transmembrane protein are clustered with the cephamycin biosynthetic genes in Nocardia lactamdurans. EMBO J. 1993, 12, 631-639. [CrossRef] [PubMed]

198. Liras, P. Biosynthesis and molecular genetics of cephamycins. Cephamycins produced by actinomycetes. Antonie Van Leeuwenhoek 1999, 75, 109-124. [CrossRef] [PubMed]

199. Kimura, H.; Miyashita, H.; Sumino, Y. Organization and expression in Pseudomonas putida of the gene cluster involved in cephalosporin biosynthesis from Lysobacter lactamgenus YK90. Appl. Microbiol. Biotechnol. 1996, 45, 490-501. [CrossRef] [PubMed]

200. Barredo, J.L.; Cantoral, J.M.; Alvarez, E.; Diez, B.; Martin, J.F. Cloning, sequence analysis and transcriptional study of the isopenicillin N synthase of Penicillium chrysogenum AS-P-78. Mol. Gen. Genet. 1989, 216, 91-98. [CrossRef]

201. MacCabe, A.P.; van Liempt, H.; Palissa, H.; Unkles, S.E.; Riach, M.B.; Pfeifer, E.; von Dohren, H.; Kinghorn, J.R. $\delta$-(L- $\alpha$-aminoadipyl)-L-cysteinyl-D-valine synthetase from Aspergillus nidulans. Molecular characterization of the acvA gene encoding the first enzyme of the penicillin biosynthetic pathway. J. Biol. Chem. 1991, 266, 12646-12654. 
202. Paradkar, A.S.; Aidoo, K.A.; Wong, A.; Jensen, S.E. Molecular analysis of a $\beta$-lactam resistance gene encoded within the cephamycin gene cluster of Streptomyces clavuligerus. J. Bacteriol. 1996, 178, 6266-6274. [CrossRef]

203. Ishida, K.; Hung, T.V.; Liou, K.; Lee, H.C.; Shin, C.H.; Sohng, J.K. Characterization of $p b p A$ and $p b p 2$ encoding penicillin-binding proteins located on the downstream of clavulanic acid gene cluster in Streptomyces clavuligerus. Biotechnol. Lett. 2006, 28, 409-417. [CrossRef]

204. Reading, C.; Cole, M. Clavulanic acid: A beta-lactamase-inhibiting beta-lactam from Streptomyces clavuligerus. Antimicrob. Agents Chemother. 1977, 11, 852-857. [CrossRef]

205. Saudagar, P.S.; Survase, S.A.; Singhal, R.S. Clavulanic acid: A review. Biotechnol. Adv. 2008, 26, $335-351$. [CrossRef] [PubMed]

206. Evans, J.; Wittler, M. Amoxicillin Clavulanate; StatPearls Publishing: Treasure Island, FL, USA, 2019.

207. Jensen, S.E.; Paradkar, A.S.; Mosher, R.H.; Anders, C.; Beatty, P.H.; Brumlik, M.J.; Griffin, A.; Barton, B. Five additional genes are involved in clavulanic acid biosynthesis in Streptomyces clavuligerus. Antimicrob. Agents Chemother. 2004, 48, 192-202. [CrossRef] [PubMed]

208. Tahlan, K.; Park, H.U.; Jensen, S.E. Three unlinked gene clusters are involved in clavam metabolite biosynthesis in Streptomyces clavuligerus. Can. J. Microbiol. 2004, 50, 803-810. [CrossRef] [PubMed]

209. Ogawara, H. Self-resistance in Streptomyces, with special reference to $\beta$-lactam antibiotics. Bull. Meiji Pharm. University 2014. [PubMed]

210. Paradkar, A. Clavulanic acid production by Streptomyces clavuligerus: Biogenesis, regulation and strain improvement. J. Antibiot. (Tokyo) 2013, 66, 411-420. [CrossRef] [PubMed]

211. Kahan, J.S.; Kahan, F.M.; Goegelman, R.; Currie, S.A.; Jackson, M.; Stapley, E.O.; Miller, T.W.; Miller, A.K.; Hendlin, D.; Mochales, S.; et al. Thienamycin, a new $\beta$-lactam antibiotic. I. Discovery, taxonomy, isolation and physical properties. J. Antibiot (Tokyo) 1979, 32, 1-12. [CrossRef]

212. El-Gamal, M.I.; Brahim, I.; Hisham, N.; Aladdin, R.; Mohammed, H.; Bahaaeldin, A. Recent updates of carbapenem antibiotics. Eur. J. Med. Chem. 2017, 131, 185-195. [CrossRef] [PubMed]

213. Nunez, L.E.; Mendez, C.; Brana, A.F.; Blanco, G.; Salas, J.A. The biosynthetic gene cluster for the $\beta$-lactam carbapenem thienamycin in Streptomyces cattleya. Chem. Biol. 2003, 10, 301-311. [CrossRef]

214. Rodriguez, M.; Nunez, L.E.; Brana, A.F.; Mendez, C.; Salas, J.A.; Blanco, G. Identification of transcriptional activators for thienamycin and cephamycin $\mathrm{C}$ biosynthetic genes within the thienamycin gene cluster from Streptomyces cattleya. Mol. Microbiol. 2008, 69, 633-645. [CrossRef]

215. Spratt, B.G.; Jobanputra, V.; Zimmermann, W. Binding of thienamycin and clavulanic acid to the penicillin-binding proteins of Escherichia coli K-12. Antimicrob. Agents Chemother. 1977, 12, 406-409. [CrossRef]

216. Aoki, H.; Sakai, H.; Kohsaka, M.; Konomi, T.; Hosoda, J. Nocardicin A, a new monocyclic $\beta$-lactam antibiotic. I. Discovery, isolation and characterization. J. Antibiot. (Tokyo) 1976, 29, 492-500. [CrossRef] [PubMed]

217. Kojo, H.; Mine, Y.; Nishida, M.; Goto, S.; Kuwahara, S. Nature of monocyclic $\beta$-lactam antibiotic nocardicin A to $\beta$-lactamases. Microbiol. Immunol. 1988, 32, 119-130. [CrossRef] [PubMed]

218. Gunsior, M.; Breazeale, S.D.; Lind, A.J.; Ravel, J.; Janc, J.W.; Townsend, C.A. The biosynthetic gene cluster for a monocyclic $\beta$-lactam antibiotic, nocardicin A. Chem. Biol. 2004, 11, 927-938. [CrossRef] [PubMed]

219. Asai, M.; Haibara, K.; Muroi, M.; Kintaka, K.; Kishi, T. Sulfazecin, a novel $\beta$-lactam antibiotic of bacterial origin. Isolation and chemical characterization. J. Antibiot. (Tokyo) 1981, 34, 621-627. [CrossRef] [PubMed]

220. Li, R.; Oliver, R.A.; Townsend, C.A. Identification and characterization of the sulfazecin monobactam biosynthetic gene cluster. Cell. Chem. Biol. 2017, 24, 24-34. [CrossRef] [PubMed]

221. Fisher, J.F.; Mobashery, S. $\beta$-Lactam resistance mechanisms: Gram-positive bacteria and Mycobacterium tuberculosis. Cold Spring Harb. Perspect. Med. 2016, 6, a025221. [CrossRef] [PubMed]

222. Bush, K. Overcoming $\beta$-lactam resistance in Gram-negative pathogens. Future Med. Chem. 2016, 8, 921-924. [CrossRef]

223. Ogawara, H. Penicillin-binding proteins in Actinobacteria. J. Antibiot. (Tokyo) 2015, 68, 223-245. [CrossRef] [PubMed]

224. Albarracín Orio, A.G.; Pinas, G.E.; Cortes, P.R.; Cian, M.B.; Echenique, J. Compensatory evolution of $p b p$ mutations restores the fitness cost imposed by $\beta$-lactam resistance in Streptococcus pneumoniae. PLoS Pathog. 2011, 7, e1002000. [CrossRef]

225. Hakenbeck, R.; Bruckner, R.; Denapaite, D.; Maurer, P. Molecular mechanisms of $\beta$-lactam resistance in Streptococcus pneumoniae. Future Microbiol. 2012, 7, 395-410. [CrossRef] 
226. Chewapreecha, C.; Marttinen, P.; Croucher, N.J.; Salter, S.J.; Harris, S.R.; Mather, A.E.; Hanage, W.P.; Goldblatt, D.; Nosten, F.H.; Turner, C.; et al. Comprehensive identification of single nucleotide polymorphisms associated with beta-lactam resistance within pneumococcal mosaic genes. PLoS Genet. 2014, 10, e1004547. [CrossRef] [PubMed]

227. Daiyasu, H.; Osaka, K.; Ishino, Y.; Toh, H. Expansion of the zinc metallo-hydrolase family of the $\beta$-lactamase fold. FEBS Lett. 2001, 503, 1-6. [CrossRef]

228. Mainardi, J.L.; Villet, R.; Bugg, T.D.; Mayer, C.; Arthur, M. Evolution of peptidoglycan biosynthesis under the selective pressure of antibiotics in Gram-positive bacteria. FEMS Microbiol. Rev. 2008, 32, 386-408. [CrossRef] [PubMed]

229. Bonomo, R.A. $\beta$-Lactamases: A focus on current challenges. Cold Spring Harb. Perspect. Med. 2017, 7, a025239. [CrossRef] [PubMed]

230. De Lencastre, H.; Tomasz, A. Reassessment of the number of auxiliary genes essential for expression of high-level methicillin resistance in Staphylococcus aureus. Antimicrob. Agents Chemother. 1994, 38, 2590-2598. [CrossRef]

231. Long, S.W.; Olsen, R.J.; Mehta, S.C.; Palzkill, T.; Cernoch, P.L.; Perez, K.K.; Musick, W.L.; Rosato, A.E.; Musser, J.M. PBP2a mutations causing high-level ceftaroline resistance in clinical methicillin-resistant Staphylococcus aureus isolates. Antimicrob. Agents Chemother. 2014, 58, 6668-6674. [CrossRef] [PubMed]

232. Poirel, L.; Pitout, J.D.; Nordmann, P. Carbapenemases: Molecular diversity and clinical consequences. Future Microbiol. 2007, 2, 501-512. [CrossRef]

233. Philippon, A.; Slama, P.; Deny, P.; Labia, R. A structure-based classification of class A $\beta$-lactamases, a broadly diverse family of enzymes. Clin. Microbiol. Rev. 2016, 29, 29-57. [CrossRef]

234. Ogawara, H. Molecular phylogenetics of $\beta$-lactamases in Actinobacteria. Bull. Meiji Pharm. Univ. 2013, 42, 1-18.

235. Nikaido, H.; Takatsuka, Y. Mechanisms of RND multidrug efflux pumps. Biochim. Biophys. Acta 2009, 1794, 769-781. [CrossRef]

236. Ahmed, M.O.; Baptiste, K.E. Vancomycin-resistant enterococci: A review of antimicrobial resistance mechanisms and perspectives of human and animal health. Microb. Drug Resist. 2018, 24, 590-606. [CrossRef] [PubMed]

237. Yim, G.; Thaker, M.N.; Koteva, K.; Wright, G. Glycopeptide antibiotic biosynthesis. J. Antibiot. (Tokyo) 2014, 67, 31-41. [CrossRef]

238. Marshall, C.G.; Lessard, I.A.; Park, I.; Wright, G.D. Glycopeptide antibiotic resistance genes in glycopeptide-producing organisms. Antimicrob. Agents Chemother. 1998, 42, 2215-2220. [CrossRef] [PubMed]

239. Xu, L.; Huang, H.; Wei, W.; Zhong, Y.; Tang, B.; Yuan, H.; Zhu, L.; Huang, W.; Ge, M.; Yang, S.; et al. Complete genome sequence and comparative genomic analyses of the vancomycin-producing Amycolatopsis orientalis. BMC Genom. 2014, 15, 363. [CrossRef] [PubMed]

240. Sosio, M.; Kloosterman, H.; Bianchi, A.; de Vreugd, P.; Dijkhuizen, L.; Donadio, S. Organization of the teicoplanin gene cluster in Actinoplanes teichomyceticus. Microbiology 2004, 150, 95-102. [CrossRef] [PubMed]

241. Pootoolal, J.; Thomas, M.G.; Marshall, C.G.; Neu, J.M.; Hubbard, B.K.; Walsh, C.T.; Wright, G.D. Assembling the glycopeptide antibiotic scaffold: The biosynthesis of A47934 from Streptomyces toyocaensis NRRL15009. Proc. Natl. Acad. Sci. USA 2002, 99, 8962-8967. [CrossRef] [PubMed]

242. Van Wageningen, A.M.; Kirkpatrick, P.N.; Williams, D.H.; Harris, B.R.; Kershaw, J.K.; Lennard, N.J.; Jones, M.; Jones, S.J.; Solenberg, P.J. Sequencing and analysis of genes involved in the biosynthesis of a vancomycin group antibiotic. Chem. Biol. 1998, 5, 155-162. [CrossRef]

243. Sosio, M.; Bianchi, A.; Bossi, E.; Donadio, S. Teicoplanin biosynthesis genes in Actinoplanes teichomyceticus. Antonie Van Leeuwenhoek 2000, 78, 379-384. [CrossRef] [PubMed]

244. Pelzer, S.; Sussmuth, R.; Heckmann, D.; Recktenwald, J.; Huber, P.; Jung, G.; Wohlleben, W. Identification and analysis of the balhimycin biosynthetic gene cluster and its use for manipulating glycopeptide biosynthesis in Amycolatopsis mediterranei DSM5908. Antimicrob. Agents Chemother. 1999, 43, 1565-1573. [CrossRef]

245. Hubbard, B.K.; Walsh, C.T. Vancomycin assembly: nature's way. Angew. Chem. Int. Ed. Engl. 2003, 42, 730-765. [CrossRef] 
246. Chiu, H.T.; Hubbard, B.K.; Shah, A.N.; Eide, J.; Fredenburg, R.A.; Walsh, C.T.; Khosla, C. Molecular cloning and sequence analysis of the complestatin biosynthetic gene cluster. Proc. Natl. Acad. Sci. USA 2001, 98, 8548-8553. [CrossRef] [PubMed]

247. Sosio, M.; Stinchi, S.; Beltrametti, F.; Lazzarini, A.; Donadio, S. The gene cluster for the biosynthesis of the glycopeptide antibiotic A40926 by Nonomuraea species. Chem. Biol. 2003, 10, 541-549. [CrossRef]

248. Marcone, G.L.; Beltrametti, F.; Binda, E.; Carrano, L.; Foulston, L.; Hesketh, A.; Bibb, M.; Marinelli, F. Novel mechanism of glycopeptide resistance in the A40926 producer Nonomuraea sp. ATCC 39727. Antimicrob. Agents Chemother. 2010, 54, 2465-2472. [CrossRef] [PubMed]

249. Marcone, G.L.; Binda, E.; Carrano, L.; Bibb, M.; Marinelli, F. Relationship between glycopeptide production and resistance in the actinomycete Nonomuraea sp. ATCC 39727. Antimicrob. Agents Chemother. 2014, 58, 5191-5201. [CrossRef] [PubMed]

250. Thaker, M.N.; Wang, W.; Spanogiannopoulos, P.; Waglechner, N.; King, A.M.; Medina, R.; Wright, G.D. Identifying producers of antibacterial compounds by screening for antibiotic resistance. Nat. Biotechnol. 2013, 31, 922-927. [CrossRef] [PubMed]

251. Schaberle, T.F.; Vollmer, W.; Frasch, H.J.; Huttel, S.; Kulik, A.; Rottgen, M.; von Thaler, A.K.; Wohlleben, W.; Stegmann, E. Self-resistance and cell wall composition in the glycopeptide producer Amycolatopsis balhimycina. Antimicrob. Agents Chemother. 2011, 55, 4283-4289. [CrossRef] [PubMed]

252. Kilian, R.; Frasch, H.J.; Kulik, A.; Wohlleben, W.; Stegmann, E. The VanRS homologous two-component system $\operatorname{VnlRS}_{\mathrm{Ab}}$ of the glycopeptide producer Amycolatopsis balhimycina activates transcription of the vanHAX $X_{S c}$ genes in Streptomyces coelicolor, but not in A. balhimycina. Microb. Drug Resist. 2016, 22, 499-509. [CrossRef]

253. Hutchings, M.I.; Hong, H.J.; Buttner, M.J. The vancomycin resistance VanRS two-component signal transduction system of Streptomyces coelicolor. Mol. Microbiol. 2006, 59, 923-935. [CrossRef] [PubMed]

254. Leclercq, R.; Derlot, E.; Duval, J.; Courvalin, P. Plasmid-mediated resistance to vancomycin and teicoplanin in Enterococcus faecium. N. Engl. J. Med. 1988, 319, 157-161. [CrossRef]

255. Courvalin, P. Vancomycin resistance in gram-positive cocci. Clin. Infect. Dis. 2006, 42 (Suppl. 1), S25-S34. [CrossRef]

256. Binda, E.; Marinelli, F.; Marcone, G. L: Old and new glycopeptide antibiotics: Action and resistance. Antibiotics 2014, 3, 572-594. [CrossRef] [PubMed]

257. Arthur, M.; Courvalin, P. Genetics and mechanisms of glycopeptide resistance in enterococci. Antimicrob. Agents Chemother. 1993, 37, 1563-1571. [CrossRef] [PubMed]

258. Ostash, B.; Saghatelian, A.; Walker, S. A streamlined metabolic pathway for the biosynthesis of moenomycin A. Chem. Biol. 2007, 14, 257-267. [CrossRef] [PubMed]

259. Makitrynskyy, R.; Rebets, Y.; Ostash, B.; Zaburannyi, N.; Rabyk, M.; Walker, S.; Fedorenko, V. Genetic factors that influence moenomycin production in streptomycetes. J. Ind. Microbiol. Biotechnol. 2010, 37, 559-566. [CrossRef] [PubMed]

260. Horbal, L.; Ostash, B.; Luzhetskyy, A.; Walker, S.; Kalinowski, J.; Fedorenko, V. A gene cluster for the biosynthesis of moenomycin family antibiotics in the genome of teicoplanin producer Actinoplanes teichomyceticus. Appl. Microbiol. Biotechnol. 2016, 100, 7629-7638. [CrossRef]

261. Taylor, S.D.; Palmer, M. The action mechanism of daptomycin. Bioorg. Med. Chem. 2016, 24, 6253-6268. [CrossRef] [PubMed]

262. Miao, V.; Coeffet-Legal, M.F.; Brian, P.; Brost, R.; Penn, J.; Whiting, A.; Martin, S. Daptomycin biosynthesis in Streptomyces roseosporus: Cloning and analysis of the gene cluster and revision of peptide stereochemistry. Microbiology 2005, 151, 1507-1523. [CrossRef]

263. Baltz, R.H. Genomics and the ancient origins of the daptomycin biosynthetic gene cluster. J. Antibiot. (Tokyo) 2010, 63, 506-511. [CrossRef]

264. Gomez Casanova, N.; Siller Ruiz, M.; Munoz Bellido, J.L. Mechanisms of resistance to daptomycin in Staphylococcus aureus. Rev. Esp. Quimioter. 2017, 30, 391-396.

265. Tran, T.T.; Munita, J.M.; Arias, C.A. Mechanisms of drug resistance: Daptomycin resistance. Ann. N. Y. Acad. Sci. 2015, 1354, 32-53. [CrossRef] 
266. Mishra, N.N.; Yang, S.J.; Chen, L.; Muller, C.; Saleh-Mghir, A.; Kuhn, S.; Peschel, A.; Yeaman, M.R.; Nast, C.C.; Kreiswirth, B.N.; et al. Emergence of daptomycin resistance in daptomycin-naïve rabbits with methicillin-resistant Staphylococcus aureus prosthetic joint infection is associated with resistance to host defense cationic peptides and mprF polymorphisms. PLoS ONE 2013, 8, e71151.

267. Davlieva, M.; Zhang, W.; Arias, C.A.; Shamoo, Y. Biochemical characterization of cardiolipin synthase mutations associated with daptomycin resistance in enterococci. Antimicrob. Agents Chemother. 2013, 57, 289-296. [CrossRef] [PubMed]

268. Diaz, L.; Tran, T.T.; Munita, J.M.; Miller, W.R.; Rincon, S.; Carvajal, L.P.; Wollam, A.; Reyes, J.; Panesso, D.; Rojas, N.L.; et al. Whole-genome analyses of Enterococcus faecium isolates with diverse daptomycin MICs. Antimicrob. Agents Chemother. 2014, 58, 4527-4534. [CrossRef] [PubMed]

269. Schneider, T.; Gries, K.; Josten, M.; Wiedemann, I.; Pelzer, S.; Labischinski, H.; Sahl, H.G. The lipopeptide antibiotic friulimicin B inhibits cell wall biosynthesis through complex formation with bactoprenol phosphate. Antimicrob. Agents Chemother. 2009, 53, 1610-1618. [CrossRef] [PubMed]

270. Muller, C.; Nolden, S.; Gebhardt, P.; Heinzelmann, E.; Lange, C.; Puk, O.; Welzel, K.; Wohlleben, W.; Schwartz, D. Sequencing and analysis of the biosynthetic gene cluster of the lipopeptide antibiotic friulimicin in Actinoplanes friuliensis. Antimicrob. Agents Chemother. 2007, 51, 1028-1037. [CrossRef] [PubMed]

271. Wang, Y.; Chen, Y.; Shen, Q.; Yin, X. Molecular cloning and identification of the laspartomycin biosynthetic gene cluster from Streptomyces viridochromogenes. Gene 2011, 483, 11-21. [CrossRef] [PubMed]

272. Koumoutsi, A.; Chen, X.H.; Henne, A.; Liesegang, H.; Hitzeroth, G.; Franke, P.; Vater, J.; Borriss, R. Structural and functional characterization of gene clusters directing nonribosomal synthesis of bioactive cyclic lipopeptides in Bacillus amyloliquefaciens strain FZB42. J. Bacteriol. 2004, 186, 1084-1096. [CrossRef] [PubMed]

273. Zhi, Y.; Wu, Q.; Xu, Y. Genome and transcriptome analysis of surfactin biosynthesis in Bacillus amyloliquefaciens MT45. Sci. Rep. 2017, 7, 40976. [CrossRef]

274. Luo, C.; Liu, X.; Zhou, H.; Wang, X.; Chen, Z. Nonribosomal peptide synthase gene clusters for lipopeptide biosynthesis in Bacillus subtilis 916 and their phenotypic functions. Appl. Environ. Microbiol. 2015, 81, 422-431. [CrossRef]

275. Tsuge, K.; Ohata, Y.; Shoda, M. Gene yerP, involved in surfactin self-resistance in Bacillus subtilis. Antimicrob. Agents Chemother. 2001, 45, 3566-3573. [CrossRef]

276. Caffrey, P.; De Poire, E.; Sheehan, J.; Sweeney, P. Polyene macrolide biosynthesis in streptomycetes and related bacteria: Recent advances from genome sequencing and experimental studies. Appl. Microbiol. Biotechnol. 2016, 100, 3893-3908. [CrossRef] [PubMed]

277. Mesa-Arango, A.C.; Scorzoni, L.; Zaragoza, O. It only takes one to do many jobs: Amphotericin B as antifungal and immunomodulatory drug. Front. Microbiol. 2012, 3, 286. [CrossRef] [PubMed]

278. Caffrey, P.; Lynch, S.; Flood, E.; Finnan, S.; Oliynyk, M. Amphotericin biosynthesis in Streptomyces nodosus: Deductions from analysis of polyketide synthase and late genes. Chem. Biol. 2001, 8, 713-723. [CrossRef]

279. Svahn, K.S.; Chryssanthou, E.; Olsen, B.; Bohlin, L.; Goransson, U. Penicillium nalgiovense Laxa isolated from Antarctica is a new source of the antifungal metabolite amphotericin B. Fungal Biol. Biotechnol. 2015, 2, 1. [CrossRef] [PubMed]

280. Dos Santos, A.G.; Marques, J.T.; Carreira, A.C.; Castro, I.R.; Viana, A.S.; Mingeot-Leclercq, M.P.; de Almeida, R.F.M.; Silva, L.C. The molecular mechanism of nystatin action is dependent on the membrane biophysical properties and lipid composition. Phys. Chem. Chem. Phys. 2017, 19, 30078-30088. [CrossRef] [PubMed]

281. Brautaset, T.; Sekurova, O.N.; Sletta, H.; Ellingsen, T.E.; Strom, A.R.; Valla, S.; Zotchev, S.B. Biosynthesis of the polyene antifungal antibiotic nystatin in Streptomyces noursei ATCC 11455: Analysis of the gene cluster and deduction of the biosynthetic pathway. Chem. Biol. 2000, 7, 395-403. [CrossRef]

282. Campelo, A.B.; Gil, J.A. The candicidin gene cluster from Streptomyces griseus IMRU 3570. Microbiology 2002, 148, 51-59. [CrossRef] [PubMed]

283. Chen, S.; Huang, X.; Zhou, X.; Bai, L.; He, J.; Jeong, K.J.; Lee, S.Y.; Deng, Z. Organizational and mutational analysis of a complete FR-008/candicidin gene cluster encoding a structurally related polyene complex. Chem. Biol. 2003, 10, 1065-1076. [CrossRef]

284. Te Welscher, Y.M.; van Leeuwen, M.R.; de Kruijff, B.; Dijksterhuis, J.; Breukink, E. Polyene antibiotic that inhibits membrane transport proteins. Proc. Natl. Acad. Sci. USA 2012, 109, 11156-11159. [CrossRef] 
285. Aparicio, J.F.; Fouces, R.; Mendes, M.V.; Olivera, N.; Martín, J.F. A complex multienzyme system encoded by five polyketide synthase genes is involved in the biosynthesis of the 26-membered polyene macrolide pimaricin in Streptomyces natalensis. Chem. Biol. 2000, 7, 895-905. [CrossRef]

286. Du, Y.L.; Li, S.Z.; Zhou, Z.; Chen, S.F.; Fan, W.M.; Li, Y.Q. The pleitropic regulator AdpA $A_{c h}$ is required for natamycin biosynthesis and morphological differentiation in Streptomyces chattanoogensis. Microbiology 2011, 157, 1300-1311. [CrossRef] [PubMed]

287. Aparicio, J.F.; Barreales, E.G.; Payero, T.D.; Vicente, C.M.; de Pedro, A.; Santos-Aberturas, J. Biotechnological production and application of the antibiotic pimaricin: Biosynthesis and its regulation. Appl. Microbiol. Biotechnol. 2016, 100, 61-78. [CrossRef] [PubMed]

288. Posch, W.; Blatzer, M.; Wilflingseder, D.; Lass-Florl, C. Aspergillus terreus: Novel lessons learned on amphotericin B resistance. Med. Mycol. 2018, 56, 73-82. [CrossRef] [PubMed]

289. Geraghty, P.; Kavanagh, K. Disruption of mitochondrial function in Candida albicans leads to reduced cellular ergosterol levels and elevated growth in the presence of amphotericin B. Arch. Microbiol. 2003, 179, 295-300. [CrossRef] [PubMed]

290. McAuliffe, O.; Ross, R.P.; Hil, C. Lantibiotics: Structure, biosynthesis and mode of action. FEMS Microbiol. Rev. 2001, 25, 285-308. [CrossRef] [PubMed]

291. Draper, L.A.; Cotter, P.D.; Hill, C.; Ross, R.P. Lantibiotic resistance. Microbiol. Mol. Biol. Rev. 2015, 79, $171-191$. [CrossRef] [PubMed]

292. Gomes, K.M.; Duarte, R.S.; de Freire Bastos, M.D. Lantibiotics produced by Actinobacteria and their potential applications (a review). Microbiology 2017, 163, 109-121. [CrossRef] [PubMed]

293. Breukink, E.; Wiedemann, I.; van Kraaij, C.; Kuipers, O.P.; Sahl, H.G.; de Kruijff, B. Use of the cell wall precursor lipid II by a pore-forming peptide antibiotic. Science 1999, 286, 2361-2364. [CrossRef] [PubMed]

294. Shin, J.M.; Gwak, J.W.; Kamarajan, P.; Fenno, J.C.; Rickard, A.H.; Kapila, Y.L. Biomedical applications of nisin. J. Appl. Microbiol. 2016, 120, 1449-1465. [CrossRef]

295. Brotz, H.; Bierbaum, G.; Markus, A.; Molitor, E.; Sahl, H.G. Mode of action of the lantibiotic mersacidin: Inhibition of peptidoglycan biosynthesis via a novel mechanism? Antimicrob. Agents Chemother. 1995, 39, 714-719. [CrossRef]

296. Ra, R.; Beerthuyzen, M.M.; de Vos, W.M.; Saris, P.E.; Kuipers, O.P. Effects of gene disruptions in the nisin gene cluster of Lactococcus lactis on nisin production and producer immunity. Microbiology 1999, 145, 1227-1233. [CrossRef] [PubMed]

297. Klein, C.; Entian, K.D. Genes involved in self-protection against the lantibiotic subtilin produced by Bacillus subtilis ATCC 6633. Appl. Environ. Microbiol. 1994, 60, 2793-2801. [PubMed]

298. Foulston, L.C.; Bibb, M.J. Microbisporicin gene cluster reveals unusual features of lantibiotic biosynthesis in actinomycetes. Proc. Natl. Acad. Sci. USA 2010, 107, 13461-13466. [CrossRef] [PubMed]

299. Knerr, P.J.; Oman, T.J.; Garcia De Gonzalo, C.V.; Lupoli, T.J.; Walker, S.; van der Donk, W.A. Non-proteinogenic amino acids in lacticin 481 analogues result in more potent inhibition of peptidoglycan transglycosylation. ACS Chem. Biol. 2012, 7, 1791-1795. [CrossRef]

300. Rince, A.; Dufour, A.; Uguen, P.; Le Pennec, J.P.; Haras, D. Characterization of the lacticin 481 operon: The Lactococcus lactis genes $l c t F, l c t E$, and $l c t G$ encode a putative $\mathrm{ABC}$ transporter involved in bacteriocin immunity. Appl. Environ. Microbiol. 1997, 63, 4252-4260. [PubMed]

301. Oman, T.J.; Boettcher, J.M.; Wang, H.; Okalibe, X.N.; van der Donk, W.A. Sublancin is not a lantibiotic but an S-linked glycopeptide. Nat. Chem. Biol. 2011, 7, 78-80. [CrossRef] [PubMed]

302. Wu, C.; Biswas, S.; Garcia De Gonzalo, C.V.; van der Donk, W.A. Investigations into the mechanism of action of sublancin. ACS Infect. Dis. 2019, 5, 454-459. [CrossRef] [PubMed]

303. Garcia De Gonzalo, C.V.; Denham, E.L.; Mars, R.A.; Stulke, J.; van der Donk, W.A.; van Dijl, J.M. The phosphoenolpyruvate: sugar phosphotransferase system is involved in sensitivity to the glucosylated bacteriocin sublancin. Antimicrob. Agents Chemother. 2015, 59, 6844-6854. [CrossRef]

304. Makino, A.; Baba, T.; Fujimoto, K.; Iwamoto, K.; Yano, Y.; Terada, N.; Ohno, S.; Sato, S.B.; Ohta, A.; Umeda, M.; et al. Cinnamycin (Ro 09-0198) promotes cell binding and toxicity by inducing transbilayer lipid movement. J. Biol. Chem. 2003, 278, 3204-3209. [CrossRef]

305. Widdick, D.A.; Dodd, H.M.; Barraille, P.; White, J.; Stein, T.H.; Chater, K.F.; Gasson, M.J.; Bibb, M.J. Cloning and engineering of the cinnamycin biosynthetic gene cluster from Streptomyces cinnamoneus cinnamoneus DSM 40005. Proc. Natl. Acad. Sci. USA 2003, 100, 4316-4321. [CrossRef] 
306. Zimmermann, N.; Jung, G. The three-dimensional solution structure of the lantibiotic murein-biosynthesis-inhibitor actagardine determined by NMR. Eur. J. Biochem. 1997, 246, 809-819. [CrossRef] [PubMed]

307. Boakes, S.; Cortes, J.; Appleyard, A.N.; Rudd, B.A.; Dawson, M.J. Organization of the genes encoding the biosynthesis of actagardine and engineering of a variant generation system. Mol. Microbiol. 2009, 72, 1126-1136. [CrossRef] [PubMed]

308. Maky, M.A.; Ishibashi, N.; Zendo, T.; Perez, R.H.; Doud, J.R.; Karmi, M.; Sonomoto, K. Enterocin F4-9, a novel O-Linked glycosylated bacteriocin. Appl. Environ. Microbiol. 2015, 81, 4819-4826. [CrossRef] [PubMed]

309. Kawada-Matsuo, M.; Yoshida, Y.; Zendo, T.; Nagao, J.; Oogai, Y.; Nakamura, Y.; Sonomoto, K.; Nakamura, N.; Komatsuzawa, $\mathrm{H}$. Three distinct two-component systems are involved in resistance to the class I bacteriocins, nukacin ISK-1 and nisin A, in Staphylococcus aureus. PLoS ONE 2013, 8, e69455. [CrossRef] [PubMed]

310. Khosa, S.; Frieg, B.; Mulnaes, D.; Kleinschrodt, D.; Hoeppner, A.; Gohlke, H.; Smits, S. Structural basis of lantibiotic recognition by the nisin resistance protein from Streptococcus agalactiae. Sci. Rep. 2016, 6, 18679. [CrossRef]

311. Falord, M.; Karimova, G.; Hiron, A.; Msadek, T. GraXSR proteins interact with the VraFG ABC transporter to form a five-component system required for cationic antimicrobial peptide sensing and resistance in Staphylococcus aureus. Antimicrob. Agents Chemother. 2012, 56, 1047-1058. [CrossRef]

312. McBride, S.M.; Sonenshein, A.L. The dlt operon confers resistance to cationic antimicrobial peptides in Clostridium difficile. Microbiology 2011, 157, 1457-1465. [CrossRef]

313. Gravesen, A.; Sorensen, K.; Aarestrup, F.M.; Knochel, S. Spontaneous nisin-resistant Listeria monocytogenes mutants with increased expression of a putative penicillin-binding protein and their sensitivity to various antibiotics. Microb. Drug Resist. 2001, 7, 127-135. [CrossRef]

314. Thedieck, K.; Hain, T.; Mohamed, W.; Tindall, B.J.; Nimtz, M.; Chakraborty, T.; Wehland, J.; Jänsch, L. The $\mathrm{MprF}$ protein is required for lysinylation of phospholipids in listerial membranes and confers resistance to cationic antimicrobial peptides (CAMPs) on Listeria monocytogenes. Mol. Microbiol. 2006, 62, 1325-1339. [CrossRef]

315. Trimble, M.J.; Mlynarcik, P.; Kolar, M.; Hancock, R.E. Polymyxin: Alternative mechanisms of action and resistance. Cold Spring Harb. Perspect. Med. 2016, 6, a025288. [CrossRef]

316. Choi, S.K.; Park, S.Y.; Kim, R.; Kim, S.B.; Lee, C.H.; Kim, J.F.; Park, S.H. Identification of a polymyxin synthetase gene cluster of Paenibacillus polymyxa and heterologous expression of the gene in Bacillus subtilis. J. Bacteriol. 2009, 191, 3350-3358. [CrossRef] [PubMed]

317. Jeannot, K.; Bolard, A.; Plesiat, P. Resistance to polymyxins in Gram-negative organisms. Int. J. Antimicrob. Agents. 2017, 49, 526-535. [CrossRef] [PubMed]

318. Srinivas, P.; Rivard, K. Polymyxin resistance in Gram-negative pathogens. Curr. Infect. Dis. Rep. 2017, 19, 38. [CrossRef] [PubMed]

319. Economou, N.J.; Cocklin, S.; Loll, P.J. High-resolution crystal structure reveals molecular details of target recognition by bacitracin. Proc. Natl. Acad. Sci. USA 2013, 110, 14207-14212. [CrossRef] [PubMed]

320. Konz, D.; Klens, A.; Schorgendorfer, K.; Marahiel, M.A. The bacitracin biosynthesis operon of Bacillus licheniformis ATCC 10716: Molecular characterization of three multi-modular peptide synthetases. Chem. Biol. 1997, 4, 927-937. [CrossRef]

321. Podlesek, Z.; Comino, A.; Herzog-Velikonja, B.; Grabnar, M. The role of the bacitracin ABC transporter in bacitracin resistance and collateral detergent sensitivity. FEMS Microbiol. Lett. 2000, 188, 103-106. [CrossRef] [PubMed]

322. Biecker, A.L.; Liu, X.; Thorson, J.S.; Yang, Z.; Van Lanen, S.G. Biosynthetic and synthetic strategies for assembling capuramycin-type antituberculosis antibiotics. Molecules 2019, 24, 433. [CrossRef]

323. Funabashi, M.; Nonaka, K.; Yada, C.; Hosobuchi, M.; Masuda, N.; Shibata, T.; Van Lanen, S.G. Identification of the biosynthetic gene cluster of A-500359s in Streptomyces griseus SANK60196. J. Antibiot. 2009, 62, 325-332. [CrossRef]

324. Cai, W.; Goswami, A.; Yang, Z.; Liu, X.; Green, K.D.; Barnard-Britson, S. The biosynthesis of capuramycin-type antibiotics: Identification of the A-102395 biosynthetic gene cluster, mechanism of self-resistance, and formation of uridine-5'-carboxamide. J. Biol. Chem. 2015, 290, 13710-13724. [CrossRef] 
325. Funabashi, M.; Yang, Z.; Nonaka, K.; Hosobuchi, M.; Fujita, Y.; Shibata, T.; Chi, X.; Van Lanen, S.G. An ATP-independent strategy for amide bond formation in antibiotic biosynthesis. Nat. Chem. Biol. 2010, 6, 581-586. [CrossRef]

326. Prosser, G.A.; de Carvalho, L.P. Metabolomics reveal D-alanine: D-alanine ligase as the target of D-cycloserine in Mycobacterium tuberculosis. ACS Med. Chem. Lett. 2013, 4, 1233-1237. [CrossRef] [PubMed]

327. Kumagai, T.; Koyama, Y.; Oda, K.; Noda, M.; Matoba, Y.; Sugiyama, M. Molecular cloning and heterologous expression of a biosynthetic gene cluster for the antitubercular agent D-cycloserine produced by Streptomyces lavendulae. Antimicrob. Agents Chemother. 2010, 54, 1132-1139. [CrossRef] [PubMed]

328. Skarzynski, T.; Mistry, A.; Wonacott, A.; Hutchinson, S.E.; Kelly, V.A.; Duncan, K. Structure of UDP-N-acetylglucosamine enolpyruvyl transferase, an enzyme essential for the synthesis of bacterial peptidoglycan, complexed with substrate UDP-N-acetylglucosamine and the drug fosfomycin. Structure 1996, 4, 1465-1474. [CrossRef]

329. Kobayashi, S.; Kuzuyama, T.; Seto, H. Characterization of the fom A and fomB gene products from Streptomyces wedmorensis, which confer fosfomycin resistance on Escherichia coli. Antimicrob. Agents Chemother. 2000, 44, 647-650. [CrossRef] [PubMed]

330. Woodyer, R.D.; Shao, Z.; Thomas, P.M.; Kelleher, N.L.; Blodgett, J.A.; Metcalf, W.W.; van der Donk, W.A.; Zhao, H. Heterologous production of fosfomycin and identification of the minimal biosynthetic gene cluster. Chem. Biol. 2006, 13, 1171-1182. [CrossRef] [PubMed]

331. Falagas, M.E.; Vouloumanou, E.K.; Samonis, G.; Vardakas, K.Z. Fosfomycin. Clin. Microbiol. Rev. 2016, 29, 321-347. [CrossRef] [PubMed]

332. Desjardins, C.A.; Cohen, K.A.; Munsamy, V.; Abeel, T.; Maharaj, K.; Walker, B.J.; Shea, T.P.; Almeida, D.V.; Manson, A.L.; Salazar, A.; et al. Genomic and functional analyses of Mycobacterium tuberculosis strains implicate ald in D-cycloserine resistance. Nat. Genet. 2016, 48, 544-551. [CrossRef] [PubMed]

333. Nakatani, Y.; Opel-Reading, H.K.; Merker, M.; Machado, D.; Andres, S.; Kumar, S.S.; Moradigaravand, D.; Coll, F.; Perdigao, J.; Portugal, I.; et al. Role of Alanine Racemase Mutations in Mycobacterium tuberculosis D-Cycloserine Resistance. Antimicrob. Agents Chemother. 2017, 61, e01575-e17. [CrossRef]

334. Zhang, S.; Chen, J.; Cui, P.; Shi, W.; Zhang, W.; Zhang, Y. Identification of novel mutations associated with cycloserine resistance in Mycobacterium tuberculosis. J. Antimicrob. Chemother. 2015, 70, 2507-2510. [CrossRef]

335. Umezawa, H.; Maeda, K.; Takeuchi, T.; Okami, Y. New antibiotics, bleomycin A and B. J. Antibiot. (Tokyo) 1966, 19, 200-209.

336. Du, L.; Sanchez, C.; Chen, M.; Edwards, D.J.; Shen, B. The biosynthetic gene cluster for the antitumor drug bleomycin from Streptomyces verticillus ATCC15003 supporting functional interactions between nonribosomal peptide synthetases and a polyketide synthase. Chem. Biol. 2000, 7, 623-642. [CrossRef]

337. Calcutt, M.J.; Schmidt, F.J. Gene organization in the bleomycin-resistance region of the producer organism Streptomyces verticillus. Gene 1994, 151, 17-21. [PubMed]

338. Sugiyama, M.; Thompson, C.J.; Kumagai, T.; Suzuki, K.; Deblaere, R.; Villarroel, R.; Davies, J. Characterisation by molecular cloning of two genes from Streptomyces verticillus encoding resistance to bleomycin. Gene 1994, 151, 11-16. [PubMed]

339. Gatignol, A.; Durand, H.; Tiraby, G. Bleomycin resistance conferred by a drug-binding protein. FEBS Lett. 1988, 230, 171-175. [CrossRef]

340. Tao, M.; Wang, L.; Wendt-Pienkowski, E.; George, N.P.; Galm, U.; Zhang, G.; Coughlin, J.M.; Shen, B. The tallysomycin biosynthetic gene cluster from Streptoalloteichus hindustanus E465-94 ATCC 31158 unveiling new insights into the biosynthesis of the bleomycin family of antitumor antibiotics. Mol. Biosyst. 2007, 3, 60-74. [CrossRef]

341. Galm, U.; Wendt-Pienkowski, E.; Wang, L.; George, N.P.; Oh, T.J.; Yi, F.; Tao, M.; Coughlin, J.M.; Shen, B. The biosynthetic gene cluster of zorbamycin, a member of the bleomycin family of antitumor antibiotics, from Streptomyces flavoviridis ATCC 21892. Mol. Biosyst. 2009, 5, 77-90. [CrossRef]

342. Coughlin, J.M.; Rudolf, J.D.; Wendt-Pienkowski, E.; Wang, L.; Unsin, C.; Galm, U.; Yang, D.; Tao, M.; Shen, B. BlmB and TlmB provide resistance to the bleomycin family of antitumor antibiotics by $\mathrm{N}$-acetylating metal-free bleomycin, tallysomycin, phleomycin, and zorbamycin. Biochemistry 2014, 53, 6901-6909. [CrossRef]

343. O’Farrell, P.A.; Gonzalez, F.; Zheng, W.; Johnston, S.A.; Joshua-Tor, L. Crystal structure of human bleomycin hydrolase, a self-compartmentalizing cysteine protease. Structure 1999, 7, 619-627. [CrossRef] 
344. Jilani, A.; Ramotar, D.; Slack, C.; Ong, C.; Yang, X.M.; Scherer, S.W.; Lasko, D.D. Molecular cloning of the human gene, $P N K P$, encoding a polynucleotide kinase $3^{\prime}$-phosphatase and evidence for its role in repair of DNA strand breaks caused by oxidative damage. J. Biol. Chem. 1999, 274, 24176-24186. [CrossRef]

345. Kumagai, T.; Nakano, T.; Maruyama, M.; Mochizuki, H.; Sugiyama, M. Characterization of the bleomycin resistance determinant encoded on the transposon Tn5. FEBS Lett. 1999, 442, 34-38. [CrossRef]

346. Drautz, H.; Zaehner, H.; Rohr, J.; Zeeck, A. Metabolic products of microorganisms. 234. Urdamycins, new angucycline antibiotics from Streptomyces fradiae. I. Isolation, characterization and biological properties. J. Antibiot. (Tokyo) 1986, 39, 1657-1669. [CrossRef]

347. Rohr, J.; Thiericke, R. Angucycline group antibiotics. Nat. Prod. Rep. 1992, 9, 103-137. [CrossRef]

348. ATC/DDD Index 2019. Available online: https://www.whocc.no/atc_ddd_index/ (accessed on 12 August 2019).

349. Chen, J.J.; Wu, P.T.; Middlekauff, H.R.; Nguyen, K.L. Aerobic exercise in anthracycline-induced cardiotoxicity: A systematic review of current evidence and future directions. Am. J. Physiol. Heart Circ. Physiol. 2017, 312, H213-H222. [CrossRef]

350. Minotti, G.; Menna, P.; Salvatorelli, E.; Cairo, G.; Gianni, L. Anthracyclines: Molecular advances and pharmacologic developments in antitumor activity and cardiotoxicity. Pharmacol. Rev. 2004, 56, 185-229. [CrossRef]

351. Hutchinson, C.R.; Colombo, A.L. Genetic engineering of doxorubicin production in Streptomyces peucetius: A review. J. Ind. Microbiol. Biotechnol. 1999, 23, 647-652. [CrossRef]

352. Dhakal, D.; Lim, S.K.; Kim, D.H.; Kim, B.G.; Yamaguchi, T.; Sohng, J.K. Complete genome sequence of Streptomyces peucetius ATCC 27952, the producer of anticancer anthracyclines and diverse secondary metabolites. J. Biotechnol. 2018, 267, 50-54. [CrossRef]

353. Guilfoile, P.G.; Hutchinson, C.R. A bacterial analog of the $m d r$ gene of mammalian tumor cells is present in Streptomyces peucetius, the producer of daunorubicin and doxorubicin. Proc. Natl. Acad. Sci. USA 1991, 88, 8553-8557. [CrossRef]

354. Lomovskaya, N.; Hong, S. k.; Kim, S.U.; Furuya, K.; Fonstein, L.; Hutchinson, C.R. The Streptomyces peucetius drrC gene encodes a UvrA-like protein essential for daunorubicin and doxorubicin resistance and production. J. Bacteriol. 1996, 178, 3238-3245. [CrossRef]

355. Dubey, R.; Kattusamy, K.; Dharmalingam, K.; Prasad, R. Daunorubicin forms a specific complex with a secreted serine protease of Streptomyces peucetius. World, J. Microbiol. Biotechnol. 2014, 30, 253-261. [CrossRef]

356. Raety, K.; Kantola, J.; Hautala, A.; Hakala, J.; Ylihonko, K.; Maentsaelae, P. Cloning and characterization of Streptomyces galilaeus aclacinomycins polyketide synthase (PKS) cluster. Gene 2002, 293, 115-122. [CrossRef]

357. Raety, K.; Kunnari, T.; Hakala, J.; Maentsaelae, P.; Ylihonko, K. A gene cluster from Streptomyces galilaeus involved in glycosylation of aclarubicin. Mol. Gen. Genet. 2000, 264, 164-172. [CrossRef]

358. Torkkell, S.; Kunnari, T.; Palmu, K.; Mantsala, P.; Hakala, J.; Ylihonko, K. The entire nogalamycin biosynthetic gene cluster of Streptomyces nogalater: Characterization of a 20-kb DNA region and generation of hybrid structures. Mol. Genet. Genom. 2001, 266, 276-288.

359. Panchuk, R.R. Signaling pathways involved in apoptosis induced by novel angucycline antibiotic landomycin E in Jurkat T-leukemia cells. Biopolym. Cell 2011, 27, 124-131. [CrossRef]

360. Zhu, L.L.; Ostash, B.; Rix, U.; Nur-e-Alam, M.; Mayers, A.; Luzhetskyy, A.; Mendez, C.; Salas, J.A.; Bechthold, A.; Fedorenko, V.; et al. Identification of the function of gene lndM2 encoding a bifunctional oxygenase-reductase involved in the biosynthesis of the antitumor antibiotic landomycin E by Streptomyces globisporus 1912 supports the originally assigned structure for landomycinone. J. Org. Chem. 2005, 70, 631-638. [CrossRef]

361. Westrich, L.; Domann, S.; Faust, B.; Bedford, D.; Hopwood, D.A.; Bechthold, A. Cloning and characterization of a gene cluster from Streptomyces cyanogenus $\mathrm{S} 136$ probably involved in landomycin biosynthesis. FEMS Microbiol. Lett. 1999, 170, 381-387. [CrossRef]

362. Faust, B.; Hoffmeister, D.; Weitnauer, G.; Westrich, L.; Haag, S.; Schneider, P.; Decker, H.; Kunzel, E.; Rohr, J.; Bechthold, A. Two new tailoring enzymes, a glycosyltransferase and an oxygenase, involved in biosynthesis of the angucycline antibiotic urdamycin A in Streptomyces fradiae Tu2717. Microbiology 2000, 146, 147-154. [CrossRef] 
363. Hall, S.R.; Toulany, J.; Bennett, L.G.; Martinez-Farina, C.F.; Robertson, A.W.; Jakeman, D.L.; Goralski, K.B. Jadomycins Inhibit type II topoisomerases and promote DNA damage and apoptosis in multidrug-resistant triple-negative breast cancer cells. J. Pharmacol. Exp. Ther. 2017, 363, 196-210. [CrossRef]

364. Forget, S.M.; McVey, J.; Vining, L.C.; Jakeman, D.L. Streptomyces venezuelae ISP5230 maintains excretion of jadomycin upon disruption of the MFS transporter JadL located within the natural product biosynthetic gene cluster. Front. Microbiol. 2017, 8, 432. [CrossRef]

365. Mak, S.; Nodwell, J.R. Actinorhodin is a redox-active antibiotic with a complex mode of action against Gram-positive cells. Mol. Microbiol. 2017, 106, 597-613. [CrossRef]

366. Caballero, J.L.; Martinez, E.; Malpartida, F.; Hopwood, D.A. Organisation and functions of the actVA region of the actinorhodin biosynthetic gene cluster of Streptomyces coelicolor. Mol. Gen. Genet. 1991, 230, 401-412. [CrossRef]

367. Fernandez-Moreno, M.A.; Caballero, J.L.; Hopwood, D.A.; Malpartida, F. The act cluster contains regulatory and antibiotic export genes, direct targets for translational control by the bldA tRNA gene of Streptomyces. Cell 1991, 66, 769-780. [CrossRef]

368. Chang, C.J.; Floss, H.G.; Soong, P.; Chang, C.T. Identity of the antitumor antibiotic litmomycin with granaticin A. J. Antibiot. (Tokyo) 1975, 28, 156. [CrossRef]

369. Sherman, D.H.; Malpartida, F.; Bibb, M.J.; Kieser, H.M.; Bibb, M.J.; Hopwood, D.A. Structure and deduced function of the granaticin-producing polyketide synthase gene cluster of Streptomyces violaceoruber Tu22. EMBO J. 1989, 8, 2717-2725. [CrossRef]

370. Ichinose, K.; Bedford, D.J.; Tornus, D.; Bechthold, A.; Bibb, M.J.; Revill, W.P.; Floss, H.G.; Hopwood, D.A. The granaticin biosynthetic gene cluster of Streptomyces violaceoruber Tu22: Sequence analysis and expression in a heterologous host. Chem. Biol. 1998, 5, 647-659. [CrossRef]

371. Ichinose, K.; Ozawa, M.; Itou, K.; Kunieda, K.; Ebizuka, Y. Cloning, sequencing and heterologous expression of the medermycin biosynthetic gene cluster of Streptomyces sp. AM-7161: Towards comparative analysis of the benzoisochromanequinone gene clusters. Microbiology 2003, 149, 1633-1645. [CrossRef]

372. Paz, M.M.; Zhang, X.; Lu, J.; Holmgren, A. A new mechanism of action for the anticancer drug mitomycin C: Mechanism-based inhibition of thioredoxin reductase. Chem. Res. Toxicol. 2012, 25, 1502-1511. [CrossRef]

373. Mao, Y.; Varoglu, M.; Sherman, D.H. Molecular characterization and analysis of the biosynthetic gene cluster for the antitumor antibiotic mitomycin C from Streptomyces lavendulae NRRL 2564. Chem. Biol. 1999, 6, 251-263. [CrossRef]

374. August, P.R.; Rahn, J.A.; Flickinger, M.C.; Sherman, D.H. Inducible synthesis of the mitomycin C resistance gene product (MCRA) from Streptomyces lavendulae. Gene 1996, 175, 261-267. [CrossRef]

375. Sheldon, P.J.; Johnson, D.A.; August, P.R.; Liu, H.W.; Sherman, D.H. Characterization of a mitomycin-binding drug resistance mechanism from the producing organism, Streptomyces lavendulae. J. Bacteriol. 1997, 179, 1796-1804. [CrossRef]

376. August, P.R.; Flickinger, M.C.; Sherman, D.H. Cloning and analysis of a locus ( $\mathrm{mcr}$ ) involved in mitomycin C resistance in Streptomyces lavendulae. J. Bacteriol. 1994, 176, 4448-4454. [CrossRef]

377. Huang, W.; Xu, H.; Li, Y.; Zhang, F.; Chen, X.Y.; He, Q.L.; Igarashi, Y.; Tang, G.L. Characterization of yatakemycin gene cluster revealing a radical S-adenosylmethionine dependent methyltransferase and highlighting spirocyclopropane biosynthesis. J. Am. Chem. Soc. 2012, 134, 8831-8840. [CrossRef]

378. Xu, H.; Huang, W.; He, Q.L.; Zhao, Z.X.; Zhang, F.; Wang, R.; Kang, J.; Tang, G.L. Self-resistance to an antitumor antibiotic: A DNA glycosylase triggers the base-excision repair system in yatakemycin biosynthesis. Angew. Chem. Int. Ed. Engl. 2012, 51, 10532-10536. [CrossRef]

379. Urasaki, Y.; Laco, G.; Takebayashi, Y.; Bailly, C.; Kohlhagen, G.; Pommier, Y. Use of camptothecin-resistant mammalian cell lines to evaluate the role of topoisomerase I in the antiproliferative activity of the indolocarbazole, NB-506, and its topoisomerase I binding site. Cancer Res. 2001, 61, 504-508.

380. Sanchez, C.; Butovich, I.A.; Brana, A.F.; Rohr, J.; Mendez, C.; Salas, J.A. The biosynthetic gene cluster for the antitumor rebeccamycin: Characterization and generation of indolocarbazole derivatives. Chem. Biol. 2002, 9, 519-531. [CrossRef]

381. Onaka, H.; Taniguchi, S.; Igarashi, Y.; Furumai, T. Characterization of the biosynthetic gene cluster of rebeccamycin from Lechevalieria aerocolonigenes ATCC 39243. Biosci. Biotechnol. Biochem. 2003, 67, 127-138. [CrossRef] 
382. Onaka, H.; Taniguchi, S.; Igarashi, Y.; Furumai, T. Cloning of the staurosporine biosynthetic gene cluster from Streptomyces sp. TP-A0274 and its heterologous expression in Streptomyces lividans. J. Antibiot. (Tokyo) 2002, 55, 1063-1071. [CrossRef]

383. Speedie, M.K.; Hornemann, U.; Floss, H.G. Isolation and characterization of tryptophan transaminase and indolepyruvate C-methyltransferase. Enzymes involved in indolmycin biosynthesis in Streptomyces griseus. J. Biol. Chem. 1975, 250, 7819-7825.

384. Vynne, N.G.; Mansson, M.; Nielsen, K.F.; Gram, L. Bioactivity, chemical profiling, and 16S rRNA-based phylogeny of Pseudoalteromonas strains collected on a global research cruise. Mar. Biotechnol. (New York) 2011, 13, 1062-1073. [CrossRef]

385. Du, Y.L.; Alkhalaf, L.M.; Ryan, K.S. In vitro reconstitution of indolmycin biosynthesis reveals the molecular basis of oxazolinone assembly. Proc. Natl. Acad. Sci. USA 2015, 112, 2717-2722. [CrossRef]

386. Vecchione, J.J.; Sello, J.K. A novel tryptophanyl-tRNA synthetase gene confers high-level resistance to indolmycin. Antimicrob. Agents Chemother. 2009, 53, 3972-3980. [CrossRef]

387. Lombo, F.; Menendez, N.; Salas, J.A.; Mendez, C. The aureolic acid family of antitumor compounds: Structure, mode of action, biosynthesis, and novel derivatives. Appl. Microbiol. Biotechnol. 2006, 73, 1-14. [CrossRef]

388. Menendez, N.; Nur-e-Alam, M.; Brana, A.F.; Rohr, J.; Salas, J.A.; Mendez, C. Biosynthesis of the antitumor chromomycin $\mathrm{A}_{3}$ in Streptomyces griseus: Analysis of the gene cluster and rational design of novel chromomycin analogs. Chem. Biol. 2004, 11, 21-32.

389. Menendez, N.; Brana, A.F.; Salas, J.A.; Mendez, C. Involvement of a chromomycin ABC transporter system in secretion of a deacetylated precursor during chromomycin biosynthesis. Microbiology 2007, 153, 3061-3070. [CrossRef]

390. Rohr, J.; Mendez, C.; Salas, J.A. The biosynthesis of aureolic acid group antibiotics. Bioorg. Chem. 1999, 27, 41-54. [CrossRef]

391. Lombo, F.; Brana, A.F.; Mendez, C.; Salas, J.A. The mithramycin gene cluster of Streptomyces argillaceus contains a positive regulatory gene and two repeated DNA sequences that are located at both ends of the cluster. J. Bacteriol. 1999, 181, 642-647.

392. Zolova, O.E.; Mady, A.S.; Garneau-Tsodikova, S. Recent developments in bisintercalator natural products. Biopolymers 2010, 93, 777-790. [CrossRef]

393. Lombo, F.; Velasco, A.; Castro, A.; de la Calle, F.; Brana, A.F.; Sanchez-Puelles, J.M.; Mendez, C.; Salas, J.A. Deciphering the biosynthesis pathway of the antitumor thiocoraline from a marine actinomycete and its expression in two streptomyces species. Chembiochem 2006, 7, 366-376. [CrossRef]

394. Biswas, T.; Zolova, O.E.; Lombo, F.; de la Calle, F.; Salas, J.A.; Tsodikov, O.V.; Garneau-Tsodikova, S. A new scaffold of an old protein fold ensures binding to the bisintercalator thiocoraline. J. Mol. Biol. 2010, 397, 495-507. [CrossRef]

395. Watanabe, K.; Hotta, K.; Praseuth, A.P.; Koketsu, K.; Migita, A.; Boddy, C.N.; Wang, C.C.; Oguri, H.; Oikawa, H. Total biosynthesis of antitumor nonribosomal peptides in Escherichia coli. Nat. Chem. Biol. 2006, 2, 423-428. [CrossRef]

396. Zhang, C.; Kong, L.; Liu, Q.; Lei, X.; Zhu, T.; Yin, J.; Lin, B.; Deng, Z.; You, D. In vitro characterization of echinomycin biosynthesis: Formation and hydroxylation of L-tryptophanyl-S-enzyme and oxidation of (2S,3S) $\beta$-hydroxytryptophan. PLoS ONE 2013, 8, e56772. [CrossRef]

397. Zhou, S.; Xiao, K.; Huang, D.; Wu, W.; Xu, Y.; Xia, W.; Huang, W. Complete genome sequence of Streptomyces spongiicola HNM0071T, a marine sponge-associated actinomycete producing staurosporine and echinomycin. Mar. Genom. 2019, 43, 61-64. [CrossRef]

398. Praseuth, A.P.; Wang, C.C.; Watanabe, K.; Hotta, K.; Oguri, H.; Oikawa, H. Complete sequence of biosynthetic gene cluster responsible for producing triostin A and evaluation of quinomycin-type antibiotics from Streptomyces triostinicus. Biotechnol. Prog. 2008, 24, 1226-1231. [CrossRef]

399. Zhao, Q.; He, Q.; Ding, W.; Tang, M.; Kang, Q.; Yu, Y.; Deng, W.; Zhang, Q.; Fang, J.; Tang, G.; et al. Characterization of the azinomycin B biosynthetic gene cluster revealing a different iterative type I polyketide synthase for naphthoate biosynthesis. Chem. Biol. 2008, 15, 693-705. [CrossRef]

400. Wang, S.; Liu, K.; Xiao, L.; Yang, L.; Li, H.; Zhang, F.; Lei, L.; Li, S.; Feng, X.; Li, A.; et al. Characterization of a novel DNA glycosylase from $S$. sahachiroi involved in the reduction and repair of azinomycin B induced DNA damage. Nucleic Acids Res. 2016, 44, 187-197. [CrossRef] 
401. Foulke-Abel, J.; Kelly, G.T.; Zhang, H.; Watanabe, C.M. Characterization of AziR, a resistance protein of the DNA cross-linking agent azinomycin B. Mol. Biosyst. 2011, 7, 2563-2570. [CrossRef]

402. Reusser, F. Ficellomycin and feldamycin; inhibitors of bacterial semiconservative DNA replication. Biochemistry 1977, 16, 3406-3412. [CrossRef]

403. Liu, Y.; Li, M.; Mu, H.; Song, S.; Zhang, Y.; Chen, K.; He, X.; Wang, H.; Dai, Y.; Lu, F.; et al. Identification and characterization of the ficellomycin biosynthesis gene cluster from Streptomyces ficellus. Appl. Microbiol. Biotechnol. 2017, 101, 7589-7602. [CrossRef]

404. Steffensky, M.; Muhlenweg, A.; Wang, Z.X.; Li, S.M.; Heide, L. Identification of the novobiocin biosynthetic gene cluster of Streptomyces spheroides NCIB 11891. Antimicrob. Agents Chemother. 2000, 44, 1214-1222. [CrossRef]

405. Thiara, A.S.; Cundliffe, E. Interplay of novobiocin-resistant and -sensitive DNA gyrase activities in self-protection of the novobiocin producer, Streptomyces sphaeroides. Gene 1989, 81, 65-72. [CrossRef]

406. Wang, Z.X.; Li, S.M.; Heide, L. Identification of the coumermycin A $\mathrm{A}_{1}$ biosynthetic gene cluster of Streptomyces rishiriensis DSM 40489. Antimicrob. Agents Chemother. 2000, 44, 3040-3048. [CrossRef]

407. Pojer, F.; Li, S.M.; Heide, L. Molecular cloning and sequence analysis of the clorobiocin biosynthetic gene cluster: New insights into the biosynthesis of aminocoumarin antibiotics. Microbiology 2002, 148, 3901-3911. [CrossRef]

408. Schmutz, E.; Muhlenweg, A.; Li, S.M.; Heide, L. Resistance genes of aminocoumarin producers: Two type II topoisomerase genes confer resistance against coumermycin $\mathrm{A}_{1}$ and clorobiocin. Antimicrob. Agents Chemother. 2003, 47, 869-877. [CrossRef]

409. FDA Approves Gemtuzumab Ozogamicin for CD33-Positive AML. Available online: https://www.fda.gov/ drugs/resources-information-approved-drugs/fda-approves-gemtuzumab-ozogamicin-cd33-positive-aml (accessed on 12 August 2019).

410. Oh, D.C.; Williams, P.G.; Kauffman, C.A.; Jensen, P.R.; Fenical, W. Cyanosporasides A and B, chloro- and cyano-cyclopenta[a]indene glycosides from the marine actinomycete "Salinispora pacifica". Org. Lett. 2006, 8, 1021-1024. [CrossRef]

411. Edo, K.; Saito, K.; Akiyama-Murai, Y.; Mizugaki, M.; Koide, Y.; Ishida, N. An antitumor polypeptide antibiotic neocarzinostatin: The mode of apo-protein-chromophore interaction. J. Antibiot. (Tokyo) 1988, 41, 554-562. [CrossRef]

412. Liu, W.; Nonaka, K.; Nie, L.; Zhang, J.; Christenson, S.D.; Bae, J.; Van Lanen, S.G.; Zazopoulos, E.; Farnet, C.M.; Yang, C.F.; et al. The neocarzinostatin biosynthetic gene cluster from Streptomyces carzinostaticus ATCC 15944 involving two iterative type I polyketide synthases. Chem. Biol. 2005, 12, 293-302. [CrossRef]

413. Chi, H.W.; Huang, C.C.; Chin, D.H. Thiols screened by the neocarzinostatin protein for preserving or detoxifying its bound enediyne antibiotic. Chemistry 2012, 18, 6238-6249. [CrossRef]

414. Sakata, N.; Ikeno, S.; Hori, M.; Hamada, M.; Otani, T. Cloning and nucleotide sequencing of the antitumor antibiotic C-1027 apoprotein gene. Biosci. Biotechnol. Biochem. 1992, 56, 1592-1595. [CrossRef]

415. Liu, W.; Christenson, S.D.; Standage, S.; Shen, B. Biosynthesis of the enediyne antitumor antibiotic C-1027. Science 2002, 297, 1170-1173. [CrossRef]

416. Samy, T.S.; Hahm, K.S.; Modest, E.J.; Lampman, G.W.; Keutmann, H.T.; Umezawa, H.; Herlihy, W.C.; Gibson, B.W.; Carr, S.A.; Biemann, K. Primary structure of macromomycin, an antitumor antibiotic protein. J. Biol. Chem. 1983, 258, 183-191.

417. Sakata, N.; Kanbe, T.; Tanabe, M.; Hayashi, H.; Hori, M.; Hotta, K.; Hamada, M. Nucleotide sequence of the macromomycin apoprotein gene and its expression in Streptomyces macromomyceticus. J. Antibiot. 1989, 42, 1704-1712. [CrossRef]

418. Hofstead, S.J.; Matson, J.A.; Malacko, A.R.; Marquardt, H. Kedarcidin, a new chromoprotein antitumor antibiotic. II. Isolation, purification and physico-chemical properties. J. Antibiot. (Tokyo) 1992, 45, 1250-1254. [CrossRef]

419. Lohman, J.R.; Huang, S.X.; Horsman, G.P.; Dilfer, P.E.; Huang, T.; Chen, Y.; Wendt-Pienkowski, E.; Shen, B. Cloning and sequencing of the kedarcidin biosynthetic gene cluster from Streptoalloteichus sp. ATCC 53650 revealing new insights into biosynthesis of the enediyne family of antitumor antibiotics. Mol. Biosyst. 2013, 9, 478-491. [CrossRef] 
420. Van Lanen, S.G.; Oh, T.J.; Liu, W.; Wendt-Pienkowski, E.; Shen, B. Characterization of the maduropeptin biosynthetic gene cluster from Actinomadura madurae ATCC 39144 supporting a unifying paradigm for enediyne biosynthesis. J. Am. Chem. Soc. 2007, 129, 13082-13094. [CrossRef]

421. Khokhlov, A.S.; Reshetov, P.D.; Chupova, L.A.; Cherches, B.Z.; Zhigis, L.S.; Stoyachemko, I.A. Chemical studies on actinoxanthin. J. Antibiot. (Tokyo) 1976, 29, 1026-1034. [CrossRef]

422. Sakata, N.; Mase, T.; Ikeno, S.; Hori, M.; Otani, T. The amino acid sequence of actinoxanthin apoprotein deduced from the base sequence of the gene. J. Antibiot. (Tokyo) 1993, 46, 1475-1477. [CrossRef]

423. Ahlert, J.; Shepard, E.; Lomovskaya, N.; Zazopoulos, E.; Staffa, A.; Bachmann, B.O.; Huang, K.; Fonstein, L.; Czisny, A.; Whitwam, R.E.; et al. The calicheamicin gene cluster and its iterative type I enediyne PKS. Science 2002, 297, 1173-1176. [CrossRef]

424. Elshahawi, S.I.; Ramelot, T.A.; Seetharaman, J.; Chen, J.; Singh, S.; Yang, Y.; Pederson, K.; Kharel, M.K.; Xiao, R.; Lew, S.; et al. Structure-guided functional characterization of enediyne self-sacrifice resistance proteins, CalU16 and CalU19. ACS Chem. Biol. 2014, 9, 2347-2358. [CrossRef]

425. Gao, Q.; Thorson, J.S. The biosynthetic genes encoding for the production of the dynemicin enediyne core in Micromonospora chersina ATCC53710. FEMS. Microbiol. Lett. 2008, 282, 105-114. [CrossRef]

426. Yan, X.; Chen, J.J.; Adhikari, A.; Teijaro, C.N.; Ge, H.; Crnovcic, I.; Chang, C.Y.; Annaval, T.; Yang, D.; Rader, C.; et al. Comparative studies of the biosynthetic gene clusters for anthraquinone-fused enediynes shedding light into the tailoring steps of tiancimycin biosynthesis. Org. Lett. 2018, 20, 5918-5921. [CrossRef]

427. Chang, C.Y.; Yan, X.; Crnovcic, I.; Annaval, T.; Chang, C.; Nocek, B.; Rudolf, J.D.; Yang, D.; Hindra; Babnigg, G.; et al. Resistance to enediyne antitumor antibiotics by sequestration. Cell Chem. Biol. 2018, 25, 1075-1085. [CrossRef]

428. Yamada, K.; Lear, M.J.; Yamaguchi, T.; Yamashita, S.; Gridnev, I.D.; Hayashi, Y.; Hirama, M. Biomimetic total synthesis of cyanosporaside aglycons from a single enediyne precursor through site-selective $p$-benzyne hydrochlorination. Angew. Chem. Int. Ed. Engl. 2014, 53, 13902-13906. [CrossRef]

429. Lane, A.L.; Nam, S.J.; Fukuda, T.; Yamanaka, K.; Kauffman, C.A.; Jensen, P.R.; Fenical, W.; Moore, B.S. Structures and comparative characterization of biosynthetic gene clusters for cyanosporasides, enediyne-derived natural products from marine actinomycetes. J. Am. Chem. Soc. 2013, 135, 4171-4174. [CrossRef]

430. Vieweg, L.; Reichau, S.; Schobert, R.; Leadlay, P.F.; Sussmuth, R.D. Recent advances in the field of bioactive tetronates. Nat. Prod. Rep. 2014, 31, 1554-1584. [CrossRef]

431. Braddock, A.A.; Theodorakis, E.A. Marine Ssirotetronates: Biosynthetic edifices that inspire drug discovery. Mar. Drugs 2019, 17, 232. [CrossRef]

432. Demydchuk, Y.; Sun, Y.; Hong, H.; Staunton, J.; Spencer, J.B.; Leadlay, P.F. Analysis of the tetronomycin gene cluster: Insights into the biosynthesis of a polyether tetronate antibiotic. Chembiochem 2008, 9, 1136-1145. [CrossRef]

433. Daduang, R.; Kitani, S.; Hashimoto, J.; Thamchaipenet, A.; Igarashi, Y.; Shin-ya, K.; Ikeda, H.; Nihira, T. Characterization of the biosynthetic gene cluster for maklamicin, a spirotetronate-class antibiotic of the endophytic Micromonospora sp. NBRC 110955. Microbiol. Res. 2015, 180, 30-39. [CrossRef]

434. Sadaka, C.; Ellsworth, E.; Hansen, P.R.; Ewin, R.; Damborg, P.; Watts, J.L. Review on abyssomicins: Inhibitors of the chorismate pathway and folate biosynthesis. Molecules 2018, 23, 1371. [CrossRef]

435. Tu, J.; Li, S.; Chen, J.; Song, Y.; Fu, S.; Ju, J.; Li, Q. Characterization and heterologous expression of the neoabyssomicin/abyssomicin biosynthetic gene cluster from Streptomyces koyangensis SCSIO 5802. Microb. Cell Fact. 2018, 17, 28. [CrossRef]

436. Jia, X.Y.; Tian, Z.H.; Shao, L.; Qu, X.D.; Zhao, Q.F.; Tang, J.; Tang, G.L.; Liu, W. Genetic characterization of the chlorothricin gene cluster as a model for spirotetronate antibiotic biosynthesis. Chem. Biol. 2006, 13, 575-585. [CrossRef]

437. Li, S.; Xiao, J.; Zhu, Y.; Zhang, G.; Yang, C.; Zhang, H.; Ma, L.; Zhang, C. Dissecting glycosylation steps in lobophorin biosynthesis implies an iterative glycosyltransferase. Org. Lett. 2013, 15, 1374-1377. [CrossRef]

438. Wang, J.; Soisson, S.M.; Young, K.; Shoop, W.; Kodali, S.; Galgoci, A.; Painter, R.; Parthasarathy, G.; Tang, Y.S.; Cummings, R. Platensimycin is a selective FabF inhibitor with potent antibiotic properties. Nature 2006, 441, 358-361. [CrossRef] 
439. Wang, J.; Kodali, S.; Lee, S.H.; Galgoci, A.; Painter, R.; Dorso, K.; Racine, F.; Motyl, M.; Hernandez, L.; Tinney, E. Discovery of platencin, a dual FabF and FabH inhibitor with in vivo antibiotic properties. Proc. Natl. Acad. Sci. USA 2007, 104, 7612-7616. [CrossRef]

440. Martens, E.; Demain, A.L. Platensimycin and platencin: Promising antibiotics for future application in human medicine. J. Antibiot. (Tokyo) 2011, 64, 705-710. [CrossRef]

441. Smanski, M.J.; Yu, Z.; Casper, J.; Lin, S.; Peterson, R.M.; Chen, Y.; Wendt-Pienkowski, E.; Rajski, S.R.; Shen, B. Dedicated ent-kaurene and ent-atiserene synthases for platensimycin and platencin biosynthesis. Proc. Natl. Acad. Sci. USA 2011, 108, 13498-13503. [CrossRef]

442. Kamigiri, K.; Suzuki, Y.; Shibazaki, M.; Morioka, M.; Suzuki, K.; Tokunaga, T.; Setiawan, B.; Rantiatmodjo, R.M. Kalimantacins A, B and C, novel antibiotics from Alcaligenes sp. YL-02632S. I. Taxonomy, fermentation, isolation and biological properties. J. Antibiot. (Tokyo) 1996, 49, 136-139. [CrossRef]

443. Mattheus, W.; Gao, L.J.; Herdewijn, P.; Landuyt, B.; Verhaegen, J.; Masschelein, J.; Volckaert, G.; Lavigne, R. Isolation and purification of a new kalimantacin/batumin-related polyketide antibiotic and elucidation of its biosynthesis gene cluster. Chem. Biol. 2010, 17, 149-159. [CrossRef]

444. Mattheus, W.; Masschelein, J.; Gao, L.J.; Herdewijn, P.; Landuyt, B.; Volckaert, G.; Lavigne, R. The kalimantacin/batumin biosynthesis operon encodes a self-resistance isoform of the FabI bacterial target. Chem. Biol. 2010, 17, 1067-1071. [CrossRef]

445. August, P.R.; Tang, L.; Yoon, Y.J.; Ning, S.; Muller, R.; Yu, T.W.; Taylor, M.; Hoffmann, D.; Kim, C.G.; Zhang, X.; et al. Biosynthesis of the ansamycin antibiotic rifamycin: Deductions from the molecular analysis of the rif biosynthetic gene cluster of Amycolatopsis mediterranei S699. Chem. Biol. 1998, 5, 69-79. [CrossRef]

446. Louw, G.E.; Warren, R.M.; Gey van Pittius, N.C.; McEvoy, C.R.; Van Helden, P.D.; Victor, T.C. A balancing act: Efflux/influx in mycobacterial drug resistance. Antimicrob. Agents Chemother. 2009, 53, 3181-3189. [CrossRef]

447. Spanogiannopoulos, P.; Waglechner, N.; Koteva, K.; Wright, G.D. A rifamycin inactivating phosphotransferase family shared by environmental and pathogenic bacteria. Proc. Natl. Acad. Sci. USA 2014, 111, 7102-7107. [CrossRef]

448. Oliva, B.; O'Neill, A.; Wilson, J.M.; O'Hanlon, P.J.; Chopra, I. Antimicrobial properties and mode of action of the pyrrothine holomycin. Antimicrob. Agents Chemother. 2001, 45, 532-539. [CrossRef]

449. Li, B.; Walsh, C.T. Identification of the gene cluster for the dithiolopyrrolone antibiotic holomycin in Streptomyces clavuligerus. Proc. Natl. Acad. Sci. USA 2010, 107, 19731-19735. [CrossRef]

450. Qin, Z.; Baker, A.T.; Raab, A.; Huang, S.; Wang, T.; Yu, Y.; Jaspars, M.; Secombes, C.J.; Deng, H. The fish pathogen Yersinia ruckeri produces holomycin and uses an RNA methyltransferase for self-resistance. J. Biol. Chem. 2013, 288, 14688-14697. [CrossRef]

451. Fukuda, D.; Haines, A.S.; Song, Z.; Murphy, A.C.; Hothersall, J.; Stephens, E.R.; Gurney, R.; Cox, R.J.; Crosby, J.; Willis, C.L.; et al. A natural plasmid uniquely encodes two biosynthetic pathways creating a potent anti-MRSA antibiotic. PLoS ONE 2011, 6, e18031. [CrossRef]

452. Li, B.; Forseth, R.R.; Bowers, A.A.; Schroeder, F.C.; Walsh, C.T. A backup plan for self-protection: S-methylation of holomycin biosynthetic intermediates in Streptomyces clavuligerus. Chembiochem 2012, 13, 2521-2526. [CrossRef]

453. Eustaquio, A.S.; McGlinchey, R.P.; Liu, Y.; Hazzard, C.; Beer, L.L.; Florova, G.; Alhamadsheh, M.M.; Lechner, A.; Kale, A.J.; Kobayashi, Y.; et al. Biosynthesis of the salinosporamide A polyketide synthase substrate chloroethylmalonyl-coenzyme A from S-adenosyl-L-methionine. Proc. Natl. Acad. Sci. USA 2009, 106, 12295-12300. [CrossRef]

454. Kale, A.J.; McGlinchey, R.P.; Lechner, A.; Moore, B.S. Bacterial self-resistance to the natural proteasome inhibitor salinosporamide A. ACS Chem. Biol. 2011, 6, 1257-1264. [CrossRef]

455. Shimotohno, K.W.; Kawamura, F.; Natori, Y.; Nanamiya, H.; Magae, J.; Ogata, H.; Endo, T.; Suzuki, T.; Yamaki, H. Inhibition of septation in Bacillus subtilis by a peptide antibiotic, edeine $\mathrm{B}_{1}$. Biol. Pharm. Bull. 2010, 33, 568-571. [CrossRef]

456. Westman, E.L.; Yan, M.; Waglechner, N.; Koteva, K.; Wright, G.D. Self resistance to the atypical cationic antimicrobial peptide edeine of Brevibacillus brevis Vm4 by the N-acetyltransferase EdeQ. Chem. Biol. 2013, 20, 983-990. [CrossRef]

457. Emmert, E.A.; Klimowicz, A.K.; Thomas, M.G.; Handelsman, J. Genetics of zwittermicin a production by Bacillus cereus. Appl. Environ. Microbiol. 2004, 70, 104-113. [CrossRef] 
458. Luo, Y.; Ruan, L.F.; Zhao, C.M.; Wang, C.X.; Peng, D.H.; Sun, M. Validation of the intact zwittermicin A biosynthetic gene cluster and discovery of a complementary resistance mechanism in Bacillus thuringiensis. Antimicrob. Agents Chemother. 2011, 55, 4161-4169. [CrossRef]

459. Petersen, A.B.; Ronnest, M.H.; Larsen, T.O.; Clausen, M.H. The chemistry of griseofulvin. Chem. Rev. 2014, 114, 12088-12107. [CrossRef]

460. Chooi, Y.H.; Cacho, R.; Tang, Y. Identification of the viridicatumtoxin and griseofulvin gene clusters from Penicillium aethiopicum. Chem. Biol. 2010, 17, 483-494. [CrossRef]

461. Bentley, R. Mycophenolic acid: A one hundred year odyssey from antibiotic to immunosuppressant. Chem. Rev. 2000, 100, 3801-3826. [CrossRef]

462. Regueira, T.B.; Kildegaard, K.R.; Hansen, B.G.; Mortensen, U.H.; Hertweck, C.; Nielsen, J. Molecular basis for mycophenolic acid biosynthesis in Penicillium brevicompactum. Appl. Environ. Microbiol. 2011, 77, 3035-3043. [CrossRef]

463. Hansen, B.G.; Genee, H.J.; Kaas, C.S.; Nielsen, J.B.; Regueira, T.B.; Mortensen, U.H.; Frisvad, J.C.; Patil, K.R. A new class of IMP dehydrogenase with a role in self-resistance of mycophenolic acid producing fungi. BMC Microbiol. 2011, 11, 202. [CrossRef]

464. Cox, G.; Wright, G.D. Intrinsic antibiotic resistance: Mechanisms, origins, challenges and solutions. Int. J. Med. Microbiol. 2013, 303, 287-292. [CrossRef]

465. Olivares, J.; Bernardini, A.; Garcia-Leon, G.; Corona, F.; Sanchez, M.B.; Martinez, J.L. The intrinsic resistome of bacterial pathogens. Front. Microbiol. 2013, 4, 103. [CrossRef]

466. Culyba, M.J.; Mo, C.Y.; Kohli, R.M. Targets for combating the evolution of acquired antibiotic resistance. Biochemistry 2015, 54, 3573-3582. [CrossRef]

467. D'Costa, V.M.; McGrann, K.M.; Hughes, D.W.; Wright, G.D. Sampling the antibiotic resistome. Science 2006, 311, 374-377. [CrossRef]

468. Crofts, T.S.; Gasparrini, A.J.; Dantas, G. Next-generation approaches to understand and combat the antibiotic resistome. Nat. Rev. Microbiol. 2017, 15, 422-434. [CrossRef]

469. Nesme, J.; Simonet, P. The soil resistome: A critical review on antibiotic resistance origins, ecology and dissemination potential in telluric bacteria. Environ. Microbiol. 2015, 17, 913-930. [CrossRef]

470. Chen, W.; Biswasm, T.; Porter, V.R.; Tsodikov, O.V.; Garneau-Tsodikova, S. Unusual regioversatility of acetyltransferase Eis, a cause of drug resistance in XDR-TB. Proc. Natl. Acad. Sci. USA 2011, 108, 9804-9808. [CrossRef]

471. Schroeder, M.R.; Stephens, D.S. Macrolide resistance in Streptococcus pneumoniae. Front. Cell Infect. Microbiol. 2016, 6, 98. [CrossRef]

472. Li, B.B.; Wu, C.M.; Wang, Y.; Shen, J.Z. Single and dual mutations at positions 2058, 2503 and 2504 of $23 S$ rRNA and their relationship to resistance to antibiotics that target the large ribosomal subunit. J. Antimicrob. Chemother. 2011, 66, 1983-1986. [CrossRef]

473. Fyfe, C.; Grossman, T.H.; Kerstein, K.; Sutcliffe, J. Resistance to macrolide antibiotics in public health pathogens. Cold Spring Harb. Perspect. Med. 2016, 6, a025395. [CrossRef]

474. Moore, I.F.; Hughes, D.W.; Wright, G.D. Tigecycline is modified by the flavin-dependent monooxygenase TetX. Biochemistry 2005, 44, 11829-11835. [CrossRef]

475. Nonaka, L.; Suzuki, S. New Mg2+-dependent oxytetracycline resistance determinant Tet 34 in Vibrio isolates from marine fish intestinal contents. Antimicrob. Agents Chemother. 2002, 46, 1550-1552. [CrossRef]

476. Galm, U.; Hager, M.H.; Van Lanen, S.G.; Ju, J.; Thorson, J.S.; Shen, B. Antitumor antibiotics: Bleomycin, enediynes, and mitomycin. Chem. Rev. 2005, 105, 739-758. [CrossRef]

477. Biggins, J.B.; Onwueme, K.C.; Thorson, J.S. Resistance to enediyne antitumor antibiotics by CalC self-sacrifice. Science 2003, 301, 1537-1541. [CrossRef]

478. Wiedenbeck, J.; Cohan, F.M. Origins of bacterial diversity through horizontal genetic transfer and adaptation to new ecological niches. FEMS Microbiol. Rev. 2011, 35, 957-976. [CrossRef]

479. Von Wintersdorff, C.J.; Penders, J.; van Niekerk, J.M.; Mills, N.D.; Majumder, S.; van Alphen, L.B.; Savelkoul, P.H.; Wolffs, P.F. Dissemination of antimicrobial resistance in microbial ecosystems through horizontal gene transfer. Front. Microbiol. 2016, 7, 173. [CrossRef]

480. Hildebrand, F.; Meyer, A.; Eyre-Walker, A. Evidence of selection upon genomic GC-content in bacteria. PLoS Genet. 2010, 6, e1001107. [CrossRef] 
481. Lassalle, F.; Perian, S.; Bataillon, T.; Nesme, X.; Duret, L.; Daubin, V. GC-Content evolution in bacterial genomes: The biased gene conversion hypothesis expands. PLoS Genet. 2015, 11, e1004941. [CrossRef]

482. Almpanis, A.; Swain, M.; Gatherer, D.; McEwan, N. Correlation between bacterial G+C content, genome size and the $\mathrm{G}+\mathrm{C}$ content of associated plasmids and bacteriophages. Microb. Genom. 2018, 4. [CrossRef]

483. Romiguier, J.; Roux, C. Analytical biases associated with GC-content in molecular evolution. Front. Genet. 2017, 8, 16. [CrossRef]

484. Munck, C.; Ellabaan, M.; Klausen, M.S.; Sommer, M.O.A. The resistome of important human pathogens. Biorxiv 2017. [CrossRef]

485. Nakabachi, A.; Yamashita, A.; Toh, H.; Ishikawa, H.; Dunbar, H.E.; Moran, N.A.; Hattori, M. The 160-kilobase genome of the bacterial endosymbiont Carsonella. Science 2006, 314, 267. [CrossRef]

486. Thomas, S.H.; Wagner, R.D.; Arakaki, A.K.; Skolnick, J.; Kirby, J.R.; Shimkets, L.J.; Sanford, R.A.; Loffler, F.E. The mosaic genome of Anaeromyxobacter dehalogenans strain 2CP-C suggests an aerobic common ancestor to the delta-proteobacteria. PLoS ONE 2008, 3, e2103. [CrossRef]

487. Andersson, D.I.; Nicoloff, H.; Hjort, K. Mechanisms and clinical relevance of bacterial heteroresistance. Nat. Rev. Microbiol. 2019, 17, 479-496. [CrossRef]

488. Sommer, M.O.A.; Munck, C.; Toft-Kehler, R.V.; Andersson, D.I. Prediction of antibiotic resistance: Time for a new preclinical paradigm? Nat. Rev. Microbiol. 2017, 15, 689-696. [CrossRef]

(C) 2019 by the author. Licensee MDPI, Basel, Switzerland. This article is an open access article distributed under the terms and conditions of the Creative Commons Attribution (CC BY) license (http://creativecommons.org/licenses/by/4.0/). 